Cochrane Database of Systematic Reviews

\title{
Electrostimulation for promoting recovery of movement or functional ability after stroke (Review)
}

Pomeroy VM, King LM, Pollock A, Baily-Hallam A, Langhorne P

Pomeroy VM, King LM, Pollock A, Baily-Hallam A, Langhorne P.

Electrostimulation for promoting recovery of movement or functional ability after stroke.

Cochrane Database of Systematic Reviews 2006, Issue 2. Art. No.: CD003241.

DOI: 10.1002/14651858.CD003241.pub2.

www.cochranelibrary.com 
TABLE OF CONTENTS

HEADER

ABSTRACT

PLAIN LANGUAGE SUMMARY

BACKGROUND

OBJECTIVES

METHODS

RESULTS

DISCUSSION

AUTHORS' CONCLUSIONS

ACKNOWLEDGEMENTS

\section{REFERENCES}

\section{CHARACTERISTICS OF STUDIES}

DATA AND ANALYSES

Analysis 1.1. Comparison 1 Electrostimulation versus no treatment, Outcome 1 Motor impairment - muscle tone. ..................

Analysis 1.2. Comparison 1 Electrostimulation versus no treatment, Outcome 2 Motor impairment - muscle function.

Analysis 1.3. Comparison 1 Electrostimulation versus no treatment, Outcome 3 Motor impairment - active joint range of movement.

Analysis 1.4. Comparison 1 Electrostimulation versus no treatment, Outcome 4 Motor impairment - physiological cost index. .. Analysis 1.5. Comparison 1 Electrostimulation versus no treatment, Outcome 5 Motor impairment - Fugl Meyer Assessment. ... Analysis 1.6. Comparison 1 Electrostimulation versus no treatment, Outcome 6 Normality of movement.

Analysis 1.7. Comparison 1 Electrostimulation versus no treatment, Outcome 7 Functional motor ability.

Analysis 1.8. Comparison 1 Electrostimulation versus no treatment, Outcome 8 Global ADL.

Analysis 2.1. Comparison 2 Electrostimulation versus placebo, Outcome 1 Motor impairment - muscle function. ....................

Analysis 2.2. Comparison 2 Electrostimulation versus placebo, Outcome 2 Motor impairment - Fugl Meyer Assessment. .........

Analysis 2.3. Comparison 2 Electrostimulation versus placebo, Outcome 3 Normality of movement.

Analysis 2.4. Comparison 2 Electrostimulation versus placebo, Outcome 4 Functional motor ability.

Analysis 2.5. Comparison 2 Electrostimulation versus placebo, Outcome 5 Global ADL.

Analysis 3.1. Comparison 3 Electrostimulation versus conventional therapy, Outcome 1 Motor impairment - muscle tone. .....

Analysis 3.2. Comparison 3 Electrostimulation versus conventional therapy, Outcome 2 Motor impairment - physiological cost index.

Analysis 3.3. Comparison 3 Electrostimulation versus conventional therapy, Outcome 3 Motor impairment - Fugl Meyer Assessment.

Analysis 3.4. Comparison 3 Electrostimulation versus conventional therapy, Outcome 4 Normality of movement. .................. Analysis 3.5. Comparison 3 Electrostimulation versus conventional therapy, Outcome 5 Functional motor ability. ................... Analysis 3.6. Comparison 3 Electrostimulation versus conventional therapy, Outcome 6 Global ADL.

Analysis 4.1. Comparison 4 Acceptability of electrostimulation, Outcome 1 Electrostimulation versus no treatment. Number of withdrawals (surrogate adverse events).

Analysis 4.2. Comparison 4 Acceptability of electrostimulation, Outcome 2 Electrostimulation versus placebo. Number of withdrawals (surrogate adverse events).

Analysis 4.3. Comparison 4 Acceptability of electrostimulation, Outcome 3 ES versus conventional. No of withdrawals (surrogate adverse events) - assume Francisco withdrawals control.

Analysis 4.4. Comparison 4 Acceptability of electrostimulation, Outcome 4 ES versus conventional. No of withdrawals (surrogate adverse events) - assume Francisco withdrawals treatment.

ADDITIONAL TABLES

APPENDICES

WHAT'S NEW

CONTRIBUTIONS OF AUTHORS

DECLARATIONS OF INTEREST

SOURCES OF SUPPORT

INDEX TERMS

2

3

3

3 
[Intervention Review]

\section{Electrostimulation for promoting recovery of movement or functional ability after stroke}

Valerie M Pomeroy ${ }^{1}$, Linda M King², Alex Pollock ${ }^{3}$, Alison Baily-Hallam4, Peter Langhorne ${ }^{5}$

1Faculty of Health, University of East Anglia, Norwich, UK. 2School of Physiotherapy, St George's University of London, London, UK. ${ }^{3}$ Nursing, Midwifery and Allied Health Professions Research Unit, Glasgow Caledonian University, Glasgow, UK. ${ }^{4}$ School of Paramedic Sciences, Physiotherapy and Radiography, University of Hertfordshire, Hatfield, UK. ${ }^{5}$ Academic Section of Geriatric Medicine, University of Glasgow, Glasgow, UK

Contact address: Valerie M Pomeroy, Faculty of Health, University of East Anglia, Norwich, NR4 7TJ, UK. v.pomeroy@uea.ac.uk.

Editorial group: Cochrane Stroke Group.

Publication status and date: Edited (no change to conclusions), published in Issue 1, 2009.

Citation: Pomeroy VM, King LM, Pollock A, Baily-Hallam A, Langhorne P. Electrostimulation for promoting recovery of movement or functional ability after stroke. Cochrane Database of Systematic Reviews 2006, Issue 2. Art. No.: CD003241. DOI: 10.1002/14651858.CD003241.pub2.

Copyright ( 2009 The Cochrane Collaboration. Published by John Wiley \& Sons, Ltd.

\section{A B S T R A C T}

\section{Background}

Electrostimulation might improve motor recovery after stroke by providing neuromuscular re-training.

\section{Objectives}

To find if electrostimulation improved functional motor ability, and the ability to undertake activities of daily living.

\section{Search methods}

We searched the Cochrane Stroke Group Trials Register (last searched August 2005), the Cochrane Central Register of Controlled Trials (CENTRAL) (The Cochrane Library Issue 1, 2004), MEDLINE (1966 to January 2004), EMBASE (1980 to January 2004), CINAHL (1982 to January 2004), AMED - Allied and Complementary Medicine Database (1985 to January 2004), Physiotherapy Evidence Database (PEDro), REHABDATA and the ISI Science Citation Index (1981 to 2003). We placed a request on the PHYSIO e-mail discussion list and contacted authors of relevant studies to elicit any unpublished or ongoing studies, searched the reference lists of included trials and contacted trialists.

\section{Selection criteria}

Randomised controlled trials of electrostimulation delivered to the peripheral neuromuscular system which was designed to improve voluntary movement control, functional motor ability and activities of daily living.

\section{Data collection and analysis}

Two review authors independently selected trials for inclusion, assessed trial quality and extracted the data.

\section{Main results}

Of the 2077 references identified, 24 trials were included in this review. For electrostimulation compared with no treatment this review found that electrostimulation improved some aspects of functional motor ability and some aspects of motor impairment and normality of movement. In addition, there was a significant difference in favour of no treatment compared with electrostimulation for an aspect of functional motor ability. For electrostimulation compared with placebo this review found that electrostimulation improved an aspect of functional motor ability. For electrostimulation compared with conventional physical therapy this review found that electrostimulation improved an aspect of motor impairment. There were no statistically significant differences between electrostimulation and control 
treatment for all other outcomes. However, these results need to be interpreted with reference to the following: (1) the majority of analyses only contained one trial; (2) variation was found between included trials in time after stroke, level of functional deficit, and dose of electrostimulation; and (3) the possibility of selection and detection bias in the majority of included trials.

\section{Authors' conclusions}

At present, there are insufficient robust data to inform clinical use of electrostimulation for neuromuscular re-training. Research is needed to address specific questions about the type of electrostimulation that might be most effective, in what dose and at what time after stroke.

\section{PLAIN LANGUAGE SUMMARY}

\section{Electrostimulation for promoting recovery of movement or functional ability after stroke}

Electrostimulation is a potential treatment to improve recovery of movement control and functional ability after stroke but the results of this review are inconclusive. After stroke many people are unable to use their affected limbs in everyday activities such as walking, ascending/descending stairs, washing hair or opening a coffee jar. One way to improve recovery might be to train affected muscles by using electrostimulation. This review examined the findings of 24 randomised controlled trials of electrostimulation provided to improve the ability to voluntarily move the affected limb and/or use the affected limb in everyday activities. The available evidence suggests that when electrostimulation is compared to no treatment then there might be a small effect on some aspects of function in favour of electrostimulation. However, the majority of findings in favour of electrostimulation were found when it was compared to a group of stroke patients who were not receiving any treatment and for all but two of the outcomes examined there were no differences between either electrostimulation and placebo or between electrostimulation and another type of physical therapy. This review also found that there were many differences between randomised controlled trials in the types of stroke patients who were included, the doses of electrostimulation and the outcome measures used. This meant that many of the comparisons made in the review related to one randomised trial rather than two or more. In addition, the numbers of participants in trials were relatively small. The results of this review therefore need to be interpreted with caution. 


\section{B A C K G R O U N D}

A large proportion of stroke patients remain moderately or severely disabled (Andrews 2000; Bonita 1997; Brown 1999) despite the considerable benefits of organised stroke care which both saves lives and reduces disability (SUTC 2001). The magnitude of resultant physical disability is illustrated by the finding that patients who are able to perform voluntary movements early after stroke may only have $45 \%$ of normal lower limb strength by the time they are discharged from in-patient rehabilitation (Andrews 2000). Even for those patients with initially mild impairment, outcome can be disappointing, and there are major health economic implications (Beech 1996).

To date there is no evidence that one physiotherapy approach is any better than any other approach (Ashburn 1993; Ernst 1990; Pollock 2003). Some studies have indicated that physiotherapy as a whole may be beneficial (Ashburn 1993; Dean 1997; Ernst 1990; Feys 1998; Kwakkel 1999). Early intervention might be better than late (Cifu 1999) but even late after stroke, physical therapy may be beneficial (Dean 1997; Wade 1992; Yekutiel 1993). Not surprisingly, the content of physical therapy might also influence outcome (Parry 1999) but at present, choice of treatment by physiotherapists appears to be mostly determined by the treatment approach which was prevalent during their training (Carr 1994; Nilsson 1992).

Therefore attention has turned to examining the effectiveness of interventions contained within the package (Pollock 2003; Pomeroy 2000a) used by physical therapists with the aim of producing an evidenced-based physical therapy package which reduces resultant disability for stroke patients. However, the large number of interventions that exist for a fairly small part of stroke rehabilitation, post-stroke shoulder pain (Pomeroy 2001), suggests that systematic examination of all interventions would be an immense task (Pomeroy 2000b). It is logical to start by evaluating those interventions which have biological plausibility.

Recent advances in neuroscience have confirmed that the brain has the ability to reorganize after stroke. Several studies have associated elements of afferent stimulation with beneficial change in brain activity including: repetition (Hallet 1998), functional goal directed activity (Nudo 1996) and electrostimulation (Golaszeski 2004; Hamdy 1998). These clues from neuroscience coincide with the less systematic observations from the physical therapy literature which suggest that repetition/intensity, functional activity, and electrostimulation might promote recovery of movement and functional ability after stroke (Pomeroy 2000a). The scientific evidence indicates therefore that motor recovery may be enhanced with the provision of an appropriate dose of afferent stimulation normally arising from functional activities. However, many people with paralysis or even paresis after stroke would not be able to participate in functional training. If paralysis or paresis precludes sufficient voluntary activation of muscle to produce functional activity then electrostimulation might be beneficial. In addition, lack of use could be expected to lead to changes in the properties of skeletal muscle after stroke because of altered descending neuromuscular drive. Indeed, these expectations are supported by the findings of general reduction in the functional capacity of skeletal muscles after stroke (Potempa 1996) unrelated to time elapsed since ictus or the severity of the paresis but related to the absence of daily physical exercise (Hachisuka 1997). Expectations are also supported by the findings that the descending commands from the damaged cortex to the paretic side fail to active high threshold alpha-motor neurones supplying Type II fibres (Tanaka 1998). That electrostimulation could enhance ability to contract skeletal muscle after stroke is exemplified in a study in which maximal dorsiflexion force at the ankle following electrical stimulation of the common peroneal nerve was shown to be equal on both paretic and non-paretic sides, although the maximal voluntary dorsiflexion on the paretic side fell far short of symmetry with the non-paretic side (Landau 2002). Research findings suggest therefore that electrostimulation given in the appropriate dose might promote recovery of movement or functional ability after stroke more than the conventional physical therapy package.

Electrostimulation has already been the focus of systematic reviews (Bolton 2004; de Kroon 2002; Glanz 1996; Handy 2003) but these did not use a comprehensive Cochrane search strategy. A recent systematic review of defined physical therapy interventions for the improvement of performance of movement and/or functional ability (Pomeroy 2000a) was limited by the use of only one review author and the inclusion of data only from published English language studies.

\section{O B J E C T IVES}

To determine if there is a difference in the recovery of movement or functional ability in patients with stroke between the provision of:

(1) electrostimulation and no treatment;

(2) electrostimulation and placebo electrostimulation;

(3) electrostimulation and conventional physical therapy interventions;

(4) different types of electrostimulation, for example transcutaneous electrical stimulation (TENS), functional electrical stimulation (FES).

\section{METHODS}

\section{Criteria for considering studies for this review}

\section{Types of studies}

Controlled trials, where participants were randomly or quasirandomly assigned to one of two or more treatment groups. Trials with or without blinding of participants, physiotherapists and assessors were included.

\section{Types of participants}

Participants in studies were adults (over 18 years) with a clinical diagnosis of stroke (WHO definition) (Hatano 1976). Participants with a diagnosis of either ischaemic stroke or haemorrhagic stroke at any time after stroke were included and confirmation of the clinical diagnosis using imaging was not compulsory. However, information pertaining to the type of stroke and the availability of confirmation of diagnosis was documented when describing the studies.

\section{Types of interventions}

Electrostimulation delivered to the peripheral neuromuscular system by external or internal electrodes and designed to improve voluntary movement control (motor impairment and normality of movement), functional motor ability and activities of daily living (ADL). This application of electrostimulation has been termed 'neuromuscular re-training' (Alon 2003). Trials which investigated an experimental condition that differed from the control condition 
by combining electrostimulation with other interventions (for example, splints) were excluded from this review. We expected to describe electrostimulation as follows.

\section{Type of electrode}

(1) External

(2) Internal

\section{Type of electrostimulation}

(1) Single channel

(2) Multi channel

(3) Patterned multi channel

(4) Functional electrical stimulation (FES; EMG triggered)

(5) Transcutaneous electrical neuromuscular stimulation (TENS)

Examination of identified studies, however, revealed that the terms used to describe the type of electrostimulation were used differently by different authors. For example, the term TENS was found to be used to describe electrostimulation that produced a muscle contraction as well as electrostimulation that did not produce a muscle contraction. Clearly, different definitions of types of electrostimulation were being used by different authors. To clarify types of electrostimulation we therefore modified the electrostimulation description so that it described the characteristics of the electrostimulation in terms of:

- whether the paretic limb was active or inactive when stimulation was given;

- whether the electrostimulation was constant or triggered/ intermittent;

- whether the electrode was external or internal;

- whether the electrostimulation did or did not produce a muscle contraction.

The resultant clinical descriptive groups were used to describe types of electrostimulation evaluated in a sample of five trials by three review authors independently (two researchers and one clinical senior physiotherapist who was independent of other dimensions of this review). Appropriate modifications were made which resulted in the final description which provides 16 possible types of electrostimulation which are shown in Additional Table 01 (Table 1).

We had also planned to include electrostimulation delivered to the central nervous system. This was omitted after considering the complexity of this review which became evident as potential trials were identified.

\section{Types of outcome measures}

This review considered outcome measures made at the end of the treatment period in identified trials. It was planned to also consider outcome measures at follow up but these were made at different time points in different trials and therefore presented difficulties for collation of data. Consequently, follow-up measures were not included in this present review and data on possible decay of treatment effects was not collected or assessed.

\section{Primary outcome measures}

The primary analyses focused on functional motor ability and the ability to undertake activities of daily living (ADL). Data were divided into actual and change values.
Measures of functional motor ability used in included trials were:

- Rivermead Mobility Index (high score indicates good outcome);

- Walking Endurance (high score indicates good outcome);

- Timed Up and Go test (low score indicates good outcome);

- Motor Assessment Scale (high score indicates good outcome);

- Box and Blocks Test (high score indicates good outcome);

- Upper Extremity Drawing Test (high score indicates good outcome);

- Action Research Arm Test (high score indicates good outcome);

- Jebsen Hand Function Test (low score indicates good outcome);

- Nine Hole Peg Test (high score indicates good outcome).

Measures of ADL used in included trials were:

- Barthel Index (high score indicates good outcome);

- Functional Independent Measure (FIM) (high score indicates good outcome).

\section{Secondary outcome measures}

The secondary analyses focused on motor impairment and the normality of movement (voluntary movement control). Measures of motor impairment used in included trials were subdivided into measures of:

- muscle tone - Ashworth and spasticity score (low score indicates good outcome);

- muscle tone - resistance to passive movement (low score indicates good outcome);

- muscle tone - Wartenberg pendulum test relaxation index (high score indicates good outcome);

- muscle function - joint movement (high score indicates good outcome);

- muscle function - sustained muscle contraction (high score indicates good outcome);

- muscle function - premotor reaction time (low score indicates good outcome);

- muscle function - motor reaction time (low score indicates good outcome);

- muscle function - isometric torque (high score indicates good outcome);

- muscle function - co-contraction ratio of agonist and antagonist muscles (low score indicates good outcome);

- muscle function - grip strength (high score indicates good outcome);

- joint range of active movement (high score indicates good outcome);

- physiological cost index (low score indicates good outcome);

- Fugl-Meyer Assessment (high score indicates good outcome).

Measures of normality of movement used in included trials were subdivided into measures of:

- gait velocity (high score indicates good outcome);

- cadence (high score indicates good outcome);

- gait cycle time (low score indicates good outcome);

- stride length (high score indicates good outcome); 
- minimum knee angle during swing phase (low score indicates good outcome);

- minimum ankle angle during swing phase (low score indicates good outcome);

- peak hip angle during swing phase (high score indicates good outcome);

- peak knee angle during swing phase (high score indicates good outcome);

- peak ankle angle during swing phase (high score indicates good outcome);

- timing of peak hip angle - per cent gait cycle (high score indicates good outcome);

- timing of peak knee angle - per cent gait cycle (high score indicates good outcome);

- timing of peak ankle angle - per cent gait cycle (high score indicates good outcome);

- Motor Activity Log - how well (high score indicates good outcome).

\section{Search methods for identification of studies}

See: 'Specialized register' section in Cochrane Stroke Group

(1) We searched the Cochrane Stroke Group Trials Register, which was last searched by the Review Group Co-ordinator in August 2005.

(2) In addition, we searched the following electronic databases: the Cochrane Central Register of Controlled Trials (CENTRAL) (The Cochrane Library Issue 1, 2004), MEDLINE (1966 to January 2004), EMBASE (1980 to January 2004), CINAHL (1982 to January 2004), AMED: Allied and Complementary Medicine Database (1985 to January 2004), and the ISI Science Citation Index (1981 to 2003). Search strategies were developed in consultation with the Cochrane Stroke Group Trials Search Co-ordinator to avoid duplication of effort (Appendix 1).

(3) We searched the reference lists of all relevant papers to identify further studies.

(4) We planned to handsearch any journals in which identified trials had been published if these journals were not included in MEDLINE, EMBASE, CINAHL or AMED, or in journals that have been searched for the Cochrane Stroke Group Trials Register or for the Cochrane Central Register of Controlled Trials. However, this was not undertaken as all journals in which identified trials had been published had been searched by The Cochrane Collaboration.

(5) Authors of relevant studies were contacted to elicit any unpublished or on-going studies that might have been undertaken.

(6) We consulted the Physiotherapy Researchers Register compiled by the Chartered Society of Physiotherapy to identify, and then write to, physiotherapists with a research interest in stroke rehabilitation to elicit any unpublished or on-going studies that might have been undertaken.

(7) The Physiotherapy Evidence Database (PEDro, an Internetbased database of clinical trials in physiotherapy) (http:// www.pedro.fhs.usyd.edu.au/index.html), was searched to identify further trials.
(8) REHABDATA, a rehabilitation database produced by the National Rehabilitation Information Centre (http:// www.naric.com/research/) was also searched.

(9) A request was placed on the PHYSIO e-mail discussion list asking the list-members if they knew of any unpublished or on-going trials.

\section{Data collection and analysis}

Following the searches, two review authors each independently assessed the titles and abstracts and, based on a description of inclusion criteria, ranked each title as 'possibly relevant' or 'definitely irrelevant'. Any trial that both review authors ranked as 'definitely irrelevant' was excluded from the list. The full reports of all remaining articles were obtained and two review authors ranked the trials as 'relevant', 'irrelevant' or 'unsure'. Any trials ranked as 'irrelevant' by both review authors were excluded. Any trials ranked as 'relevant' by both review authors were included. Where there was disagreement between review authors, or where the review authors were 'unsure', disagreement or uncertainty was resolved through discussion between the review authors. If the review authors were unable to agree or both were uncertain of the relevance of any trial, the trial was included at this stage.

\section{Classification of types of electrostimulation}

Based on the classification of types of electrostimulation (Table 1), independent review authors classified the interventions administered in each trial. If review authors disagreed on the classification, this was resolved by referral to the original paper. This process resulted in agreement and it was therefore not necessary to contact study authors for clarification or to consult with the clinical senior physiotherapist who was independent to this review.

\section{Documentation of methodological quality}

The two independent review authors documented the methodological quality of included studies. Documentation was made of:

(1) generation of allocation sequence, that is allocation sequence cannot influence order of recruitment of participants to the trial (selection bias)

(2) true concealment of randomisation up to time of allocation (selection bias);

(3) blindness of participants to treatment group (performance bias);

(4) blindness of providers of care to treatment group (performance bias);

(5) differences in control or underlying treatments, that is differences in the care provided apart from the intervention being evaluated (performance bias);

(6) protocol deviations, specifically, breaking of eligibility criteria for participants or divergence from prescribed treatments (attrition bias);

(7) analysis deviations, specifically, absence of intention-to-treat principle in data analysis or lack of report of withdrawals and reasons why (attrition bias);

(8) assessors blinded to interventions given (detection bias);

(9) selective reporting of results, for example specification of predefined primary outcomes and analyses (detection bias).

The assessment system was the standard Cochrane classification: 
- $\mathrm{A}=$ adequate;

- $\mathrm{B}=$ Unclear;

- $\mathrm{C}=$ inadequate;

- $\mathrm{D}=$ Not used.

An aspect of standard design that is not always possible to apply in rehabilitation research is blinding of participants and providers. To judge performance bias therefore for this review we gave a grading of $C$ for 'participants blinded' if we considered that it was possible to provide a placebo electrostimulation and yet this was not done, whereas if it appeared that provision of a placebo electrostimulation was not possible then the grade of $D$ was assigned. For 'providers blinded', a $\mathrm{C}$ grading was given if we considered that it was possible to provide a placebo that meant that the provider was unaware of what form of intervention was being given. Of course, if the electrostimulation was designed to produce a muscle contraction the provider would be aware if this did not occur and could infer that the placebo intervention was being given. In these circumstances we assigned a $D$ grading.

Two review authors independently assessed the methodological quality of each included study. Any disagreements were resolved through referral to the original paper. This process resulted in agreement and therefore it was unnecessary to contact study authors for clarification or to consult with the clinical senior physiotherapist who was independent of this review.

\section{Data extraction}

Two review authors independently extracted data, and contacted the study authors to clarify data or obtain missing data wherever possible. Documentation was made (where possible) on:

(1) the characteristics of participants in the experimental and control groups;

(2) inclusion and exclusion criteria for the trial;

(3) all assessed outcomes.

Any disagreements were resolved by discussion between the review authors.

\section{Analysis of results}

We planned to compare:

(1) electrostimulation and no treatment;

(2) electrostimulation and placebo electrostimulation;

(3) electrostimulation and conventional therapy;

(4) different types of electrostimulation.

Studies were placed in the electrostimulation versus no treatment comparison if they provided electrostimulation to the experimental group and nothing in the control group. To avoid the potential confounding factor of intensity of treatment, we also placed studies in this comparison if both groups received conventional therapy and the only difference was that the experimental group also received electrostimulation.

For each comparison, the study results for measures of motor and ADL ability, measures of motor impairment, and measures of movement were used. The Cochrane Collaboration's Review Manager software (RevMan 4.2) was used to calculate the weighted treatment effect and 95\% confidence intervals across trials. Different trials used different outcome measures. If trials used different outcomes but it was possible to combine them they are presented as standardised mean differences (SMD). We determined the SMD using the random-effects model.

To find the acceptability of electrostimulation intervention we calculated the relative risk for adverse events as assessed by the surrogate marker of withdrawal of participants during the treatment phase of all included trials (Moseley 2003). To clarify this analysis, we examined the reasons for withdrawal of participants.

Homogeneity between trials was tested using the 12 statistic, with a value greater than $50 \%$ considered to indicate substantial heterogeneity. We also planned to investigate the possible reasons for heterogeneity in sensitivity analyses for concealed compared to unconcealed allocation, blinded compared with unblinded outcome assessment and, the effect of including trial data which omitted data for participants who did not complete the treatment phase (intention-to-treat analysis).

Interpretation of the analysis was made with reference to the methodological quality of the studies reviewed.

\section{RES U L T S}

\section{Description of studies}

The search strategy identified 2077 potentially relevant references. Screening of the titles and abstracts by the two independent review authors eliminated the vast majority of these, leaving 56 potentially relevant references. Of these, 29 references (six of which used the same participants) did not meet the inclusion criteria and these are listed in the 'Characteristics of excluded studies' table together with the reasons for their exclusion. One paper (Mokrusch 1997) described an ongoing study and this is detailed in the 'Characteristics of ongoing studies' table. One reference was for an abstract that was not available in OVID in August 2005 and this has therefore been placed in 'Studies awaiting assessment'. Of the remaining 25 references, two used the same participant group and there are therefore 24 trials which are included in this present review (Bogataj 1995; Burridge 1997; Cauraugh 2000; Cauraugh 2002; Cauraugh 2003; Chae 1998; Cozean 1988; Daly 2004; Francisco 1998; Gosman-Hedstrom 1998; Heckman 1997; Johansson 2001; Kimberley 2004; King 1996; Linn 1999; Macdonell 1994; Merletti 1978; Pei 2001; Popovic 2003; Powell 1999; Sonde 1998; Tekeoolu 1998; Wright 2004; Yan 2005).

\section{Participants}

The 24 trials included 888 participants (median 30, range 11 to 102) who completed the baseline measurements. Eight trials (Chae 1998; Cozean 1988; Daly 2004; Francisco 1998; Gosman-Hedstrom 1998; Johansson 2001; Powell 1999; Yan 2005) reported participant withdrawals before outcome measures were undertaken $(n=53)$. There were therefore 835 participants who underwent outcome measurements at the end of the intervention. The reasons for withdrawal are given in the Results section.

Two of the 24 trials did not provide any data on the age of participants (Cauraugh 2003; Wright 2004). The mean age of participants in the remaining 22 trials ranged from 52.05 to 76.50 years. Other information about participants was inconsistently reported in the trials and it is therefore not possible to provide a definitive description of participants. Only 17 trials provided a mean time after stroke which ranged from 9.4 days (Yan 2005) to 4.29 years (Burridge 1997). Only 14 trials provided information 
about the side of hemiparesis in the experimental and control participants included in this review. In these trials, approximately $54 \%$ of participants had a left hemiparesis. A mere eight of the 24 trials provided any data on stroke type or stroke lesion (Daly 2004; Heckman 1997; Johansson 2001; Kimberley 2004; Linn 1999; Pei 2001; Popovic 2003; Powell 1999) which is insufficient information from which to describe the participants in this review.

\section{Interventions}

Not all intervention categories (Table 1) were used in the 24 trials. Categories used were:

- Category 4 (paretic limb inactive, external electrode, constant stimulus, no contraction produced) - 1 trial (Tekeoolu 1998);

- Category 5 (paretic limb active, external electrode, triggered or intermittent stimulus, contraction produced) - 10 trials (Bogataj 1995; Cauraugh 2000; Cauraugh 2002; Cauraugh 2003; Cozean 1988; Francisco 1998; Heckman 1997; Kimberley 2004; Popovic 2003; Wright 2004);

- Category 7 (paretic limb inactive, external electrode, triggered or intermittent stimulus, contraction produced) - 7 trials (Burridge 1997; Chae 1998; King 1996; Linn 1999; Powell 1999; Sonde 1998; Yan 2005);

- Category 8 (paretic limb inactive, external electrode, constant stimulus, contraction produced) - 1 trial (Johansson 2001);

- Category 12 (paretic limb inactive, internal electrode, constant stimulus, no contraction produced) - 1 trial (Pei 2001);

- Category 13 (paretic limb active, internal electrode, triggered or intermittent stimulus, contraction produced) - 1 trial (Daly 2004);

- Category 15 (paretic limb inactive, internal electrode, triggered or intermittent stimulus, contraction produced) - 1 trial (Gosman-Hedstrom 1998);

- Categories 5 and 7 combined (paretic limb active, external electrode, triggered or intermittent stimulus, contraction produced and paretic limb inactive, external electrode, triggered or intermittent stimulus, contraction produced) - 2 trials (Macdonell 1994, Merletti 1978).

Thus the majority of trials used electrostimulation delivered by external electrodes which produced or enhanced contraction of paretic muscle.

Dose of electrostimulation combined global temporal aspects of the intensity (time period per day), frequency (number of intervention sessions per week) and duration (number of weeks) of treatment with the specific magnitude of electrostimulation in terms of parameters including: amplitude, frequency, pulse width and ramping up or down. Dose of electrostimulation is therefore complex and there is considerable scope for variation. Indeed, dose of electrostimulation varied between trials for both aspects of the prescription. For global temporal aspects across these 24 trials the duration of treatment ranged from one day to three months although one trial reported that the intervention continued for the length of the rehabilitation stay. The frequency of intervention ranged between one to five times a week. Intensity also varied across trials and ranged from 10 minutes to six hours a day. Details of the specific magnitude of electrostimulation dose are more difficult to summarise. In some trials the specific magnitude of electrostimulation was directed by the effect of electrostimulation on individual participants. For example, amplitude set to $80 \%$ of the amplitude which produced non-volitional movement in the joint of interest (Bogataj 1995) and pulse frequency controlled to provide the maximum contraction within tolerable levels of discomfort (Cozean 1988). Interestingly, there was little evidence within the trials that either aspect of the dose of electrostimulation was based on experimental studies of efficacy; a subjective impression which is not confined to this review (Alon 2003). It was therefore not possible to extract specific details of global temporal and specific magnitude dose of electrostimulation for all trials.

Fifteen of the 24 trials compared an experimental group who received an electrostimulation intervention combined with a form of conventional (non-electrostimulation) therapy with a control group who received the same form of conventional (non-electrostimulation) therapy. We placed these 15 trials into the comparison group of electrostimulation versus no treatment as all participants received conventional therapy. Placebo forms of electrostimulation were compared with active electrostimulation in five trials and electrostimulation was compared with conventional (non-electrostimulation) therapy in four trials. None of the 24 included trials compared different forms of electrostimulation. The comparison of interventions for each trial is documented in the 'Characteristics of included studies' table.

\section{Outcome measures}

Many different outcome measures were included in the 24 trials; however it was possible to group these into the four categories (see 'Types of outcome measures' section).

\section{Risk of bias in included studies}

The results of the methodological assessment of the 24 trials included in this review are provided in Table 2 (Table 2). Details of the possibility of bias are given in the following subsections and also in Table 2. Essentially:

- selection bias could have been present in the majority of trials as procedures for generation of allocation sequence and/or concealment of that sequence were unclear or inadequate in the majority of studies;

- the possibility for performance bias is difficult to judge in this present review as although the majority of trials did not use participant blinding or provider blinding this could be because it was not possible to do so in the majority of the included trials because of the characteristics of electrostimulation and the comparator interventions. For this reason, and because the avoidance of differences in underlying care was only assessed as inadequate in four trials, we consider the possibility of performance bias to be minimal in this present review;

- the possibility for attrition bias was considered minimal in the majority of trials included in this review;

- the presence of detection bias is a possibility for the majority of included trials mainly because of a lack of clarity or the inadequate use of blinded assessment.

\section{Selection bias}

Selection bias was assessed by the methods of generation of allocation sequence and allocation concealment. The method of generation of random allocation and concealment of the allocation was unclear from the descriptions given in published papers of the majority of trials included in this present review. Allocation generation was assessed as adequate in only five trials (Cauraugh 
2003; Gosman-Hedstrom 1998; Johansson 2001; Powell 1999; Yan 2005) and allocation concealment in only five trials (Cauraugh 2003; Francisco 1998; Gosman-Hedstrom 1998; Johansson 2001; Powell 1999). Generation of allocation was considered to be inadequate in three trials (Bogataj 1995; Burridge 1997; Chae 1998) and allocation concealment was considered to be inadequate in five trials (Bogataj 1995; Burridge 1997; Chae 1998; Heckman 1997; Popovic 2003).

\section{Performance bias}

Performance bias was assessed by whether or not participants were blinded to the intervention they received, providers were blinded to the intervention they provided and whether or not there were any differences in care between the experimental and control groups apart from the intervention being evaluated. The procedures used for blinding participants were assessed as adequate in only five trials (Chae 1998; Cozean 1988; Kimberley 2004; Tekeoolu 1998; Yan 2005) and the procedures used for blinding providers were assessed as adequate in two trials (Cozean 1988; Kimberley 2004) and inadequate in only four trials (Popovic 2003; Powell 1999; Sonde 1998; Tekeoolu 1998). However, it must be appreciated that it is arguable that it was not possible to blind participants or providers to the experimental or 'control' intervention in the majority of trials because the experimental electrostimulation in the majority of trials was designed to produce a muscle contraction and when compared with conventional therapy is obvious what is being delivered (see 'Description of studies' - interventions and the documentation of methodological quality sections). The avoidance of differences in underlying care for the two groups was only considered inadequate in three trials (Bogataj 1995; Burridge 1997; Pei 2001). Overall, taking the difficulty of providing participant and provider blinding together with the lack of differences in underlying care between comparator groups in included trials, we consider that the possibility of performance bias to be minimal in this present review.

\section{Attrition bias}

Attrition bias was assessed by the presence of any deviations from the protocols (for example, breaking of eligibility criteria for participants or deviation from prescribed treatments) and the presence of analysis deviation (for example, absence of intentionto-treat principle in data analysis or lack of report of withdrawals). Attrition bias was absent from the majority of trials with 20 trials assessed as not deviating from the prescribed protocol and 14 trials not exhibiting analysis deviation. However, caution is required as attrition bias has been assessed from published reports of trials and therefore from what is reported in scientific papers which often need to adhere to specific word count limits.

\section{Detection bias}

Detection bias was assessed by whether or not assessors were blinded to the interventions given and whether or not there was selective reporting of results (for example, deviation from predefined outcomes and analysis). From information provided in the published papers blinding of assessors was considered as adequate in 11 trials, unclear in 10 trials and inadequate in three trials. The avoidance of selective reporting of results was assessed as adequate in 14 trials, unclear in one trial and inadequate in nine trials.

\section{Effects of interventions}

\section{Comparison 1: Electrostimulation versus no treatment}

There were 15 trials in this comparison (Burridge 1997; Cauraugh 2000; Cauraugh 2002; Cauraugh 2003; Daly 2004; GosmanHedstrom 1998; Heckman 1997; King 1996; Linn 1999; Macdonell 1994; Merletti 1978; Pei 2001; Popovic 2003; Powell 1999; Sonde 1998).

Because the majority of studies measured more than one aspect of: motor impairment-muscle tone, motor impairment-muscle function, motor impairment-active joint range of movement, normality of movement and functional motor ability, some randomised patients appeared in more than one section. Therefore, independent subtotals were not added together.

Statistically significant differences between electrostimulation and no treatment were only found for:

- motor impairment muscle function - motor reaction time actual values, SMD $1.18(95 \% \mathrm{Cl} 0.00$ to 2.37$)$ in favour of electrostimulation;

- motor impairment muscle function - isometric torque change values, SMD $1.02(95 \% \mathrm{Cl} 0.46$ to 1.59$)$ in favour of electrostimulation;

- motor impairment active joint range of movement - lower limb actual values, SMD $0.84(95 \% \mathrm{Cl} 0.07$ to 1.62$)$ in favour of electrostimulation;

- functional motor ability - box and blocks test actual values, SMD 1.28 ( $95 \% \mathrm{Cl} 0.00$ to 2.56 ) in favour of electrostimulation;

- functional motor ability - upper extremity drawing test actual values, SMD $-1.40(95 \% \mathrm{Cl}-2.25$ to -0.65$)$ in favour of no treatment.

All statistically significant findings, except those for functional motor ability - box and blocks test actual values were derived from analyses containing one trial only.

\section{Comparison 2: Electrostimulation versus placebo}

There were five trials in this comparison (Chae 1998; Johansson 2001; Kimberley 2004; Tekeoolu 1998; Yan 2005). As the majority of studies measured more than one aspect of functional motor ability some randomised patients appeared in more than one analysis. Therefore the independent subtotals were not added together.

This review found a statistically significant difference between participants receiving electrostimulation and participants receiving a placebo for:

- muscle function - co-contraction ratio of agonist and antagonist muscles, SMD 0.93 (95\% Cl 0.14 to 1.72);

- functional motor ability - Jebsen Hand Function Test feeding actual values, SMD 1.36 (95\% Cl 0.24 to 2.48 ).

However, both of these differences in favour of electrostimulation resulted from the analysis of only one study.

\section{Comparison 3: Electrostimulation versus conventional therapy interventions}

There were four trials in this comparison (Bogataj 1995; Cozean 1988; Francisco 1998; Wright 2004). As the majority of studies 
measured more than one aspect of normality of movement and functional motor ability some randomised patients appeared in more than one section. Therefore the independent subtotals were not added together.

A statistically significant difference was only found for motor impairment - Fugl Meyer Assessment, and this was in favour of electrostimulation compared with conventional therapy, SMD 1.06 (95\% $\mathrm{Cl} 0.25$ to 1.88 ).

\section{Comparison 4: Acceptability of electrostimulation}

There were a total of 53 participants who withdrew before the outcome measurements due to: pain or discomfort from surface stimulation (experimental $=7$, control $=1$ ); adverse reaction (experimental $=1$, control $=0)$; medical problems (experimental $=$ 5 , control $=5$ ); participants died (experimental $=3$, control $n=6$ ); cognitive problems (experimental $=0$, control $=1$ ); social support system compromised (experimental $=0$, control $=1$ ); declined to finish treatment (experimental $=5$, control $=2$ ); unable to stimulate without motor activation (experimental $=0$, control $=1$ ); unable to undertake assessment (experimental $=1$, control $=0$ ); discharged early (experimental $=0$, control $=1$ ); unknown (experimental $=1$, control $=0$ ). One study reported 5 withdrawals (experimental = 3 , control $=2$ ) but it is unclear what the reasons were for these particular participants (Powell 1999). One study reported seven withdrawals because of medical instability but no information was provided about experimental allocation of these participants (Francisco 1998).

Of the 53 participants who withdrew only 9 were reported as experiencing either pain, discomfort or adverse events. A further seven participants declined to finish treatment but specific reasons for this decision were not given. In essence, 53 of 888 participants (6\%) withdrew and only 9 of 888 participants (1\%) withdrew because of an adverse event that could be expected to be directly related to electrostimulation. This level of withdrawals does not indicate unacceptability of electrostimulation to people who have suffered a stroke.

Statistical analyses support the conclusion that electrostimulation was found to be acceptable to participants in the included trials (as measured by withdrawal before outcome measurement). No statistically significant differences were found between the number of withdrawals from the electrostimulation and no treatment groups and from the electrostimulation and placebo groups. Two of the four studies which compared electrostimulation and conventional therapy reported withdrawals from the trial during the treatment phase (Cozean 1988; Francisco 1998). However one of these trials did not provide information about the randomised allocation of those participants who withdrew (Francisco 1998). We therefore calculated the relative risk of withdrawal from the comparator groups with (sensitivity analysis) and without the assumption that all the withdrawals from the trial of Francisco and colleagues (Francisco 1998) were from the electrostimulation group rather than the conventional therapy group. This analysis showed that the relative risk of withdrawal from the electrostimulation group increased from 0.48 (95\% $\mathrm{Cl} 0.05$ to 4.65$)$ to 3.21 (95\% Cl 0.58 to 17.85 ) with the assumption that all withdrawals in the Francisco trial occurred in the electrostimulation group. However, neither analysis found that there were statistically significant differences between electrostimulation and conventional therapy. This meta- analysis detected no heterogeneity for number of withdrawals in the included trials.

\section{DISCUSSION}

The aim of this review was to find whether recovery of movement and functional ability after stroke could be enhanced by electrostimulation. This review considered data at outcome, and follow-up data was not included. The findings are divided into three sections, electrostimulation compared with no treatment, electrostimulation compared with placebo and electrostimulation compared with conventional therapy.

When electrostimulation is compared with no treatment this review found a statistically significant difference in favour of no treatment for functional motor ability upper extremity drawing test actual values and that electrostimulation improved:

(1) motor impairment - muscle function

- motor reaction time

- isometric torque

- active joint range of movement

\section{(2) functional motor ability}

\section{- Box and Blocks Test}

However, these statistically significant differences in favour of electrostimulation for aspects of motor impairment and functional motor ability resulted from data of single studies. Therefore low power is an area of concern and represents a threat to the validity of these results. It is therefore important to be cautious about these findings. This review also found that electrostimulation was acceptable to participants as assessed by the finding of no statistically significant difference between groups for withdrawal of participants during the treatment phase. However, it could be important that there was a trend for more participants to withdraw from the electrostimulation groups especially as the number of participants included in trials was relatively low. It is also possible that participants might not have received a full course of treatment because of intervention-related problems. It has not been possible to examine this possibility in this review.

When electrostimulation is compared with a placebo intervention this review found statistically significant differences between groups in favour of electrostimulation for functional motor ability - Jebsen Hand Function Test feeding and muscle function - cocontraction of agonist and antagonist muscles. However, both of these results were based on data from one study only. Cautious interpretation of this difference in favour of electrostimulation is therefore required. This review also found that electrostimulation was acceptable to participants as assessed by the finding of no statistically significant difference between groups for withdrawal of participants during the treatment phase.

When electrostimulation is compared with a conventional therapy intervention this review found that electrostimulation probably improves motor impairment as assessed by the Fugl-Meyer Assessment. No significant differences were found between groups for normality of movement, functional motor ability or global ADL. Electrostimulation was found to be acceptable to participants as assessed by the finding of no statistically significant 
difference between groups for withdrawal of participants during the treatment phase.

In summary, this review found the majority of benefits of electrostimulation in the comparison of electrostimulation with no treatment. That the majority of benefits were found for the comparison of electrostimulation and no treatment is not surprising as intensity of treatment is thought to be important for outcome (Kwakkel 2004). It is arguable therefore that the benefits found for electrostimulation in this review might be mostly due to the increased intensity of therapy apart from the one supporting finding of improvement in motor impairment (Fugl-Meyer Assessment) when electrostimulation is compared to conventional therapy. This interpretation is supported by the finding of no difference in motor score reported as part of the results of an earlier Cochrane review which investigated primarily whether electrostimulation prevented and/or reduced shoulder pain after stroke (Price 2001). However, four other systematic reviews have concluded that electrostimulation does have a beneficial effect on aspects of motor function after stroke (Bolton 2004; de Kroon 2002; Glanz 1996; Handy 2003). There are, though, limitations to these four systematic reviews as they included non-randomised studies (Bolton 2004; Glanz 1996); included studies which combined electrostimulation with other interventions such as visual feedback (de Kroon 2002; Glanz 1996); included follow up as well as outcome data (de Kroon 2002); included a study with a sample containing both people with a head injury and people with stroke (Handy 2003); and included studies from which it was not possible to extract data precisely as these were presented graphically (Handy 2003). We had also identified two further studies (Faghri 1994; Wang 2000) but received no reply from the trial authors to our communications and were therefore unable to obtain the raw data. We therefore consider that more confidence can be placed in the findings of our present review than in the four previous systematic reviews as it is more comprehensive and has included more appropriate primary trials.

Although we consider the present review to be more robust methodologically than the four other systematic reviews that drew positive conclusions about the effects of electrostimulation after stroke, there is a possibility that potential benefits could have been missed in this present review because of the organisation of the analysis. For example, the systematic review undertaken by Bolton and colleagues (Bolton 2004) suggests that eventtriggered electrostimulation improves functional outcome after stroke. This type of electrostimulation is described in this present review as groups 5 and 7 and these descriptors were used most often for the types of electrostimulation evaluated in the included trials (19 of 24 trials). Visual inspection of the results displayed in the graphs suggests that omission of data from trials evaluating electrostimulation in groups other than 5 and 7 (Daly 2004; Gosman-Hedstrom 1998; Johansson 2001; Pei 2001; Tekeoolu 1998) would probably: (1) provide an extra statistically significant difference in favour of electrostimulation compared with no treatment for normality of movement; and (2) remove the statistically significant difference in favour of electrostimulation compared with no treatment for global ADL. As both of the probable changes would occur within the electrostimulation versus no treatment comparison and as this comparison is probably confounded by the extra intensity of treatment provided to the experimental groups any changes from a re-analysis would not be clinically important. We considered undertaking a sensitivity analysis to check our visual interpretation but the number of trials available within electrostimulation groups other than 5 and 7 are insufficient to allow meta-analysis in the different comparisons and therefore any results would be inconclusive. The results of this present systematic review therefore do not allow any inferences to be made about the comparative effectiveness of different types of electrostimulation.

Functional electrical stimulation is a form of triggered electrostimulation that is being used clinically in the UK to improve the ability of people to walk after stroke. The primary trials that have influenced clinical practice in the UK have been those conducted by Burridge and colleagues (Burridge 1997). At first sight it appears that this present review contradicts the prevalent positive interpretation of the findings of these studies. However, the aim of this present review was to investigate the effects of using electrostimulation to change voluntary movement control (motor impairment and normality of movement), functional motor ability and ADL whilst electrostimulation was not being delivered to participants (neuromuscular re-training) and not to investigate the use of electrostimulation as what has been termed a 'neuroprosthesis/orthosis' (Alon 2003). We therefore used outcome measurement data from participants walking without FES being applied (Burridge 1997). This difference in examination of available data has led to the apparent disagreement with clinical use of FES and reviews conducted by other researchers (Kottink 2004).

Variation between primary trials is an important limitation that needs to be considered when interpreting the findings of this present review. For example, participant groups varied between included trials in time after stroke (ranged from 15.7 days to 4.29 years) and varied in the degree of functional deficit (included being able to stand unsupported and walk 10 metres, difficulty voluntarily initiating and controlling extension movements and also muscle grade $2 / 5$ or less). It is possible that time after stroke and the degree of ability to voluntarily contract a muscle might affect response to electrostimulation. Another source of variation are the different conventional therapies used as comparator treatments in included trials which were: passive and active approaches to gait therapy (Bogataj 1995); biofeedback (Cozean 1988); range of motion and strengthening exercises (Francisco 1998); and, Orthomercia SupraLite ankle-foot orthosis (Wright 2004). Yet another source of variation was provided by the different outcome measures which were not always possible to combine and resulted in some units of analysis containing data from one study only.

A further source of variation was the dose of electrostimulation which varied between included trials. It is possible that effectiveness might differ between different doses of electrostimulation. Which dose or doses might be more effective than others cannot be determined from this present review especially as it was unclear from the included trials whether dose of therapy was based on experimental studies of efficacy. This flaw in experimental design has also been highlighted by others (Alon 2003).

Methodological limitations in the quality of several of the included trials limit the ability of this review to reach firm conclusions about the effectiveness of electrostimulation. We detected the possibility that both selection bias and detection bias could have been present in the majority of included trials. We therefore recommend cautious interpretation of the findings of this present review. 


\section{AUTHORS' CONCLUSIONS}

\section{Implications for practice}

Whether or not electrostimulation should be used for neuromuscular re-training after stroke cannot be answered with the data available at present. Although data suggest some benefits for aspects of motor impairment and also for global ADL these results need to be interpreted with reference to the findings that most of these benefits occurred when electrostimulation was combined with conventional therapy and compared to conventional therapy. Intensity of treatment might therefore have influenced the findings. Cautious interpretation of these findings is also indicated by methodological flaws in the trials included in this present review including the apparent lack of an experimental basis for the dose of electrostimulation investigated. Further caution is suggested because the results of this review were mostly informed from data from single studies rather than two or more studies.

\section{Implications for research}

Electrostimulation is thought to be a beneficial intervention for neuromuscular re-training after stroke and yet robust data to inform its use are lacking. Trials are needed which investigate well defined types of electrostimulation which have biological plausibility and are delivered in doses shown in experimental
Phase I studies to be efficacious in enhancing the recovery of motor impairment, functional motor ability and/or ADL. Before undertaking such Phase I studies a logical first step is to undertake a systematic review (without meta-analysis) of investigative studies of electrostimulation (Phase I, II and III) to find whether there is preliminary evidence of efficacy for any dose of the 16 types of electrostimulation described in this review (Table 1). Where preliminary evidence to inform Phase III studies is lacking then it would be advisable to undertake Phase I studies of different types of electrostimulation to determine which dose might be most efficacious with least adverse effects for which groups of stroke survivors.

\section{ACKNOWLEDGEMENTS}

We are grateful to Anthea Dendy for her clinical expertise in developing the description of the types of electrostimulation interventions. We are also grateful to Hazel Fraser and Brenda Thomas of the Cochrane Stroke Group for their patience in dealing with our questions and expertise in delivering the answers. The expertise of Olwen Revill and Anna El-Jouzi, librarians at St George's University of London, was invaluable during the literature searching and also in helping to obtain papers which had been published in journals which turned out to be difficult to locate. We express our thanks to both of them. 


\section{R E F E R E N C E S}

\section{References to studies included in this review}

Bogataj 1995 \{published data only\}

Bogataj U, Gros N, Kljajic M, Acimovic R, Malezic M. The rehabilitation of gait in patients with hemiplegia: a comparison between conventional therapy and multichannel stimulation therapy. Physical Therapy 1995;75(6):490-502.

\section{Burridge 1997 \{published data only\}}

Burridge JH, Taylor P, Hagan S, Wood D, Swain I. The effect of common peroneal nerve stimulation on quadriceps spasticity in hemiplegia. Physiotherapy 1997;83(2):82-9.

* Burridge JH, Taylor PN, Hagan SA, Wood DE, Swain ID. The effects of common peroneal stimulation on the effort and speed of walking: a randomized controlled trial with chronic hemiplegic patients. Clinical Rehabilitation 1997;11:201-10.

\section{Cauraugh 2000 \{published data only\}}

Cauraugh J, Light K, Kim S, Thigpen M, Behrman A. Chronic motor dysfunction after stroke. Recovering wrist and finger extension by electromyography-triggered neuromuscular stimulation. Stroke 2000;31:1360-4.

\section{Cauraugh 2002 \{published data only\}}

Cauraugh JH, Kim S. Two coupled motor recovery protocols are better than one: Electromyogram-triggered neuromuscular stimulation and bilateral movements. Stroke 2002;33:1589-94.

\section{Cauraugh 2003 \{published data only\}}

Cauraugh JH, Kim SB. Chronic stroke motor recovery: duration of active neuromuscular stimulation. Journal of the Neurological Sciences 2003;215:13-9.

\section{Chae 1998 \{published data only\}}

Chae J, Bethoux F, Bohinc T, Dobos L, Davis T, Friedl A. Neuromuscular stimulation for upper extremity motor and functional recovery in acute hemiplegia. Stroke 1998;29:975-9.

\section{Cozean 1988 \{published data only\}}

Cozean CD, Pease WS, Hubbell SL. Biofeedback and functional electric stimulation in stroke rehabilitation. Archives of Physical Medicine and Rehabilitation 1988;69:401-5.

\section{Daly 2004 \{unpublished data only\}}

Daly JJ, Roenigk KL, Butler KM, Gansen JL, Rogers J, Ruff RL. Response of sagittal plane gait kinematics to weight supported treadmill training and functional neuromuscular stimulation following stroke. Journal of Rehabilitation Research \& Development in press, 2004.

\section{Francisco 1998 \{published data only\}}

Francisco G, Chae J, Chawla H, Kirshblum S, Zorowitz R, Lewis $\mathrm{G}$, et al. Electromyogram-triggered neuromuscular stimulation for improving the arm function of acute stroke survivors: a randomized pilot study. Archives of Physical Medicine and Rehabilitation 1998;79:570-5.

\section{Gosman-Hedstrom 1998 \{published data only\}}

Gosman-Hedstrom G, Claesson L, Klingenstierna U, Carlsson J, Olausson B, Frizell M, et al. Effects of acupuncture treatment on daily life activities and quality of life. A controlled, prospective and randomized study of acute stroke patients. Stroke 1998;29:2100-8.

\section{Heckman 1997 \{published data only\}}

Heckmann J, Mokrusch T, Krockel A, Warnke S, von Stockert WT, Neundorfer B. EMG-triggered electrical muscle stimulation in the treatment of central hemiparesis after a stroke. European Journal of Physical Medicine and Rehabilitation 1997;7:138-41.

\section{Johansson 2001 \{published data only\}}

Johansson BB, Haker E, von Arbin M, Britton M, Langstrom G, Terent $A$, et al. Acupuncture and transcutaneous nerve stimulation in stroke rehabilitation. Stroke 2001;32:707-13.

\section{Kimberley 2004 \{published data only\}}

Kimberley TJ, Lewis SM, Auerbach EJ, Dorsey LL, Lojovich JM, Carey JR. Electrical stimulation driving functional improvements and cortical changes in subjects with stroke. Experimental Brain Research 2004;154:450-60.

\section{King 1996 \{published data only\}}

King TI II. The effect of neuromuscular electrical stimulation in reducing tone. American Journal of Occupational Therapy 1996;50(1):62-4.

\section{Linn 1999 \{published data only\}}

Linn SL, Granat MH, Lees KR. Prevention of shoulder subluxation after stroke with electrical stimulation. Stroke 1999;30:963-8.

\section{Macdonell 1994 \{published data only\}}

Macdonell RAL, Triggs WJ, Leikauskas J, Bourque M, Robb K, Day BJ, et al. Functional electrical stimulation to the affected lower limb and recovery after cerebral infarction. Journal of Stroke and Cerebrovasular Diseases 1994;4:155-60.

\section{Merletti 1978 \{published and unpublished data\}}

Merletti R, Zelaschi F, Latella D, Galli M, Angeli S, Sessa MB. A control study of muscle force recovery in hemiparetic patients during treatment with functional electrical stimulation. Scandinavian Journal of Rehabilitation Medicine 1978;10:147-54.

Pei 2001 \{published data only\}

Pei J, Sun L, Chen R, Tianming Z, Yuezhou Q, Dongjian Y. The effect of electro-acupuncture on motor function recovery in patients with acute cerebral infarction: a randomly controlled trial. Journal of Traditional Chinese Medicine 2001;21(4):270-2.

\section{Popovic 2003 \{published data only\}}

Popovic MB, Popovic DB, Sinkjaer T, Stefanovic A, Schwirtlich L. Clinical evaluation of functional electrical therapy in acute hemiplegic subjects. Journal of Rehabilitation Research \& Development 2003;40(5):443-54. 
Powell 1999 \{published data only\}

Powell J, Pandyan AD, Granat M, Cameron M, Stott DJ. Electrical stimulation of wrist extensors in poststroke hemiplegia. Stroke 1999;30:1384-9.

\section{Sonde 1998 \{published data only\}}

Sonde L, Fernaeus SE, Nilsson CG, Viitanen M. Stimulation with low frequency $(1.7 \mathrm{~Hz})$ transcutaneous electric nerve stimulation (low-TENS) increases motor function of the poststroke paretic arm. Scandinavian Journal of Rehabilitation Medicine 1998;30:95-9.

\section{Tekeoolu 1998 \{published data only\}}

Tekeoolu Y, Adak B, Goksoy T. Effect of transcutaneous electrical nerve stimulation (TENS) on Barthel Activities of Daily Living (ADL) Index score following stroke. Clinical Rehabilitation 1998;12:277-80.

\section{Wright 2004 \{unpublished data only\}}

Wright PA, Mann GE, Swain I. A comparison of electrical stimulation and the conventional ankle foot orthosis in the correction of a dropped foot following stroke. Final report to funder 2004

\section{Yan 2005 \{published data only\}}

Yan T, Hui-Chan CWY, Li LSW. Functional electrical stimulation improves motor recovery of the lower extremity and walking ability of subjects with first acute stroke. A randomized placebocontrolled trial. Stroke 2005;36:80-5.

\section{References to studies excluded from this review}

\section{Baker 1986 \{published data only\}}

Baker LL, Parker K. Neuromuscular electrical stimulation of the muscles surrounding the shoulder. Physical Therapy 1986;12:1930-7.

\section{Berner 2004 \{published data only\}}

Berner YN, Kimchi O L, Sponkoiny V, Finkeltov B. The effect of electric stimulation treatment on the functional rehabilitation of acute geriatric patients with stroke - a preliminary study. Archives of Gerontology and Geriatrics 2004;39:125-32.

\section{Bowman 1979 \{published data only\}}

Bowman BR, Bake LL, Waters RL. Positional feedback and electrical stimulation: an automated treatment for the hemiplegic wrist. Archives of Physical Medicine and Rehabilitation 1979;60(11):497-502.

\section{Cauraugh 2003d \{published data only\}}

Cauraugh JH, Kim SH. Stroke motor recovery: active neuromuscular stimulation and repetitive practice schedules. Journal of Neurology Neurosurgery and Psychiatry 2003;74(11):1562-6.

\section{Chantraine 1999 \{published data only\}}

Chantraine A, Baribeault A, Uebelhart D, Gremion G. Shoulder pain and dysfunction in hemiplegia: effects of functional electrical stimulation. Archives of Physical Medicine and Rehabilitation 1999;80:328-31.

\section{Chen 2000 \{published data only\}}

Chen $\mathrm{C}-\mathrm{H}$, Chen T-W, Weng M-C, Wang W-T, Wang Y-L, Huang M$\mathrm{H}$. The effect of electroacupuncture on shoulder subluxation for stroke patients. Kaohsiung Journal Medical Science 2000;16:525-32.

\section{de Kroon 2004 \{published data only\}}

de Kroon JR, ljzerman MJ, Lankhorst GJ, Zilvold G. Electrical stimulation of the upper limb in stroke: stimulation of the extensors of the hand vs alternate stimulation of flexors and extensors. American Journal of Physical Medicine and Rehabilitation 2004;83:592-600.

Faghri 1994 \{published data only\}

Faghri PD, Rodgers MM. The effects of functional neuromuscular stimulation-augmented physical therapy program in the functional recovery of hemiplegic arm in stroke patients. Clinical Kinesiology 1997;51:9-15.

* Faghri PD, Rodgers MM, Glaser RM, Bors JG, Ho C, Akuthota P. The effects of functional electrical stimulation on shoulder subluxation, arm function recovery, and shoulder pain in hemiplegic stroke patients. Archives of Physical Medicine and Rehabilitation 1994;75:73-9.

\section{Gritsenko 2004 \{published data only\}}

Gritsenko V, Prochazka A. A Functional Electric Stimulation assisted exercise therapy system for hemiplegic hand function. Archives of Physical Medicine and rehabilitation 2004;85:881-5.

\section{Hesse 1995 \{published data only\}}

Hesse S, Jahnke MT, Luecke D, Mauritz KH. Short-term electrical stimulation enhances the effectiveness of Botulinum toxin in the treatment of lower limb spasticity in hemiparetic patients. Neuroscience Letters 1995;201:37-40.

\section{Hesse 1998 \{published data only\}}

Hesse S, Reiter F, Konrad M, Jahnke MT. Botulinum toxin type A and short-term electrical stimulation in the treatment of upper limb flexor spasticity after stroke: a randomized, double-blind, placebo-controlled trial. Clinical Rehabilitation 1998;12:381-8.

Johansson 1995 \{published data only\}

Johansson BJ. Acupuncture in stroke rehabilitation. Acupuncture in Medicine 1995;13(2):81-4.

Johnson 2002 \{published data only\} Johnson CA, Wood DE, Swain ID, Tromans AM, Strike P, Burridge J. A pilot study to investigate the combined use of Botulinum neurotoxin type $A$ and functional electrical stimulation, with physiotherapy, in the treatment of spastic dropped foot in subacute stroke. Artificial Organs 2002;26(3):263-6

\section{Johnson 2004 \{published data only\}}

Johnson CA, Burridge JH, Strike PW, Wood DE, Swain ID. The effect of combined use of Botulinum toxin type $A$ and Functional Electric Stimulation in the treatment of spastic drop foot after stroke: a preliminary investigation. Archives of Physical Medicine and Rehabilitation 2004;85:902-9. 
Khaslavskaia 2002 \{published data only\}

Khaslavskaia S, Ladouceur M, Sinkjaer T. Increase in tibialsi anterior motor cortex excitability following repetitive electrical stimulation of the common peroneal nerve. Experimental Brain Research 2002;145:309-15.

\section{Kobayashi 1999 \{published data only\}}

Kobayashi H, Onishi H, Ihashi K, Yagi R, Handa Y. Reduction in subluxation and improved muscle function of the hemiplegic shoulder joint after therapeutic electrical stimulation. Journal of Electromyography and Kinesiology 1999;9:327-36.

Landau 2002 \{published data only\} Landau WM, Sahrmann SA. Preservation of directly stimulated muscle strength in hemiplegia due to stroke. Archives of Neurology 2002;59:1453-7.

Levin 1992 \{published data only\} Levin MF, Hui-Chan CWY. Relief of hemiparetic spasticity by TENS is associated with improvement in reflex and voluntary motor functions. Electroencephalography and Clinical Neurophysiology: Electromyography and Motor Control 1992:85:131-42.

\section{Magnusson 1994 \{published data only\}}

Magnusson MK, Johansson K, Johansson BB. Sensory stimulation promotes normalization of postural control after stroke. Stroke 1994;25:1176-80.

\section{Naeser 1994 \{published data only\}}

Naeser MA, Alexander MP, Stiassny-Eder D, Nobles Lannin L, Bachman D. Acupuncture in the treatment of hand paresis in chronic and acute stroke patients - improvement observed in all cases. Clinical Rehabilitation 1994;8:127-41.

\section{Popovic 2002 \{published data only\}}

Popovic MB, Popovic DB, Schwirlich L, Sinkjaer T. Functional electrical therapy: clinical trial in chronic hemiplegic subjects. Neuromodulation 2004;7:133-40.

* Popovic MB, Popovic DB, Sinjaer T, Stefanovic A, Schwirtlich L. Restitution of reaching and grasping promoted by functional electrical therapy. Artificial Organs 2002;26(3):271-5.

\section{Takebe 1976 \{published data only\}}

Takbe K, Basmajian JV. Gait analysis in stroke patients to assess treatments of foot-drop. Archives of Physical Medicine and Rehabilitation 1976;57:305-10.

Wang 2000 \{published data only\}

* Wang R-Y, Chan R-C, Tsai M-W. Functional electrical stimulation on chronic and acute hemiplegic shoulder subluxation. American Journal of Physical Medicine and Rehabilitation 2000;79(4):385-94.

Wang RY, Yang YR, Tsai MW, Wang WTJ, Chan RC. Effects of functional electric stimulation on upper limb motor function and shoulder range of motion in hemiplegic patients. American Journal of Physical Medicine and Rehabilitation 2002;81:283-90.
Winchester 1983 \{published data only\}

Winchester P, Montgomery J, Bowman B, Hislop H. Effects of feedback stimulation training and cyclical electrical stimulation on knee extension in hemiparetic patients. Physical Therapy 1983;63(7):1096-103.

\section{Wong 1999 \{published data only\}}

Wong AMK, Su T-Y, Tang F-T, Cheng P-T, Liaw M-Y. Clinical trial of electrical acupuncture on hemiplegic stroke patients. American Journal of Physical Medicine and Rehabilitation 1999;78:117-22.

\section{Yu 2004 \{published data only\}}

Yu DT, Chae J, Walker ME, Kirsteins A, Elovic EP, Flanagan SR, et al. Intramuscular neuromuscular electric stimulation for poststroke shoulder pain: a multicenter randomized clinical trial. Archives of Physical Medicine and Rehabilitation 2004;85:695-704.

\section{References to studies awaiting assessment}

Umarova 2005 \{published data only\}

Umarova RM, Tanashyan MM, Chernikova LA, Krotenkova MV. Neuromuscular electrostimulation of paretic muscles in acute stage of stroke. Cerebrovascular Diseases 2005;19 Suppl 2:93.

\section{References to ongoing studies}

Mokrusch 1997 \{published data only\}

Mokrusch T. Stroke-induced spastic hemiparesis with EMGtriggered electrostimulation. Neurologie und Rehabilitation 1997;2:82-6.

\section{Additional references}

\section{Alon 2003}

Alon G. Use of neuromuscular electrical stimulation in neurorehabilitation: a challenge to all. Journal of Rehabilitation Research and Development 2003;40:ix-xii.

\section{Andrews 2000}

Andrews AW, Bohannon RW. Distribution of muscle strength impairments following stroke. Clinical Rehabilitation 2000;14:79-87.

\section{Ashburn 1993}

Ashburn A, Partridge C, de Souza L. Physiotherapy in the rehabilitation of stroke: a review. Clinical Rehabilitation 1993;7:337-45.

\section{Beech 1996}

Beech R. Economic evaluation of stroke care. In: Wolf C, Rudd T, Beech R editor(s). Stroke services and research: an overview with recommendations for future research. London: The Stroke Association, 1996.

\section{Bolton 2004}

Bolton DAE, Cauraugh JH, Hausenblas HA. Electromyogramtriggered neuromuscular stimulation and stroke motor 
recovery of arm/hand functions: a meta-analysis. Journal of the Neurological Sciences 2004;223:121-7.

\section{Bonita 1997}

Bonita R, Solomon N, Broad JB. Prevalence of stroke and strokerelated disability: estimates from the Auckland stroke studies. Stroke 1997;28:1898-902.

\section{Brown 1999}

Brown RD, Ransom J, Hass S, Petty GW, O'Fallon MW, Whisnant JP, et al. Use of nursing home after stroke and dependence on stroke severity: a population-based analysis. Stroke 1999;30:924-9.

\section{Carr 1994}

Carr JH, Mungovan SF, Shepherd RB, Dean CM, Nordholm LA. Physiotherapy in stroke rehabilitation: bases for Australian physiotherapists' choice of treatment. Physiotherapy Theory and Practice 1994;10:201-9.

\section{Cifu 1999}

Cifu DX, Stewart DG. Factors affecting functional outcome after stroke: a critical review of rehabilitation interventions. Archives of Physical Medicine and Rehabilitation 1999;80:S35-9.

\section{de Kroon 2002}

de Kroon JR, van der Lee JH, IJzerman MJ, Lankhorst GJ. Therapeutic electrical stimulation to improve motor control and functional abilities of the upper extremity after stroke: a systematic review. Clinical Rehabilitation 2002;16:350-60.

\section{Dean 1997}

Dean CM, Shepherd RB. Task-related training improves performance of seated reaching tasks after stroke. A randomised controlled trial. Stroke 1997;28:722-8.

\section{Ernst 1990}

Ernst $\mathrm{E}$. A review of stroke rehabilitation and physiotherapy. Stroke 1990;21:1081-5.

\section{Feys 1998}

Feys HM, DeWeerdt W, Selz BE, Cox Steck GA, Spichiger R, Vereeck LE, et al. Effect of a therapeutic intervention for the hemiplegic upper limb in the acute phase after stroke. A single-blind, randomised, controlled multicentre trial. Stroke 1998;29:785-92.

\section{Glanz 1996}

Glanz M, Klawansky S, Stason W, Berkey C, Chalmers T. Functional electrostimulation in poststroke rehabilitation: a meta-analysis of the randomised controlled trials. Archives of Physical Medicine and Rehabilitation 1996;77:549-53.

\section{Golaszeski 2004}

Golaszewski SM, Siedentopf CM, Koppelstaetter F, Rhomberg P, Guendisch GM, Schlager A, et al. Modulatory effects on human sensorimotor cortex by whole-hand afferent electrical stimulation. Neurology 2004;62:2262-9.

\section{Hachisuka 1997}

Hachisuka K, Umezu Y, Ogata H. Disuse muscle atrophy of lower limbs in hemiplegic patients. Archives of Physical Medicine and Rehabilitation 1997;78:13-8.

\section{Hallet 1998}

Hallet M, Wassermann EM, Cohen LG, Chielowska J, Gerloff C. Cortical mechanisms of recovery of function after stroke. Neurorehabilitation 1998;10:131-42.

\section{Hamdy 1998}

Hamdy S, Rothwell JC, Aziz Q, Singh KD, Thompson DG. Longterm reorganization of human motor cortex driven by shortterm sensory stimulation. Nature Neuroscience 1998;1(1):64-8.

\section{Handy 2003}

Handy J, Salinas S, Blanchard SA, Aitken MJ. Meta-analysis examining the effectiveness of electrical stimulation in improving functional use of the upper limb in stroke patients. Physical and Occupational Therapy in Geriatrics 2003;21:67-78.

\section{Hatano 1976}

Hatano S. Experience from a multicentre stroke register: a preliminary report. Bulletin of the World Health Organisation 1976;54:541-53.

\section{Kottink 2004}

Kottink AIR, Oostendorp LJM, Buurke RPT, Nene AV, Hermans HJ, ljzerman MJ. The orthotic effect of functional electric stimulation on the improvement of walking in stroke patients with a dropped foot: a systematic review. Artificial Organs 2004;28:577-86.

\section{Kwakkel 1999}

Kwakkel G, Wagnenaar RC, Twisk JWR, Lankhorst GJ, Koestier JC. Intensity of leg and arm training after primary middle-cerebral-artery stroke: a randomised trial. Lancet 1999;354:191-6.

\section{Kwakkel 2004}

Kwakkel G, van Peppen R, Wagenaar RC, Dauphinee SW, Richards C, Ashburn A, et al. Effects of augmented exercise therapy time after stroke. A meta-analysis. Stroke 2004;35:2529-36.

\section{Moseley 2003}

Moseley AM, Stark A, Cameron ID, Pollock A. Treadmill training and bodyweight support for walking after stroke. Cochrane Database of Systematic Reviews 2003, Issue 3. [Art. No.: CD002840. DOI: 10.1002/14651858.CD002840]

\section{Nilsson 1992}

Nilsson LM, Nordholm LA. Physical therapy in stroke rehabilitation: bases for Swedish physiotherapists' choice of treatment. Physiotherapy Theory and Practice 1992;8:49-55.

\section{Nudo 1996}

Nudo RJ, Wise BM, SiFuentes F, Miliken GW. Neural substrates for the effects of rehabilitative training on motor recovery after ischemic infarct. Science 1996;272:1791-4. 


\section{Parry 1999}

Parry RH, Lincoln NB, Vass CD. Effect of severity of arm impairment on response to additional physiotherapy early after stroke. Clinical Rehabilitation 1999;13:187-98.

\section{Pollock 2003}

Pollock A, Baer G, Pomeroy V, Langhorne P. Physiotherapy treatment approaches for the recovery of postural control and lower limb function following stroke. Cochrane Database of Systematic Reviews 2003, Issue 3. [Art. No.: CD001920. DOI: 10.1002/14651858.CD001920]

\section{Pomeroy 2000a}

Pomeroy VM, Tallis RC. Physical therapy to improve movement performance and functional ability post-stroke. Part 1: Existing evidence. Reviews in Clinical Gerontology 2000;10:261-90.

\section{Pomeroy 2000b}

Pomeroy VM, Tallis RC. Need to focus research in stroke rehabilitation. Lancet 2000;355:836-7.

\section{Pomeroy 2001}

Pomeroy VM, Niven DS, Barrow S, Faragher EB, Tallis RC. Unpacking the black box of nursing and therapy practice for post-stroke shoulder pain: a precursor to evaluation. Clinical Rehabilitation 2001;15:67-83.

\section{Potempa 1996}

Potempa K, Braun L, Tinknell T, Popovich J. Benefits of aerobic exercise after stroke. Sports Medicine 1996;21:337-46.

\section{CHARACTERISTICS OF STUDIES}

Characteristics of included studies [ordered by study ID]

\section{Price 2001}

Price CIM, Pandyan AD. Electrical stimulation for preventing and treating post-stroke shoulder pain. Cochrane Database of Systematic Reviews 2001, Issue 2. [Art. No.: CD001698. DOI: 10.1002/14651858.CD001698]

\section{SUTC 2001}

Stroke Unit Trialists' Collaboration. Organised inpatient (stroke unit) care for stroke. Cochrane Database of Systematic Reviews 2001, Issue 2. [Art. No.: CD000197. DOI: 10.1002/14651858.CD000197]

\section{Tanaka 1998}

Tanaka S, Hachisuka K, Ogata H. Muscle strength of trunk flexion-extension in post-stroke hemiplegic patients. American Journal of Physical Medicine and Rehabilitation 1998;77:288-90.

\section{Wade 1992}

Wade DT, Collen FM, Robb GF, Warlow CP. Physiotherapy intervention late after stroke and mobility. $B M J$ 1992;304:609-13.

\section{Yekutiel 1993}

Yekutiel M, Guttman E. A controlled trial of the retraining of the sensory function of the hand in stroke patients. Jouranl of Neurology Neurosurgery and Psychiatry 1993;56:241-4.

* Indicates the major publication for the study

Bogataj 1995

Methods Design: A randomised crossover trial (in this review we only extracted data from baseline to crossover point). Randomisation: 'randomly assigned'. Dropouts: None reported.

Participants

20 inpatients recruited, all were right-side dominant.

Experimental: 5 male \& 5 female, 2 left hemiplegia \& 8 right hemiplegia, mean age 53.4 years (SD 11.5), mean time after stroke 116 days (SD 66).

Control: 6 male \& 4 female, 9 left hemiplegia \& 1 right hemiplegia, mean age 59.1 years (SD 9), time after stroke 104 days (SD 62).

Study criteria: (1) could stand independently or with aid of one or two therapists; (2) muscle contraction with indicated movement in the corresponding joint obtained by functional electrical stimulation for each muscle treated; (3) exertion during therapy would not adversely affect participant's health; (4) preserved perceptual and intellectual abilities; (5) no suspected or confirmed cardiovascular infarction or demand pacemaker; (6) no extreme reflex activity; (7) no hypersensitivity; (8) no pain; (9) no lower motor neurone lesion; (10) no changes to skin in area of stimulation; (11) no changes in bone-joint structures; (12) agreed to application of functional electrical stimulation.

Duration: 3 weeks
Experimental:
Category $=5$.
Multichannel functional electrical stimulation therapy given for 30 to 60 minutes per session (including
application of electrodes), once a day, 5 times a week for 3 weeks. Amplitudes of the stimulating pulses
set to $80 \%$ of amplitude which produced non-volitional movement in joint. Stimulation sequence was
determined for each participant so that optimum correction of anomalies was achieved. During stim-



peroneal nerve, soleus, hamstrings, quadriceps femoris group, gluteus maximus and, optionally, to triceps brachii.

Control: Conventional gait therapy consisting of a 'passive and active approach'. The emphasis was on the active approach which consisted of Bobath techniques, PNF, visual biofeedback, audiovisual biofeedback, gait training and use of orthoses. The passive approach included icing, heating, brushing, positioning and use of a tilt table. Therapy was provided once a day, 5 times a week for 3 weeks. Comparison: Electrostimulation vs conventional.

\begin{tabular}{ll}
\hline Outcomes & Baseline measurement: beginning of therapy period. \\
& Outcome measurement: End of therapy period i.e. 3 weeks. \\
Included outcomes: (1) stride length; (2) gait velocity; (3) cadence; (4) Fugl-Meyer Assessment. \\
Other outcomes: (1) vertical ground reaction force during stance phase; (2) trajectory of centre of pres- \\
sure under each foot in stance phase.
\end{tabular}

Notes The type of electrode used was changed at some point during the study and this may be a confounding factor.

Excluded patients who refused application of functional electrical stimulation.

Some weight shifting was facilitated by a therapist accompanying experimental participants walking with electrostimulation applied. This replicates some of the conventional therapy provided to the control group but it appears that this was minimal. However, this could be a confounding factor affecting interpretation of the results of this trial.

Some missing data in experimental group.

\section{Risk of bias}

\begin{tabular}{lll}
\hline Bias & Authors' judgement & Support for judgement \\
\hline Allocation concealment? & High risk & C - Inadequate \\
\hline
\end{tabular}

Burridge 1997

$\begin{array}{ll}\text { Methods } & \text { Design: Randomised controlled trial, parallel group } \\ & \text { Randomisation: Block randomisation. Before recruitment of participants a list of } 34 \text { numbers were ran- } \\ & \text { domly allocated to experimental or control. List not held by researchers and allocated to groups as re- } \\ \text { cruited to study. } & \\ \text { Dropouts: None reported. }\end{array}$

Participants
Participants recruited from consultants, GP and physiotherapy referrals.
Some participants referred themselves after reading an article in the 'Independent' newspaper.
Experimental: $\mathrm{n}=16,10$ male and 9 right hemiparesis. Mean age was 52 years 3 months (SD 14 years 3
months) and a mean time after stroke of 3 years 7 months.
Control: $\mathrm{n}=16,13$ male and 8 right hemiparesis. Mean age was 61 years 3 months (SD 8 years 6
months) and mean time after stroke was 4 years 11 months.
Study criteria: (1) hemiplegia of at least 6 months duration; (2) a single foot drop as a result of a CVA;
(3) sufficient dorsiflexion of the ankle with electrical stimulation to enable heel strike when walking
and without undue discomfort; (4) unimpaired cognition; (5) understanding of the use of the device; (6)
positive motivation; (7) able to stand unsupported and able to walk 10 metres (walking aids allowed
but not use of another person); (8) able to stand from sitting without help and walk a minimum of 50
metres before the CVA; (9) no other medical conditions severe enough to impair walking; (10) no hyper-
sensitivity to the sensation of the stimulation.

Interventions Duration: $4 / 5$ weeks (1 month).

Experimental: 
Category $=7$. Electrical stimulation was provided externally to the common peroneal nerve to produce tibialis anterior contraction during the swing phase of gait. The level of stimulation was controlled by the participants who were taught to adjust this to achieve an effective heel strike. Experimental participants were also provided with 10, 1-hour physiotherapy sessions given over a 1-month period by Bobath-trained therapists but some of this time was spent adjusting stimulation parameters Control:

The control therapy was 10, 1-hour physiotherapy sessions given over 1-month by Bothath-trained physiotherapists.

Comparison: Electrostimulation vs no treatment.

Baseline measurement: before intervention began.
Outcome measurement: At end of 4/5 week (1 month) intervention period.
Included outcomes: (1) walking speed without stimulation; (2) physiological cost index without stimu-
lation; (3) Wartenberg pendulum test relaxation index for hemiplegic leg
Other outcomes: (1) walking speed with stimulation for experimental and without stimulation for con-
trol group; (2) physiological cost index with stimulation for experimental group and without stimula-
tion for control group; (3) Wartenberg pendulum test area under the curve for hemiplegic leg.

Notes One of the study criteria excluded potential participants who had no observed improvement in walking with stimulation.

The co-intervention for the experimental group was not identical to that provided for the control group as it included adjusting the stimulation parameters for best dorsiflexion effect and not just provision of conventional physical therapy.

We excluded the outcome comparison of the experimental group walking with electrostimulation and control group walking without stimulation but included the outcome comparison of the experimental group walking without electrostimulation and control group walking without stimulation. This decision was taken to match the measurement conditions of the experimental and control group as it remains a possibility that the walking ability of the control group might have been better with electrostimulation than it was without it.

\section{Risk of bias}

\begin{tabular}{lll}
\hline Bias & Authors' judgement & Support for judgement \\
\hline Allocation concealment? & High risk & C - Inadequate \\
\hline
\end{tabular}

\section{Cauraugh 2000}

\section{Methods}

Design: A randomised crossover trial (in this review we only extracted data from baseline to crossover point). Randomisation: 'randomly assigned to either an experimental or control group' Dropouts: None reported.

Participants

11 participants, 6 female and 10 right hemisphere stroke. Mean age 61.64 (SD 9.57) years. Mean time after stroke 3.49 (SD 2.56) years.

Study criteria: (1) no more than 75\% motor recovery; (2) able to voluntarily extend the wrist 20 degrees against gravity from a 90 degrees flexion position; (3) no other neurological deficits.

Participants instructed to initiate wrist/finger extension so that a target level of voluntary EMG activity triggered the neuromuscular stimulation to assist the muscles to reach a full range of motion. Experimental participants also received therapy received by control participants but not the voluntary practice of lifting the wrist as this was part of the electrostimulation sessions.

Control: 
General passive range of motion activity with hemiparetic arm. Short period of gentle stretching to the wrist and finger flexors. Participants tried to voluntarily lift their wrist for 2 sessions of 30 trials.

Comparison: electrostimulation vs no treatment.

Outcomes

Outcome measurement: After 2 weeks intervention.

Included outcomes: (1) Box and Blocks Test; (2) sustained muscle contraction.

Other outcomes: Unavailable from published paper or from author after a direct response, (1) Fugl-

Meyer Assessment; (2) premotor reaction time; (3) motor reaction time; (4) total reaction time.

Notes

\section{Risk of bias}

\begin{tabular}{lll}
\hline Bias & Authors' judgement & Support for judgement \\
\hline Allocation concealment? & Unclear risk & B - Unclear \\
\hline
\end{tabular}

Cauraugh 2002

Design: Randomised controlled trial, parallel groups.
Randomisation: Randomly assigned with the restriction that only 5 were assigned to the control
group.
Dropouts: None reported.

Participants 25 participants were recruited to this study but only 15 participants (10 in experimental and 5 in control group) are included in this review. The mean age for the 25 participants was 63.7 years, mean time since stroke was 39.1 months. 12 participants had a left hemiplegia and 13 a right hemiplegia. Study criteria: (1) suffered a stroke at least one year before recruitment to study; (2) diagnosis of no more than 2 strokes on the same side of the brain; (3) mild to moderate upper extremity chronic hemiparesis; (4) lower limit of 10 degrees from a 90 degree wrist flexed position; (5) an upper limit of $80 \%$ motor recovery as indicated by comparing the rectified EMG activation patterns and sustained force contractions of the impaired and unimpaired limbs; (6) absence of other neurological deficits including a pacemaker; (7) no use of drugs for spasticity.

Interventions Duration: 2 weeks.

Experimental:

Category $=5$.

EMG triggered stimulation to extensor communis digitorum and extensor carpi ulnaris. When target threshold of EMG activity was voluntarily achieved the stimulation was triggered of 1 second ramp up, 5 seconds biphasic stimulation at $50 \mathrm{~Hz}$, pulse width 200ms, 1 second ramp down and mA range of 16 to 29. Parameters were set that assisted the muscles to execute a full range of motion. Each trial was separated by 25 seconds of rest. A session consisted of 3 sets of 30 successful EMG-triggered trials (approximately 1 hour 30 minutes). 6 hours of training ( 4 days) were completed during 2 weeks. All experimental participants received unilateral arm movement training given to the control group. Control: Unilateral arm movement training. After stretching, participants tried to voluntarily extend their wrist/fingers for 5 seconds followed by 25 seconds of rest. These repeated movement attempts and rest periods continued for approximately 90 minutes.

Comparison: Electrostimulation vs no treatment.

\section{Outcomes Baseline measurement: Pre-intervention.}

Outcome measurement: After the intervention at 2 weeks.

Included outcomes: (1) box and blocks test; (2) premotor reaction time; (3) motor reaction time; (4) sustained muscle contraction unilateral.

Other outcomes: (1) sustained muscle contraction bilateral. 
Cauraugh 2002 (Continued)

Risk of bias

\begin{tabular}{lll}
\hline Bias & Authors' judgement & Support for judgement \\
\hline Allocation concealment? & Unclear risk & B - Unclear \\
\hline
\end{tabular}

Cauraugh 2003

Methods Design: Randomised controlled trial, three parallel groups (2 groups included in this review see notes below).

Randomisation: 'The randomisation procedure was consistent with recommendations by Altman and Schulz' (Altman, Schulz. BMJ 2001;323:446-7).

Dropouts: None recorded.

Participants $\mathrm{n}=16$.
Experimental: $\mathrm{n}=10,6$ female and 8 left hemisphere strokes.
Control: $\mathrm{n}=6,2$ female and 3 left hemisphere stroke.
Study criteria: (1) suffered a stroke more than 12 months before recruitment; (2) partial paralysis in
wrist/fingers; (3) difficulty voluntarily initiating and controlling extension movements; (4) diagnosis of
no more than 2 strokes on the same side of the brain; (5) able to extend 10 degrees from a 90 degree
wrist flexed position but no more than $80 \%$ motor recovery as indicated by comparing the rectified
EMG activation patterns and sustained force contractions of the impaired and unimpaired limbs; (6) ab-
sence of other neurological deficits; (7) able to follow directions.

Interventions Duration: 2 weeks.

Experimental:

Category $=5$.

EMG-triggered electrostimulation to take muscles into full range wrist/finger extension. Electrostimulation given for 5 seconds with a 1 second ramp up, biphasic stimulation at $50 \mathrm{~Hz}, \mathrm{~mA}$ range of $17-28$, pulse width of $200 \mathrm{~ms}$ and 1 second ramp down. Training given for 6 hours across 4 days in a 2 week period. All experimental participants also received the control intervention.

Control: Bilateral movement training consisting of mirror movements on the unimpaired wrist/fingers simultaneously with the initiation of the impaired wrist/fingers extension movement attempts. Training given for 6 hours across 4 days in a 2 week period. Comparison: Electrostimulation vs no treatment.

Outcomes Baseline measurement: Pre-intervention.

Outcome measurement: After intervention at 2 weeks.

Included outcomes: (1) Box and Blocks test; (2) sustained muscle contraction; (3) pre-motor reaction time unilateral.

Other outcomes: (1) pre-motor reaction time bilateral.

\section{Notes}

This study also examined the effects of providing electrostimulation for 5 second as well as 10 second bursts. However, these data were not included in analysis as data could not be combined. We therefore included the 10 second data in the analysis as this condition provided a higher intensity of treatment.

\section{Risk of bias}

\begin{tabular}{lll}
\hline Bias & Authors' judgement & Support for judgement \\
\hline Allocation concealment? & Low risk & A - Adequate \\
\hline
\end{tabular}


Design: Randomised controlled trial, parallel groups.

Randomisation: No specific statement about randomisation process was provided apart from 'randomly assigned' in the abstract. However it was stated in the paper that if participants withdrew from the study then the next participant recruited would be allocated to the assigned group of the last participant to withdraw.

Dropouts: 46 participants initially enrolled in the study of which 28 completed the treatment protocol, 14 in the experimental and 14 in the control group. 18 participants were excluded from the study because: (1) pain or discomfort from surface stimulation (7 experimental and 1 control); (2) pulmonary embolism and MI (1 control); (3) new onset seizure ( 1 control); (4) chest pain (1 experimental); did not finish treatment protocol and declined further treatment ( 3 experimental and 2 control); (5) possible further hemiparesis (1 control); (6) unable to stimulate without motor activation (1 control).

Participants

46 participants recruited to study.

Experimental: completed $n=14,7 \%$ female and $5 \%$ right hemiparesis. Mean age 59.4 (SD 11.1) years. Mean time after stroke 13.6 (SD 7.1) days).

Control: completed $n=14,8 \%$ female and $8 \%$ right hemiparesis. Mean age 60 (SD 15.1). Mean time after stroke 17.8 (SD 5.9) days.

Study criteria: (1) stroke survivors admitted to an acute inpatient rehabilitation service within 4 weeks of unilateral stroke; (2) aged 18 years or older; (3) no potentially fatal cardiac arrhythmias; (4) no demand cardiac pacemaker; (5) no seizures in the 2 years before admission; (6) no active reflex sympathetic dystrophy; (7) no prior stroke with residual motor weakness; (8) no lower motor lesion of the impaired upper extremity; (9) no spinal cord injury; (10) no traumatic brain injury; (11) no multiple sclerosis; (12) no Parkinson's disease.

Interventions

Duration: 15 sessions

Experimental:

Category $=7$.

15 sessions of stimulation of the extensor digitorum communis and extensor carpi radialis. Intensity set to produce full wrist and finger extension with a duty cycle of 10 seconds on, 10 seconds off. A symmetric biphasic waveform with amplitude ranging between 0 and $60 \mathrm{~mA}$, a pulse width of $300 \mathrm{~ms}$, frequency between 25 and $50 \mathrm{~Hz}$ and a ramp up and down time of 2 seconds each. The current amplitude and stimulus frequency were set to participant comfort. All experimental participants also received standard physiotherapy, occupational therapy and speech and language therapy routine to the inpatient facility.

Control: 15 sessions of surface stimulation but with electrodes placed away from all motor points. Stimulation produced only cutaneous stimulation just beyond sensory threshold and without any motor activation. All experimental participants also received standard physiotherapy, occupational therapy and speech and language therapy routine to the inpatient facility. Comparison: Electrostimulation vs placebo.

Outcomes Baseline measurement: Pre-intervention.

Outcome measurement: After 15 sessions of the intervention.

Included outcomes: (1) Fugl-Meyer Upper Extremity Score; (2) FIM self-care section.

Notes Intention-to-treat principle not followed in analysis.

\section{Risk of bias}

\begin{tabular}{lll}
\hline Bias & Authors' judgement & Support for judgement \\
\hline Allocation concealment? & High risk & C - Inadequate \\
\hline
\end{tabular}

\section{Cozean 1988}

Methods

Design: Randomised controlled trial with 4 groups, 2 of which are relevant to and included in this review.

Randomisation: 'randomly assigned to one of four groups'. 


Participants $\mathrm{n}=19$.
Experimental: $\mathrm{n}=10$ recruited and 8 completed, 6 male, 2 female and 4 right hemiparesis. Mean age 52
years. Four participants had suffered a stroke more than 1 year before they were recruited to the study.
Control: $\mathrm{n}=9$ recruited and 8 completed, 2 male, 6 female and 5 right hemiparesis. Mean age 62 years.
5 participants had suffered a stroke more than 1 year before they were recruited to the study.
Study criteria: (1) medically stable rehabilitation in-patients with single CVA; (2) cognitive ability to co-
operate; (3) ability to ambulate short distance with assistance of a single therapist; (4) spastic equinus
posturing of affected leg.

Interventions Duration: 6 weeks.

Experimental:

Category $=5$.

Electrostimulation to produce contraction of tibialis anterior and, in some patients, relaxation of gastrocnemius. Sessions were provided for 30 minutes, 3 times a week for 6 weeks. The pulse frequency was controlled to provide the maximum contraction within tolerable levels of discomfort.

Control:

A standard physical therapy regime consisting of passive and active range of motion exercises for all major joints and muscle groups of both legs. Strengthening exercises were provided for all major joints/ muscle groups of both legs. Special attention was focused on ankle and foot control in the affected limb and specific ambulation training was provided to overcome dynamic gait abnormalities. Comparison: Electrostimulation vs conventional.

\begin{tabular}{ll}
\hline Outcomes & $\begin{array}{l}\text { Baseline measurement: Before intervention. } \\
\text { Outcome measurement: } 4 \text { weeks after intervention ended. } \\
\text { Included outcomes: (1) stride length; (2) minimum ankle angle during swing phase; (3) minimum knee } \\
\text { angle during swing phase; (4) gait cycle time. }\end{array}$ \\
\hline Notes & $\begin{array}{l}\text { Experimental participants were permitted access to the stimulator at times other than during the treat- } \\
\text { ment periods. } \\
\text { Intention-to-treat principle not followed in analysis. }\end{array}$ \\
\hline
\end{tabular}

\section{Risk of bias}

\begin{tabular}{lll}
\hline Bias & Authors' judgement & Support for judgement \\
\hline Allocation concealment? & Unclear risk & B - Unclear \\
\hline
\end{tabular}

Daly 2004

\begin{tabular}{|c|c|}
\hline Methods & $\begin{array}{l}\text { Design: Randomised controlled trial, parallel groups. } \\
\text { Randomisation: 'Subjects were assigned to one of two treatment groups using a randomisation proce- } \\
\text { dure that incorporated stratification according to stroke severity'. } \\
\text { Dropouts: } \mathrm{n}=1 \text { from control groups as social support system was compromised. }\end{array}$ \\
\hline Participants & $\begin{array}{l}n=16 . \\
\text { Experimental: } n=8 \text {. Mean age 59.4, range 43-68, years. Mean years after stroke was 4, range } 1-15 \text {. } \\
\text { Control: } n=7 \text { ( } 1 \text { dropout before outcome). Mean age } 64.9 \text {, range } 50-81 \text {, years. Mean years after stroke } \\
\text { was 3.7, range 2-9. } \\
\text { Study criteria: (1) scoring } 0-29 \text { on Fugl-Meyer Coordination Scale; (2) chronic persistent swing phase } \\
\text { deficits characterised by absent or attenuated limb flexion during swing phase; (3) ability to follow 2- } \\
\text { stage commands; (4) endurance to participate in } 1.5 \text { hours of therapy, } 4 \text { days a week; (5) no peripheral } \\
\text { neuropathy; (6) no acute degenerative diseases of musculoskeletal or nervous systems; ( } 7 \text { ) no allergy to } \\
\text { electrode materials; (8) no cardiac pacemaker. }\end{array}$ \\
\hline
\end{tabular}


Daly 2004 (Continued)

Interventions Duration: 3 months

Experimental:

Category $=13$.

Electrostimulation with intramuscular electrodes implanted into tibialis anterior, peroneur longus/ brevis, short head of biceps femoris, semi-tendonosus and semimembranous or long head of biceps femoris. Experimental participants treated for 3 months with 1.5 hour long sessions given 4 times per week. A specialised computer program was used to individualise the stimulation patterns for each participant. The activation level for each muscle was set according to patient comfort and then according to the movement desired but mostly set to approximate normal joint movement excursion. The stimulation ranges were $30 \mathrm{~Hz}, 4-20 \mathrm{~mA}$ and $5-150 \mathrm{~ms}$. All experimental participants also received the control treatment.

Control: Experimental participants treated for 3 months with 1.5 hour long sessions given 4 times per week. Each session consisted of: (1) 30 minutes strengthening and co-ordination training; (2) 30 minutes overground gait training; (3) 30 minutes bodyweight supported treadmill gait training. Comparison: Electrostimulation vs no treatment.

Outcomes Baseline measurement: Before intervention.

Outcome measurement: After the intervention at 3 months.

Included outcomes: All made without electrostimulation or orthotic devices: (1) peak swing hip flexion;

(2) timing of peak hip flexion (\% gait cycle); (3) peak swing knee flexion; (4) timing of peak knee flexion (\% gait cycle); (5) mid-swing ankle dorsiflexion; (6) timing of mid-swing ankle dorsiflexion (\% gait cycle).

Notes

Intention-to-treat principle was not followed in the analysis.

\section{Risk of bias}

\begin{tabular}{lll}
\hline Bias & Authors' judgement & Support for judgement \\
\hline Allocation concealment? & Unclear risk & B - Unclear \\
\hline
\end{tabular}

Francisco 1998

Methods Design: Randomised controlled trial, parallel groups.

Randomisation: Participants assigned to groups using a computer generated random number table. Dropouts: $\mathrm{n}=7$ because of medical instability requiring transfer to acute medical care facilities.
Participants
$\mathrm{n}=16$ recruited.
Experimental: $n=4$ completed, 2 male and 1 left hemisphere stroke. Mean age 60 (SD 15.6) years. Mean time after stroke 17.5 (SD 2.4) days.
Control: $n=5$ completed, 2 male and 5 left hemisphere stroke. Mean age 69.6 (SD 16.2) years. Mean time after stroke 18.2 (SD 2.3) days.
Study criteria: (1) first time stroke survivors admitted to a rehabilitation hospital within 6 weeks of stroke onset; (2) single nonhaemorrhagic lesion; (3) detectable EMG signal from extensor carpi radialis of hemiparetic arm; (4) volitional wrist extension in synergy or isolation with muscle grade of less than $3 / 5$; (5) no neurological co-morbidity that impaired strength in the affected upper extremity; (6) no tak- ing medication that impaired neuromuscular performance; (7) no pacemaker; (8) not an insensate fore- arm.
Interventions
Duration: Length of rehabilitation stay.
Experimental:
Category $=5$.
EMG-triggered electrostimulation using an all or none stimulus was set for maximum range of move- ment. Duty cycle set for 5 seconds on and 5 seconds off. Frequency adjusted to participant comfort be- tween 20 and $100 \mathrm{~Hz}$, pulse width of $0.2 \mathrm{~ms}, 0-60 \mathrm{~mA}$, biphasic square wave. Stimulus threshold gradual- ly increased with each session as voluntary recruitment increased. Participants received two 30-minute 
Francisco 1998 (Continued)

treatment sessions, five times a week for the duration of their rehabilitation stay. All experimental participants also received standard stroke rehabilitation.

Control: In addition to standard stroke rehabilitation the control group received two additional 30-

minute individual therapy sessions a day for range of motion and strengthening exercises for the wrist. Comparison: Electrostimulation vs conventional.

\begin{tabular}{|c|c|c|}
\hline Outcomes & $\begin{array}{l}\text { Baseline measuremen } \\
\text { Outcome measureme } \\
\text { Included outcomes: }(1\end{array}$ & $\begin{array}{l}\text { Upon admission. } \\
\text { : Upon discharge. } \\
\text { Fugl-Meyer upper extremity assessment; (2) FIM self care component. }\end{array}$ \\
\hline Notes & $\begin{array}{l}\text { No data provided abo } \\
\text { phase. }\end{array}$ & initial group allocation of participants who withdrew during the treatment \\
\hline \multicolumn{3}{|l|}{ Risk of bias } \\
\hline Bias & Authors' judgement & Support for judgement \\
\hline Allocation concealment? & Unclear risk & B - Unclear \\
\hline
\end{tabular}

Gosman-Hedstrom 1998

Design: Randomised controlled trial, 3 groups.
Randomisation: Computer generated randomisation held at a randomisation centre. Researcher tele-
phoned the centre providing the stratification data for each participant as they were recruited to the
study.
Dropouts: $\mathrm{n}=4$ from experimental group, 2 died. 1 medical problem and 1 refused to participate. From
control group, $\mathrm{n}=3$, all 3 died.

Participants Experimental: $\mathrm{n}=37$ recruited of whom 33 completed. Of initial group 17 were female with a mean age of 75 years and 20 were male with a mean age of 77 years.

Control: $n=33$ recruited of whom 30 completed. Of initial group 24 were female with a mean age of 78 years and 11 were male with a mean age of 74 years.

Study criteria: (1) aged 40+ years; (2) acute focal ischaemic non-haemorrhagic lesion less than 1 week before randomisation; (3) could not walk without support; (4) could not eat and/or dress without assistance; (5) able to co-operate; (6) no other disease necessitating hospital or nursing home care; (7) no severe asphasia; (8) no earlier cerebral lesion with a documented need of care; (9) no cardiac pacemaker.

\begin{tabular}{ll}
\hline Interventions & Duration: 10 weeks. \\
& Experimental: \\
& Category $=15$. \\
& Deep electroacupuncture ( $30 \mathrm{~mm}$ long needles). Electrostimulation provided at $2 \mathrm{~Hz}$. Two 30 minute \\
& sessions a week for 10 weeks. All experimental participants also received the control intervention. \\
Control: Conventional stroke rehabilitation (no details in paper) \\
Comparison: Electrostimulation vs no treatment.
\end{tabular}

\begin{tabular}{ll}
\hline Outcomes & $\begin{array}{l}\text { Baseline measurement: The day before intervention begun. } \\
\text { Outcome measurement: } 3 \text { months after intervention began. } \\
\text { Included outcomes: (1) Barthel Index. } \\
\text { Other outcomes: (1) Scandinavian stroke study group neurological score; (2) Sunnaas Index of ADL. }\end{array}$ \\
\hline Notes & The intention-to-treat principal was followed at the 3 month outcome. \\
& We did not include the group allocated to acupuncture in this review.
\end{tabular}

\section{Risk of bias}


Gosman-Hedstrom 1998 (Continued)

\begin{tabular}{lll} 
Bias & Authors' judgement & Support for judgement \\
\hline Allocation concealment? & Low risk & A - Adequate \\
\hline
\end{tabular}

\section{Heckman 1997}

$\begin{array}{ll}\text { Methods } & \text { Design: Randomised controlled trial, parallel groups. } \\ \text { Randomisation: Prospective generated random order into which participants were placed. } \\ \text { Dropouts: None reported. }\end{array}$
Participants Experimental: $\mathrm{n}=14,9$ male and 8 right hemisphere lesion. Mean age 50.1 (28-74 years and mean time after stroke 56.1 (23-94) days.
Control: $\mathrm{n}=14,8$ male and 5 right hemisphere lesion. Mean age 54 (37-72) years and mean time after stroke $61.6(26-170)$ days.
Study criteria: (1) right-handed stroke patients; (2) large supratentorial cerebrovascular lesions, is- chaemic or haemorrhagic; (3) no previous stroke; (4) no dementia; (5) no bilateral lesions; (6) clinically stable; (7) hemiparesis.

Duration: 4 weeks.
Experimental:
Category = 5.
Transcutaneous electrical stimulation triggered by voluntary EMG activity in the target muscle (upper
ar extensors, forearm hand extensors, knee flexors, ankle extensors) to produce joint movements. Each
group of muscles was stimulated 15 times during each session given 5 times a week for 4 weeks. The
stimulus was set to achieve a maximum effect of movement but not of force. The level of voluntary EMG
activity required to trigger stimulation was approximately $80 \%$ of the maximum surface EMG activity.
Stimulus was 0.3 ms biphasic sinus wave pulses at $80 \mathrm{~Hz}$ with a constant current of 20 to $60 \mathrm{~mA}$ for 1 sec-
ond. All experimental participants received the control intervention.
Control:
Conventional physiotherapy based on the principles of Bobath. Occupational therapy also provided.
Therapy given for 45 minutes 5 times a week.
Comparison: Electrostimulation vs no treatment.

Outcomes Baseline measurement: Pre-intervention.

Outcome measurement: 1 week after intervention ended.

Included outcomes: (1) spasticity relaxation index knee; (2) spasticity relaxation index elbow; (3) active range of movement ankle extensors; (4) active range of movement hand extensors; (5) Barthel Index Other outcomes: (1) spasticity overall score upper limb: (2) spasticity overall score lower limb; (3) clonus; (4) deep tendon reflex activity.

Notes

Omitted overall spasticity scores as score was $0=$ flaccid, $1=$ normal up to $3=$ hyperexcitable. Therefore not always possible to say that a higher score indicated an increase in abnormality of spasticity.

\section{Risk of bias}

\begin{tabular}{lll}
\hline Bias & Authors' judgement & Support for judgement \\
\hline Allocation concealment? & Unclear risk & B - Unclear \\
\hline
\end{tabular}

Johansson 2001

Methods

Design: Randomised controlled trial. parallel groups 
Johansson 2001 (Continued)

Randomisation: Computer generated random allocation. Allocation concealed in consecutively numbered opaque envelopes. Envelope opened by research therapist and not by local study co-ordinator or evaluators.

Dropouts: At outcome measure 3 from TENS group ( 1 died, 1 adverse reaction, 1 unknown) and 5 from placebo group (3 died, 1 comorbidity, 1 at patient's own request).

Experimental: $\mathrm{n}=51,45 \%$ female. Mean age 77 (SD9) years. 48 participants completed.
Control: $\mathrm{n}=51,51 \%$ female. Mean age 76 (SD 11) years. 46 participants completed.
Study criteria: (1) acute stroke 5 to 7 days before randomisation; (2) if recurrent stroke then no func-
tional impairment before the present event; (3) Barthel Index 70 or less in combination with the inabili-
ty to perform Nine Hole Peg Test within 60 seconds or inability to walk 10 metres without an aid or per-
son support; (4) no previous neurological, psychiatric or other disorder making it difficult to pursue
treatment or evaluations; (5) ability to comprehend information about the trial; (6) no concurrent par-
ticipation in another trial of interventions supposed to affect neurological and functional outcome.

Interventions

Duration: 30 minutes, twice a week for 10 weeks.

Experimental:

Category $=8$

High-intensity, low-frequency $(2 \mathrm{~Hz})$ TENS. The amplitude was strong enough to produce visible muscle contractions. All experimental participants also received conventional physiotherapy, occupational therapy and speech and language therapy if needed.

Control:

Subliminal high-intensity, low-frequency TENS. No skin sensation and no visible muscle contractions. All control participants also received conventional physiotherapy, occupational therapy and speech and language therapy if needed.

Comparison: electrostimulation vs placebo.

\begin{tabular}{ll}
\hline Outcomes & Baseline measurement: Randomisation. \\
& Outcome measurement: 3 months after stroke. \\
Included outcomes: (1) Rivermead Mobility Index; (2) walking speed; (3) Barthel Index. \\
Other outcomes: (1) ability to walk 10 metres; Nottingham Health profile quality of life domains.
\end{tabular}

Notes This was a 3-group study but only 2 groups were included in this review. The acupuncture group was excluded because the control group was better matched to the other experimental group.

Intention-to-treat principle was followed in data analysis.

\section{Risk of bias}

\begin{tabular}{lll}
\hline Bias & Authors' judgement & Support for judgement \\
\hline Allocation concealment? & Low risk & A - Adequate \\
\hline
\end{tabular}

Kimberley 2004

$\begin{array}{ll}\text { Methods } & \text { Design: Randomised controlled trial, parallel groups. } \\ & \text { Randomisation: Randomly assigned to treatment or control group. } \\ & \text { Dropouts: None reported. }\end{array}$

Participants

Experimental: $\mathrm{n}=8,5$ male and 4 right hemiparesis. Mean age 58.38 (SD 14.52) years. Mean time after stroke 28.38 (SD 18.68) months).

Control: $n=8,6$ male and 4 right hemiparesis. Mean age 62.75 (SD 13.8) years. Mean time after stroke 38.50 (SD 30.72) months.

Study criteria: (1) at least 6 months after stroke; (2) at least 10 degrees of active flexion/extension movement at the metacarpophalangeal joint of the index finger; (3) a score of 25 or more (of 30) on the Mini-Mental State Examination. 
Kimberley 2004 (Continued) Interventions
Duration:

6 hours a day, for 10 days over a 3 week period.

Experimental:

Category $=5$

Half of treatment was EMG threshold triggered electrostimulation producing stronger contractions than those achieved voluntarily. Half of treatment was with the machine automatically stimulating the muscle to contract without the requirement for the patient to trigger it through voluntary muscle contraction. Asymmetrical, rectangular biphasic, constant current with a pulse width $200 \mathrm{~ms}$, frequency $50 \mathrm{~Hz}$ and with intensity set to produce finger and wrist extension movements. Evoked contraction lasted 5 seconds plus a 1 second ramp up and 1 second ramp down. A 15 second rest period was given between contractions.

Control: A similar device to that used with experimental participants that shows a light during the 'on' phases but which did not deliver any current. For half the treatment participants actively lifted the hand when they saw the light come on. For the other half of the treatment they did not lift the hand. Comparison: electrostimulation vs placebo.

\section{Outcomes Baseline measurement: pre-intervention.}

Outcome measurement: post-intervention.

Included outcomes: (1) isometric strength of index finger extension; (2) Motor activity Log, how well;

(3) Box and Block Test; (4) Jebsen Hand Function Test , page turn (seconds); (5) Jebsen Hand Func-

tion Test, small objects (seconds); (6) Jebsen Hand Function Test, feeding (seconds); (7) Jebsen Hand

Function Test, stacking (seconds); (8) Jebsen Hand Function Test, light cans (seconds); (9) Jebsen Hand

Function Test, heavy cans (seconds).

Other outcomes: (1) fMRI; (2) Motor Activity Log, how much; (3) finger-movement tracking.

\section{Notes}

\section{Risk of bias}

\begin{tabular}{lll}
\hline Bias & Authors' judgement & Support for judgement \\
\hline Allocation concealment? & Unclear risk & B - Unclear \\
\hline
\end{tabular}

King 1996

$\begin{array}{ll}\text { Methods } & \text { Design: Randomised controlled trial. } \\ & \text { Randomisation: Randomly assigned to group. } \\ & \text { Dropouts: None reported. }\end{array}$

Dropouts: None reported.

Participants
Experimental: $\mathrm{n}=11$.
Control: $\mathrm{n}=10$.
Study criteria: (1) chronic wrist flexor spasticity as a result of CVA; (2) participating in a rehabilitation
program; (3) ability to understand the evaluation and treatment to be given.

Interventions Duration:

1 session lasting 10 minutes

Experimental:

Category $=7$.

Neuromuscular electrostimulation over the flexor surface of the forearm for contract/relax. Stimulation was given over a 10 minute period at $45 \mathrm{~Hz}, 250 \mathrm{~ms}$ pulse width, ramp up/down time of 3 seconds, on/off time of 10 seconds, 15-20mA. All experimental participants also received the control intervention at the same time as the electrostimulation.

Control: Continuous passive stretch for 10 minutes.

Comparison: electrostimulation vs no treatment. 
King 1996 (Continued)

Before 10 minutes treatment

Outcome measurement:

After 10 minutes treatment.

Included outcomes: Static muscle tone as assessed by toque of the wrist flexors in response to passive stretch.

Notes

\section{Risk of bias}

\begin{tabular}{lll}
\hline Bias & Authors' judgement & Support for judgement \\
\hline Allocation concealment? & Unclear risk & B - Unclear \\
\hline
\end{tabular}

\section{Linn 1999}

$\begin{array}{ll}\text { Methods } & \text { Design: Randomised controlled trial, parallel groups. } \\ & \text { Randomisation: 'randomised into treatment and control groups before initial assessments'. } \\ & \text { Dropouts: None reported. }\end{array}$

Participants $\mathrm{n}=40$.
Experimental: $\mathrm{n}=20,8$ male, 4 right hemiparesis, mean age 71 years.
Control: $\mathrm{n}=20,10$ male, 5 right hemiparesis, mean age 73 years.
Study criteria: (1) CVA resulted in significant motor deficit of the upper limb with grades of 2 or less on
manual muscle test; (2) no previous pathology to the shoulder; (3) adequate communication ability to
cope with a verbal rating score for pain; (4) no cardiac pacemaker or metal; (5) no women of childbear-
ing age; (6) recruitment and all initial measures must have been completed and treatment commenced
within 48 hours of admission to the acute stroke unit.

Interventions Duration: 4 weeks.

Experimental: Category $=7$.

Stimulation of supraspinatus and posterior deltoid so that movement provided good correction of subluxation. Electrostimulation consisted of asymmetrical biphasic pulses, $300 \mathrm{~ms}$ pulse width, $30 \mathrm{~Hz}$ frequency, a 15 second on time incorporating a ramp up time of 3 seconds and a 15 seconds off time. Sessions were given 4 times each day with a minimum of 2 hours between sessions, for 4 weeks. The length of each session increased gradually from 30 minutes in week 1 to 60 minutes in week 4 . All experimental participants also received the control intervention.

Control:

Conventional physiotherapy and occupational therapy for 4 weeks.

Comparison: electrostimulation vs no treatment.

\begin{tabular}{ll}
\hline Outcomes & Baseline measurement: Before intervention. \\
& Outcome measurement: After 4 weeks intervention. \\
Included outcomes: (1) Motor Assessment Scale upper arm section. & Other outcomes: (1) arm girth; (2) shoulder subluxation.
\end{tabular}

Notes

\section{Risk of bias}

\begin{tabular}{lll}
\hline Bias & Authors' judgement & Support for judgement \\
\hline Allocation concealment? & Unclear risk & B - Unclear \\
\hline
\end{tabular}


Macdonell 1994

Methods

Design: Randomised controlled trial, parallel groups.

Randomisation: Twenty were randomised to the experimental group and the remaining 18 acted as a control group.

Dropouts: None reported.

Participants
\[ \begin{array}{l}\mathrm{n}=38, \text { mean } 25 \text { (11-41) days after stroke. } \\ \text { Experimental: } \mathrm{n}=20,12 \text { male. Mean age } 65 \text { (SD 9) years. Mean time after stroke } 25 \text { (11-37) days. } \\ \text { Control: } \mathrm{n}=18,16 \text { male. Mean age } 68 \text { (SD 9) years. Mean time after stroke } 26 \text { (15-41) days. } \\ \text { Study criteria: (1) weakness of dorsiflexion grade } 4 \text { or less on MRC scale; (2) CT confirmed cerebral in- } \\ \text { farction; (3) to remain as in-patients for at least } 4 \text { weeks; (4) no significant cardiac disease or cardiac } \\ \text { conduction disturbance; (5) no peripheral neuropathy; (6) no significant medical conditions likely to } \\ \text { interfere with completion of the study; (7) no major psychiatric, behavioural disturbances, aphasia or } \\ \text { cognitive loss; (8) no previous stroke with residual deficit; (9) no severe deformity or obesity of the low- } \\ \text { er limbs that might prevent adequate electrical stimulation; (10) no ankle plantar flexion contractures } \\ \text { of } 5 \text { degrees or more; (11) no severe hemisensory loss or higher level dysfunction. }\end{array} \]

Interventions Duration: 4 weeks.

Experimental:

Category $5+$ category 7 .

FES to common peroneal nerve during walking and cyclical stimulation to produce dorsiflexion of the ankle in the affected leg. FES (category 5) was given 3 days a week for 20 minute sessions. The FES stimulation was given at a frequency of $30-50 \mathrm{~Hz}$ and duration of $0.3 \mathrm{~ms}$. The stimulus was co-ordinated to assist passive, active and active assisted exercises and functional activities. Stimulus intensity was adjusted to achieve a maximal contraction against gravity but within each participant's tolerance. The cyclical electrostimulation cycle was 10 seconds on, 30 seconds off, frequency of $30-50 \mathrm{~Hz}$ and duration $0.3 \mathrm{~ms}$. Stimulus intensity adjusted to achieve a maximal contraction against gravity but within each participant's tolerance. The time for electrostimulation was gradually increased to between 30 and 40 minutes a day over several days according to participant tolerance. All experimental participants also received the control intervention.

Control: physical therapy consisting of passive movements to affected leg or active assisted exercise depending of each participant's ability. Therapy also included functional exercises such as rolling and gait training.

Comparison: Electrostimulation vs no treatment.

Outcomes Baseline measurement: At entry into the study.

Outcome measurement: After the 4 week intervention.

Included outcomes: (1) Barthel Index; (2) Fugl-Meyer Lower Limb Assessment

Other outcomes: (1) Massachusetts General Hospital Functional Ambulation Classification.

Notes Combined two forms of electrostimulation, category 5 and category 7.

\section{Risk of bias}

\begin{tabular}{lll}
\hline Bias & Authors' judgement & Support for judgement \\
\hline Allocation concealment? & Unclear risk & B - Unclear \\
\hline
\end{tabular}

\section{Merletti 1978}

\begin{tabular}{ll}
\hline Methods & $\begin{array}{l}\text { Design: Randomised controlled trial, parallel groups. } \\
\text { Randomisation: 'randomly divided into two groups' } \\
\text { Dropouts: None reported. }\end{array}$ \\
\hline Participants & $\mathrm{n}=49$. Time from lesion from 1 to 15 months. \\
& Experimental: $\mathrm{n}=24$. Mean age 55.17 (SD 13.79) years. \\
Control: $\mathrm{n}=25$. Mean age 57.04 (SD 13.39) years.
\end{tabular}


Merletti 1978 (Continued)

Study criteria: (1) hospitalised hemiparetic patients; (2) aetiology of CVA; (3) ability to understand measurement procedure; (4) no ankle joint block; (5) limited or absence of spasticity of plantar flexors; (6) absent or limited sensibility disturbances.

Duration: 4 weeks.
Experimental:
Categories 5 and 7 .
Peroneal nerve stimulation via surface electrodes applied either during walking or whilst seated. Used
trains of monopolar rectangular pulses with a pulse duration of $0.3 m s$, frequency of $30 \mathrm{~Hz}$, timing of
1.5 seconds on and 3 seconds off. Amplitude and electrode position were adjusted to produce the best
functional movement. Electrical stimulation given for 20 minutes a day, 6 days a week for 4 weeks. All
experimental participants also received the control intervention.
Control:
'Traditional physiotherapy and neuromuscular facilitation treatment according to the Kabat and Bo-
bath techniques'. Therapy given for one hour a day.
Comparison: Electrostimulation vs no treatment.

Outcomes Baseline measurement: Before intervention.

Outcome measurement: At 4 weeks after intervention ended.

Included outcomes: (1) maximal voluntary moment of ankle dorsiflexion.

Notes

Combined two forms of electrostimulation, category 5 and category 7.

\section{Risk of bias}

\begin{tabular}{lll}
\hline Bias & Authors' judgement & Support for judgement \\
\hline Allocation concealment? & Unclear risk & B - Unclear \\
\hline
\end{tabular}

\section{Pei 2001}

$\begin{array}{ll}\text { Methods } & \text { Design: Randomised controlled trial, parallel groups. } \\ \text { Randomisation: Random allocation to experimental and control group. } \\ \text { Dropouts: None reported. }\end{array}$

Participants Experimental: $\mathrm{n}=43,28$ male. Mean age 71.61 (SD 10.14) years. Mean time after stroke 3.32 (SD 2.47) days.

Control: $n=43,24$ male. Mean age 69.34 (SD 12.06) years. Mean time after stroke 3.09 (SD 2.56) days. Study criteria: (1) acute cerebral infarction; (2) disease course of 1-7 days.

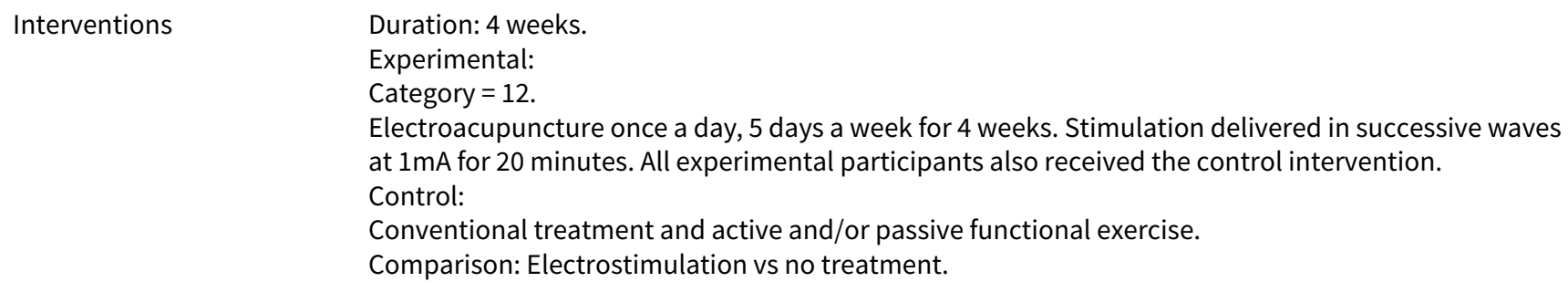

Outcomes Baseline measurement: Before treatment. Outcome measurement: After 4 weeks treatment. Included outcomes: (1) Fugl-Meyer Assessment; (2) Barthel Index. Other outcomes: (1) Chinese Stroke Scale. 
Pei 2001 (Continued)

Risk of bias

\begin{tabular}{lll}
\hline Bias & Authors' judgement & Support for judgement \\
\hline Allocation concealment? & Unclear risk & B - Unclear \\
\hline
\end{tabular}

Popovic 2003

Methods Design: Randomised controlled trial, parallel groups.

Randomisation: Participants randomly assigned to experimental or control group.

Dropouts: None reported.

Participants

Experimental: $\mathrm{n}=14,11$ right hemiparesis. Mean age 59.43 (SD 10.90) years. Mean time since stroke 6.79 (SD 2.33) weeks.

Control: $n=14,10$ right hemiparesis, mean age 60.36 (SD 7.70) years. Mean time since stroke 6.43 (SD

1.91) weeks.

Study criteria: (1) imaging confirmed ischaemic or haemorrhagic CVA; (2) between 2 weeks and 6 months after stroke; (3) aged over 18 years; (4) able to give informed consent; (5) able to understand how to apply ES for controlling the grasp; (6) independent in ADL prior to stroke; (7) no severe medical condition in upper limbs precluding participation in the study; (8) no previous injury, disease or contracture affecting either upper limb; (9) no electrical devices e.g. pacemaker.

Interventions Duration: 3 weeks.

Experimental:

Category $=5$.

Electrostimulation applied to extensor digitorum communis, flexor digitorum profundus/superficialis, extensor pollicis longus and abductor pollis/opponens. Participants used a switch to start a stimulation pattern to grasp or release an object. Pulse duration, frequency and amplitude set to minimise discomfort and yet provide external assistance to movement. Typical values were $50 \mathrm{~Hz}, 300 \mathrm{~ms}$ and $15-45 \mathrm{~mA}$. Stimulation was applied for 3 weeks for 30 minutes daily. All experimental participants also received the control intervention.

Control:

Reaching actively for and functionally using ADL objects.

Comparison: Electrostimulation vs no treatment.

Outcomes Baseline measurement: At the start of the study.

Outcome measurement: After the 3 weeks of treatment.

Included outcomes: (1) upper extremity functioning test, number of repetitions; (2) co-ordination of upper limb, drawing test

Other outcomes: (1) muscle tone, Ashworth; (2) upper extremity motor activity log amount scale; (3) upper extremity motor activity log, how well scale.

\section{Notes}

It was not possible to include the other outcomes as no data were available for the outcome measurement time point.

\section{Risk of bias}

\begin{tabular}{lll}
\hline Bias & Authors' judgement & Support for judgement \\
\hline Allocation concealment? & Unclear risk & B - Unclear \\
\hline
\end{tabular}


Powell 1999 (Continued)

Randomisation Computer generated randomisation order placed in sealed envelopes by an individual not involved in the study. Participants were randomised after baseline measures.

Dropouts: $n=5$. Reasons were that participants died $(n=3)$ or they suffered a further neurological event $(n=2)$.

Participants

Experimental: $\mathrm{n}=30$ recruited and 27 completed treatment. Of the 30 participants recruited, 18 had a left hemiparesis, their mean age was 60 (SD 10.8) years and the mean time after stroke was 23.9 (SD 7.7) days.

Control: $\mathrm{n}=30$ recruited and 28 completed treatment. Of the 30 participants recruited, 20 had a left hemiparesis, their mean age was 66.4 (SD 12.2) years and the mean time after stroke was 22.9 (SD 5.5) days.

Study criteria: (1) intracerebral haemorrhage or infarction confirmed by CT scan; (2) hemiparesis due to acute stroke; (3) MRC grade of wrist extensors $4 / 5$ or worse at 2/4 weeks after stroke; (4) no previous wrist problem; (5) able to understand the study.

Interventions

Duration: 8 weeks.

Experimental:

Category $=7$.

Electrostimulation of wrist and finger extensors with external electrodes placed for optimally balanced joint movement. Pulse width of $300 \mathrm{~ms}$, frequency of $20 \mathrm{~Hz}$, amplitude set at minimum level required to produce full wrist extension. Stimulation on time of 5 seconds included 1 second ramping up period and a 1.5 second ramping down period. The muscle contract/relax ratio was progressively increased by shortening the relaxation time from $5 / 20$ on/off to $5 / 5$ seconds on/off. The intervention was given in 30 minute sessions, 3 times a day for 8 weeks. All experimental participants also received the standard therapy given to the control group.

Control:

Standard therapy from the ward rehabilitation team using a combination of Bobath and Movement Science approaches depending on individual patient needs. All control participants also received a visit of up to 10 minutes three times a week from the therapist providing the experimental intervention. This visit was to discuss rehabilitation progress with the aim of controlling for the extra attention given to the experimental group.

Comparison: Electrostimulation vs no treatment.

Baseline measurement: Before intervention.
Outcome measurement: After 8 weeks of intervention.
Included outcomes: (1) isometric torque about the wrist at 0 degrees; (2) muscle tone - Ashworth; (3)
grip strength; (4) ARAT score; (5) 9HPT; (6) Barthel Index.
Other outcomes: (1) resting angle of wrist; (2) end range angle for passive range of motion at wrist; (3)
end range for active range of motion at wrist.

Notes The intention-to-treat principle was not followed in data analysis.

\section{Risk of bias}

Bias Authors' judgement Support for judgement

Allocation concealment? Low risk A-Adequate

\section{Sonde 1998}

\begin{tabular}{ll}
\hline Methods & Design: Randomised controlled trial, parallel groups. \\
& Randomisation: 'randomised into two groups'. \\
& Dropouts: None reported.
\end{tabular}

Participants Experimental: $n=26,19$ male and 16 right hemiparesis. Mean age 71 (SD 6) years. Mean time after stroke 9.1 (2.2) months. 
Study criteria: (1) first ever stroke; (2) paretic arm (scored 0-50 points on Fugl-Meyer Assessment); (3) 6-12 months after stroke.

$\begin{array}{ll}\text { Interventions } & \text { Duration: } 3 \text { months. } \\ & \text { Experimental: } \\ & \text { category }=7 \text {. } \\ & \text { Low TENS to wrist extensors, elbow extensors and shoulder abductors. Stimulation of } 1.7 \mathrm{~Hz} \text { in } 8 \text { pulse } \\ \text { trains with an interval of } 14 \text { ms. Treatment was initiated by physiotherapist and then patients contin- } \\ \text { ued at home. Stimulation sessions lasted for } 60 \text { minutes and were given } 5 \text { days a week for } 3 \text { months. All } \\ \text { experimental participants also received the control intervention. } \\ \text { Control: Physiotherapy at a day centre usually provided twice a week. } \\ \text { Comparison: Electrostimulation vs no treatment. }\end{array}$

Outcomes Baseline measurement: At start of study. Outcome measurement: At end of study. Included outcomes: (1) Fugl-meyer score; (2) Modified Ashworth scale; (3) Barthel Index. Other outcomes: (1) deep sensibility; (2) superficial sensibility; (3) passive range of movement; (4) active range of movement.

Notes

\section{Risk of bias}

\begin{tabular}{lll}
\hline Bias & Authors' judgement & Support for judgement \\
\hline Allocation concealment? & Unclear risk & B - Unclear \\
\hline
\end{tabular}

\section{Tekeoolu 1998}

\begin{tabular}{ll}
\hline Methods & Design: Randomised controlled trial, parallel groups. \\
& Randomisation: 'randomly assigned using block randomisation to one of two groups'. \\
Dropouts: None reported.
\end{tabular}

Participants Experimental: $\mathrm{n}=30,17$ male and 14 left hemiparesis. Mean age 55.9 (SD 7.0) years. Mean time after stroke 40.8 (SD 11.4) days.

Control: $n=30,14$ male, 13 right hemiparesis. Mean age 52.2 (SD 5.4) years. Mean time after stroke 44.3 (SD 13.1) days.

Study criteria: (1) stroke confirmed by CT; (2) affected by discrete loss of motor function but able to stand and walk if assisted.

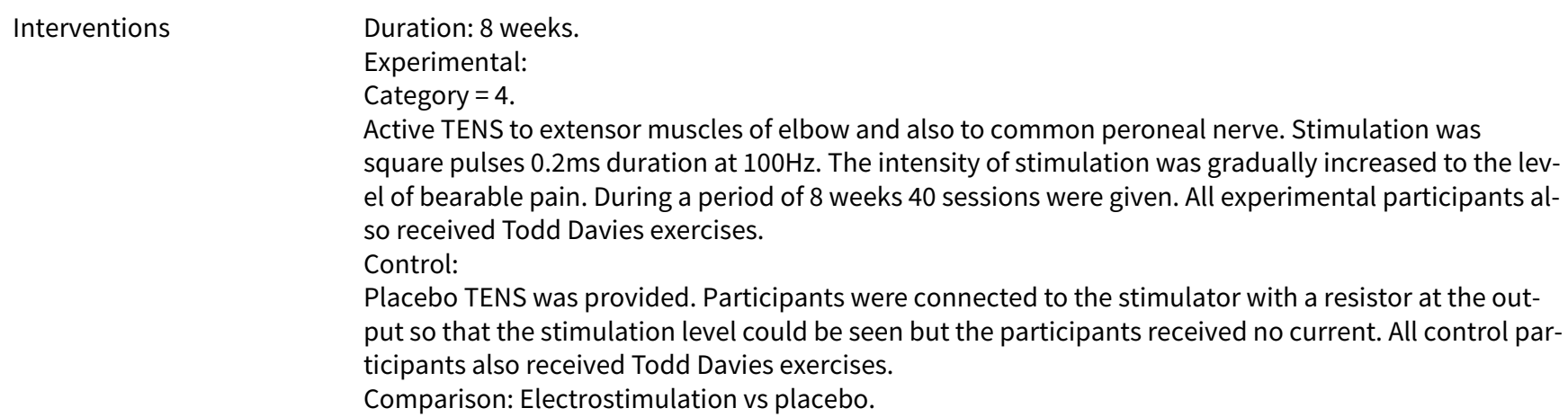


Tekeoolu 1998 (Continued)

Included outcomes: (1) Barthel Index.

Not yet included outcomes: (1) elbow spasticity, Ashworth score; (2) knee spasticity, Ashworth score;

(3) ankle spasticity, Ashworth score. Study authors contacted for data.

\section{Notes}

\section{Risk of bias}

\begin{tabular}{lll}
\hline Bias & Authors' judgement & Support for judgement \\
\hline Allocation concealment? & Unclear risk & B - Unclear \\
\hline
\end{tabular}

\section{Wright 2004}

$\begin{array}{ll}\text { Methods } & \text { Design: Randomised controlled trial. } \\ & \text { Randomisation: Randomly assigned to experimental or control treatment. } \\ & \text { Dropouts: None reported. }\end{array}$

$\begin{array}{ll}\text { Participants } & \text { Experimental: } \mathrm{n}=12 . \\ & \text { Control: } \mathrm{n}=11 . \\ & \text { Study criteria: } \\ & \text { Not available in final report but awaiting information from study authors. }\end{array}$

\begin{tabular}{ll}
\hline Interventions & Duration: 12 weeks. \\
& Experimental: \\
& Category $=5$. \\
& Odstock dropped foot stimulator. \\
Control: & Orthomercia Supra-Lite ankle-foot orthosis. \\
Comparison: Electrostimulation vs conventional.
\end{tabular}

$\begin{array}{ll}\text { Outcomes } & \text { Baseline measurement: } \\ & \text { Unclear from final report. } \\ & \text { Outcome measurement: } \\ \text { After } 12 \text { weeks treatment. } & \\ \text { Included outcomes: } & \text { all without FES or orthosis. (1) walking speed; (2)) physiological cost index; (3) Rivermead Mobility In- } \\ \text { dex; (4) spasticity; (5) endurance, distance walked in } 3 \text { minutes. }\end{array}$

Notes

\section{Risk of bias}

\begin{tabular}{lll}
\hline Bias & Authors' judgement & Support for judgement \\
\hline Allocation concealment? & Unclear risk & B - Unclear \\
\hline
\end{tabular}

\section{Yan 2005}

Methods

Design: Single-blind randomised controlled trial with 3 groups, 2 of which are relevant to and included in this review.

Randomisation: Jensen's computerised method of minimisation to one of three groups. Participants allocated after giving informed consent.

Dropouts: $n=4$. 
Yan 2005 (Continued)

From experimental group, gastric bleeding, $n=1$; could not undergo assessment, $n=1$.

From control group, another stroke, $n=1$; discharged early, $n=1$.

Participants
Experimental: $\mathrm{n}=15$ recruited and 13 completed, 7 male and 6 female, 7 right and 6 left hemiplegia.
Mean age 68.2 (SD 7.7) years, mean time after stroke 8.7 (SD 5.8) days.
Control: $\mathrm{n}=17$ recruited and 15 completed, 7 male and 6 female, 6 right and 9 left hemiplegia. Mean
age 73.3 (SD 8.1) years, mean time after stroke 10.1 (SD 2.8) days.
Study criteria: (1) unilateral stroke within carotid artery system according to CT; (2) aged 45 to 85 years;
(3) independent in daily activities before stroke; (4) no brain stem or cerebellar lesions; (5) no medical
comorbidity; (6) no cognitive impairment (scored 7 or above on abbreviated mental test).

Interventions

Duration: 3 weeks.

Experimental:

Category $=7$.

FES provided by 2 dual channel stimulators connected with a program timer to form one stimulating unit for FES. Surface electrodes were placed on quadriceps, hamstrings, Tibialis anterior and medial gastrocnemius with participants in side-lying with paretic lower limb supported in a sling. Intervention was provided for 30 minutes a day, 5 days a week for 3 weeks. Stimulation consisted of $0.3 \mathrm{~ms}$ pulses given at $30 \mathrm{~Hz}$ using the maximum intensity tolerated using an activation sequence that mimicked normal gait.

Control:

Placebo FES.

Stimulation provided from an electrical stimulation device with a disconnected circuit. The treatment frequency and period were identical to experimental FES except that stimulation was provided for 60 minutes per day. Participants were told that they might or might not feel the stimulation.

Outcomes

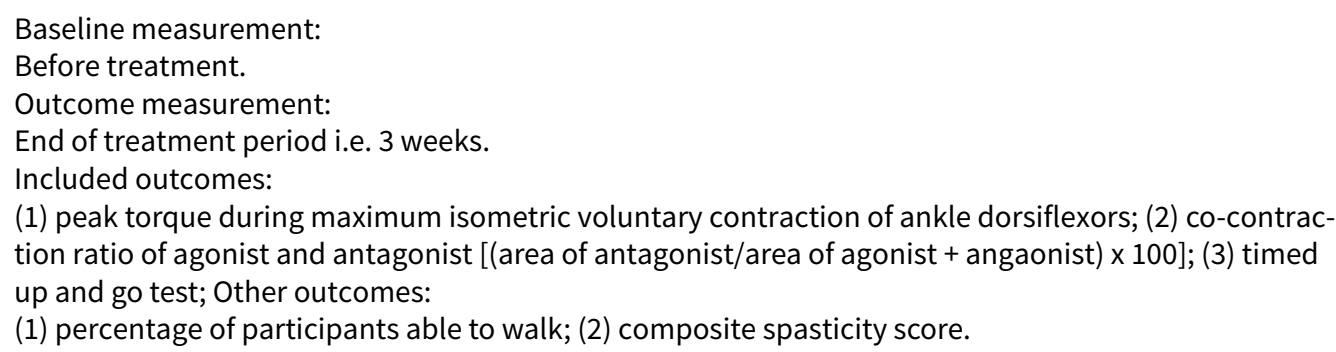

(1) peak torque during maximum isometric voluntary contraction of ankle dorsiflexors; (2) co-contraction ratio of agonist and antagonist [(area of antagonist/area of agonist + angaonist) $x$ 100]; (3) timed up and go test; Other outcomes:

(1) percentage of participants able to walk; (2) composite spasticity score.

\section{Notes}

\section{Risk of bias}

Bias Authors' judgement Support for judgement

Allocation concealment? Unclear risk B - Unclear

Electrostimulation category key is given in Additional Table 01

9HPT: Nine Hole Peg Test

ADL: activities of daily living

ARAT: Action Research Arm Test

$\mathrm{CT}$ : computerised tomography

CVA: cerebrovascular accident

EMG: electromyography

ES: electrical stimulation

FES: functional electrical stimulation

FIM: functional independence measure

fMRI: functional magnetic resonance imaging

GP: general practitioner

MI: myocardial infarction

MRC: Medical Research Council 
PNF: proprioceptive neuromuscular facilitation

SD: standard deviation

TENS: transcutaneous electrical nerve stimulation

vs: versus

Characteristics of excluded studies [ordered by study ID]

\begin{tabular}{ll}
\hline Study & Reason for exclusion \\
\hline Baker 1986 & No motor or ADL data provided. \\
\hline Berner 2004 & Not a randomised controlled trial. \\
\hline Bowman 1979 & $\begin{array}{l}\text { Experimental intervention of electrostimulation also included visual and auditory feedback and } \\
\text { the effect of electrostimulation alone could not be distinguished. }\end{array}$ \\
\hline Cauraugh 2003d & $\begin{array}{l}\text { In addition to electrostimulation the two experimental groups received either random practice or } \\
\text { blocked practice of movement, whereas the no-stimulation control group received passive move- } \\
\text { ment and attempted voluntary movement. It is therefore not possible to isolate the effects of elec- } \\
\text { trostimulation in either of the experimental groups as the additional therapy received was not } \\
\text { replicated in the control group. }\end{array}$ \\
\hline
\end{tabular}

Chantraine $1999 \quad$ Participant group of 120 hemiplegic patients included 19 with head injury and it was not possible to use stroke patient data only.

Chen 2000 Control group contained at least one participant aged under 18 years and therefore the study did
not meet the inclusion criteria for this review.

de Kroon 2004 The same type of electrostimulation was provided for both groups but to different muscle groups, therefore the study did not meet the inclusion criteria for this review.

Faghri 1994

This paper reported the same study as did Faghri 1997 but also included data on the degree of gleno-humeral subluxation, therefore we decided to include the study as reported in Faghri 1997. However, it is not possible to extract accurate data from the graphs provided in Faghri 1997. Furthermore, the study author was unable to access the raw data.

\begin{tabular}{ll}
\hline Gritsenko 2004 & Not a randomised controlled trial. \\
\hline Hesse 1995 & $\begin{array}{l}\text { No outcome measurements provided at the end of the electrostimulation treatment period. Out- } \\
\text { come measures provide } 3.5 \text { weeks after treatment ended. }\end{array}$ \\
\hline Hesse 1998 & No outcome measurements provided at the end of the electrostimulation treatment period. \\
\hline Johansson 1995 & $\begin{array}{l}\text { Participants in experimental group received manual stimulation through acupuncture needles as } \\
\text { well as electrostimulation, therefore it is not possible to distinguish the effects of electrostimula- } \\
\text { tion alone. }\end{array}$ \\
\hline Johnson 2002 & $\begin{array}{l}\text { The experimental condition consisted of electrostimulation and botulinum toxin, therefore it was } \\
\text { not possible to distinguish the effect of electrostimulation alone. }\end{array}$ \\
\hline Johnson 2004 & $\begin{array}{l}\text { The experimental intervention combines FES and botulinum toxin therefore it was not possible to } \\
\text { distinguish the effect of electrostimulation alone. }\end{array}$ \\
\hline Khaslavskaia 2002 & \begin{tabular}{l} 
Not a randomised controlled trial. \\
\hline Kobayashi 1999
\end{tabular} \\
\hline $\begin{array}{l}\text { The control group consisted of those participants who refused electrostimulation therefore the } \\
\text { study is not a randomised trial. }\end{array}$
\end{tabular}




\begin{tabular}{|c|c|}
\hline Study & Reason for exclusion \\
\hline Landau 2002 & Not a randomised trial. \\
\hline Levin 1992 & Not a randomised trial. \\
\hline Magnusson 1994 & Not a randomised trial. \\
\hline Naeser 1994 & Not a randomised trial. \\
\hline Popovic 2002 & $\begin{array}{l}\text { This paper describes an ongoing study the full report of which is in Popovic } 2003 \text { (included in this } \\
\text { review). The control participants for Popovic } 2002 \text { and Popovic } 2004 \text { are the same. }\end{array}$ \\
\hline Takebe 1976 & Although this study was undertaken on groups of participants only case studies were reported. \\
\hline Wang 2000 & $\begin{array}{l}\text { The study reported in this paper is the same study as reported in Wang } 2002 \text { and this paper did not } \\
\text { report motor or ADL data. Also data were presented in graph format and it was not possible to ex- } \\
\text { tract accurately the values for means and standard deviations. The study authors were contacted } \\
\text { for the missing data but no reply was received. }\end{array}$ \\
\hline Winchester 1983 & $\begin{array}{l}\text { The experimental intervention included two forms of electrostimulation, visual positional feedback } \\
\text { and auditory positional feedback and it was therefore not possible to distinguish the effects of ei- } \\
\text { ther form of electrical stimulation. }\end{array}$ \\
\hline Wong 1999 & No outcome measurements provided at the end of the electrostimulation treatment period. \\
\hline Yu 2004 & $\begin{array}{l}\text { The only measures reported in this paper are for shoulder pain and effect of pain on daily activities. } \\
\text { Therefore this study did not meet the inclusion criteria for this review. }\end{array}$ \\
\hline
\end{tabular}

ADL: activities of daily living

FES: functional electrical stimulation

Characteristics of ongoing studies [ordered by study ID]

Mokrusch 1997

Trial name or title

Treatment of stroke-induced spastic hemiparesis with EMG-triggered electrostimulation.

Methods

\begin{tabular}{ll}
\hline Participants & 44 participants, 24 male. Mean age 59 (8.3) years. Mean time after stroke 6 (1 to 9) weeks. \\
\hline Interventions & Experimental 1: \\
& Category $=5$. \\
& Electrostimulation triggered by participant's EMG activity. All participants also received control in- \\
& tervention. \\
& Experimental 2: \\
& Category $=7$. \\
& Electrostimulation without any muscle activity by the participant. All participants also received \\
& the control intervention. \\
& Control: \\
& Physio and ergo therapy.
\end{tabular}
Outcomes
(1) Pendulum test upper and lower extremities; (2) Ashworth scores upper and lower extremities;
(3) Contraction capacity upper and lower extremities; (4) Barthel Index; (5) FIM score. 
Mokrusch 1997 (Continued)

Contact information First author as given on 1997 paper.

Notes We made several attempts to contact the first author but have been unable to make contact to ascertain if the trial was completed and results published elsewhere.

EMG: electromyography

\section{DATA AND ANALYSES}

\section{Comparison 1. Electrostimulation versus no treatment}

\begin{tabular}{|c|c|c|c|c|}
\hline Outcome or subgroup title & $\begin{array}{l}\text { No. of } \\
\text { studies }\end{array}$ & $\begin{array}{l}\text { No. of } \\
\text { partici- } \\
\text { pants }\end{array}$ & Statistical method & Effect size \\
\hline 1 Motor impairment - muscle tone & 5 & & $\begin{array}{l}\text { Std. Mean Difference (IV, Ran- } \\
\text { dom, } 95 \% \mathrm{CI} \text { ) }\end{array}$ & Subtotals only \\
\hline 1.1 Lower limb - actual values & 2 & 60 & $\begin{array}{l}\text { Std. Mean Difference (IV, Ran- } \\
\text { dom, } 95 \% \mathrm{CI} \text { ) }\end{array}$ & $-0.17[-0.68,0.34]$ \\
\hline 1.2 Upper limb - actual values & 2 & 72 & $\begin{array}{l}\text { Std. Mean Difference (IV, Ran- } \\
\text { dom, } 95 \% \mathrm{CI} \text { ) }\end{array}$ & $-0.17[-0.64,0.30]$ \\
\hline 1.3 Upper limb - change values & 2 & 76 & $\begin{array}{l}\text { Std. Mean Difference (IV, Ran- } \\
\text { dom, } 95 \% \mathrm{CI} \text { ) }\end{array}$ & $1.16[-1.23,3.55]$ \\
\hline 2 Motor impairment - muscle function & 5 & & $\begin{array}{l}\text { Std. Mean Difference (IV, Ran- } \\
\text { dom, } 95 \% \mathrm{CI} \text { ) }\end{array}$ & Subtotals only \\
\hline 2.1 Joint moment - actual values & 1 & 49 & $\begin{array}{l}\text { Std. Mean Difference (IV, Ran- } \\
\text { dom, } 95 \% \mathrm{CI} \text { ) }\end{array}$ & $0.52[-0.05,1.09]$ \\
\hline 2.2 Sustained muscle contraction - actual values & 3 & 42 & $\begin{array}{l}\text { Std. Mean Difference (IV, Ran- } \\
\text { dom, } 95 \% \mathrm{CI} \text { ) }\end{array}$ & $-0.78[-2.39,0.84]$ \\
\hline 2.3 Premotor reaction time - actual values & 2 & 31 & $\begin{array}{l}\text { Std. Mean Difference (IV, Ran- } \\
\text { dom, } 95 \% \mathrm{Cl} \text { ) }\end{array}$ & $0.71[-0.05,1.48]$ \\
\hline 2.4 Motor reaction time - actual values & 1 & 15 & $\begin{array}{l}\text { Std. Mean Difference (IV, Ran- } \\
\text { dom, } 95 \% \mathrm{CI} \text { ) }\end{array}$ & $1.18[0.00,2.37]$ \\
\hline 2.5 Isometric torque - change values & 1 & 55 & $\begin{array}{l}\text { Std. Mean Difference (IV, Ran- } \\
\text { dom, } 95 \% \mathrm{CI} \text { ) }\end{array}$ & $1.02[0.46,1.59]$ \\
\hline 2.6 Grip strength - change values & 1 & 55 & $\begin{array}{l}\text { Std. Mean Difference (IV, Ran- } \\
\text { dom, } 95 \% \mathrm{Cl} \text { ) }\end{array}$ & $0.38[-0.16,0.91]$ \\
\hline $\begin{array}{l}3 \text { Motor impairment - active joint range of move- } \\
\text { ment }\end{array}$ & 1 & & $\begin{array}{l}\text { Std. Mean Difference (IV, Ran- } \\
\text { dom, } 95 \% \mathrm{CI} \text { ) }\end{array}$ & Subtotals only \\
\hline 3.1 Lower limb - actual values & 1 & 28 & $\begin{array}{l}\text { Std. Mean Difference (IV, Ran- } \\
\text { dom, } 95 \% \mathrm{Cl} \text { ) }\end{array}$ & $0.84[0.07,1.62]$ \\
\hline
\end{tabular}




\begin{tabular}{|c|c|c|c|c|}
\hline Outcome or subgroup title & $\begin{array}{l}\text { No. of } \\
\text { studies }\end{array}$ & $\begin{array}{l}\text { No. of } \\
\text { partici- } \\
\text { pants }\end{array}$ & Statistical method & Effect size \\
\hline 3.2 Upper limb - actual values & 1 & 28 & $\begin{array}{l}\text { Std. Mean Difference (IV, Ran- } \\
\text { dom, } 95 \% \mathrm{Cl} \text { ) }\end{array}$ & $0.49[-0.27,1.24]$ \\
\hline 4 Motor impairment - physiological cost index & 1 & & $\begin{array}{l}\text { Std. Mean Difference (IV, Ran- } \\
\text { dom, } 95 \% \mathrm{CI} \text { ) }\end{array}$ & Subtotals only \\
\hline 4.1 Actual values & 1 & 32 & $\begin{array}{l}\text { Std. Mean Difference (IV, Ran- } \\
\text { dom, } 95 \% \mathrm{CI} \text { ) }\end{array}$ & $-0.36[-1.06,0.34]$ \\
\hline 5 Motor impairment - Fugl Meyer Assessment & 3 & & $\begin{array}{l}\text { Std. Mean Difference (IV, Ran- } \\
\text { dom, } 95 \% \mathrm{CI} \text { ) }\end{array}$ & Subtotals only \\
\hline 5.1 Actual values & 3 & 168 & $\begin{array}{l}\text { Std. Mean Difference (IV, Ran- } \\
\text { dom, } 95 \% \mathrm{Cl} \text { ) }\end{array}$ & $1.24[-0.88,3.37]$ \\
\hline 6 Normality of movement & 2 & & $\begin{array}{l}\text { Std. Mean Difference (IV, Ran- } \\
\text { dom, } 95 \% \mathrm{Cl} \text { ) }\end{array}$ & Subtotals only \\
\hline 6.1 Gait velocity - actual values & 1 & 32 & $\begin{array}{l}\text { Std. Mean Difference (IV, Ran- } \\
\text { dom, } 95 \% \mathrm{Cl} \text { ) }\end{array}$ & $0.32[-0.38,1.01]$ \\
\hline $\begin{array}{l}6.2 \text { Peak hip angle during swing phase - actual } \\
\text { values }\end{array}$ & 1 & 15 & $\begin{array}{l}\text { Std. Mean Difference (IV, Ran- } \\
\text { dom, } 95 \% \mathrm{Cl} \text { ) }\end{array}$ & $-0.69[-1.75,0.36]$ \\
\hline $\begin{array}{l}6.3 \text { Peak knee angle during swing phase - actual } \\
\text { values }\end{array}$ & 1 & 15 & $\begin{array}{l}\text { Std. Mean Difference (IV, Ran- } \\
\text { dom, } 95 \% \mathrm{CI} \text { ) }\end{array}$ & $0.07[-0.94,1.09]$ \\
\hline $\begin{array}{l}6.4 \text { Peak ankle angle during swing phase - actual } \\
\text { values }\end{array}$ & 1 & 15 & $\begin{array}{l}\text { Std. Mean Difference (IV, Ran- } \\
\text { dom, } 95 \% \mathrm{CI} \text { ) }\end{array}$ & $0.07[-0.94,1.09]$ \\
\hline $\begin{array}{l}6.5 \text { Timing of peak hip angle (\% gait cycle) - actu- } \\
\text { al values }\end{array}$ & 1 & 15 & $\begin{array}{l}\text { Std. Mean Difference (IV, Ran- } \\
\text { dom, } 95 \% \mathrm{Cl} \text { ) }\end{array}$ & $-0.86[-1.93,0.22]$ \\
\hline $\begin{array}{l}6.6 \text { Timing of peak knee angle (\% gait cycle) - ac- } \\
\text { tual values }\end{array}$ & 1 & 15 & $\begin{array}{l}\text { Std. Mean Difference (IV, Ran- } \\
\text { dom, } 95 \% \mathrm{CI} \text { ) }\end{array}$ & $-0.17[-1.18,0.85]$ \\
\hline $\begin{array}{l}6.7 \text { Timing of peak ankle angle (\% gait cycle) - } \\
\text { actual values }\end{array}$ & 1 & 15 & $\begin{array}{l}\text { Std. Mean Difference (IV, Ran- } \\
\text { dom, } 95 \% \mathrm{CI} \text { ) }\end{array}$ & $-0.22[-1.24,0.80]$ \\
\hline 7 Functional motor ability & 6 & & $\begin{array}{l}\text { Std. Mean Difference (IV, Ran- } \\
\text { dom, } 95 \% \mathrm{Cl} \text { ) }\end{array}$ & Subtotals only \\
\hline 7.1 Motor Assessment Scale - actual values & 1 & 40 & $\begin{array}{l}\text { Std. Mean Difference (IV, Ran- } \\
\text { dom, } 95 \% \mathrm{CI} \text { ) }\end{array}$ & $0.02[-0.60,0.64]$ \\
\hline 7.2 Box and Blocks Test - actual values & 3 & 42 & $\begin{array}{l}\text { Std. Mean Difference (IV, Ran- } \\
\text { dom, } 95 \% \mathrm{CI} \text { ) }\end{array}$ & $1.28[-0.00,2.56]$ \\
\hline 7.3 Upper Extremity Drawing Test - actual values & 1 & 28 & $\begin{array}{l}\text { Std. Mean Difference (IV, Ran- } \\
\text { dom, } 95 \% \mathrm{Cl} \text { ) }\end{array}$ & $-1.40[-2.25,-0.56]$ \\
\hline 7.4 Action Research Arm Test - change values & 1 & 55 & $\begin{array}{l}\text { Std. Mean Difference (IV, Ran- } \\
\text { dom, } 95 \% \mathrm{CI} \text { ) }\end{array}$ & $0.47[-0.07,1.01]$ \\
\hline
\end{tabular}




\begin{tabular}{lllll}
\hline Outcome or subgroup title & $\begin{array}{l}\text { No. of } \\
\text { studies }\end{array}$ & $\begin{array}{l}\text { No. of } \\
\text { partici- } \\
\text { pants }\end{array}$ & Statistical method & Effect size \\
\hline 7.5 Nine Hole Peg Test - change values & 1 & 55 & $\begin{array}{l}\text { Std. Mean Difference (IV, Ran- } \\
\text { dom, 95\% Cl) }\end{array}$ & 0.0 [-0.53, 0.53] \\
\hline 8 Global ADL & 6 & & $\begin{array}{l}\text { Std. Mean Difference (IV, Ran- } \\
\text { dom, 95\% Cl) }\end{array}$ & Subtotals only \\
\hline 8.1 Actual values & 4 & 196 & $\begin{array}{l}\text { Std. Mean Difference (IV, Ran- } \\
\text { dom, 95\% Cl) }\end{array}$ & $2.01[-0.10,4.12]$ \\
\hline 8.2 Change values & & 118 & $\begin{array}{l}\text { Std. Mean Difference (IV, Ran- } \\
\text { dom, 95\% Cl) }\end{array}$ & $0.02[-0.34,0.39]$ \\
\hline
\end{tabular}

Analysis 1.1. Comparison 1 Electrostimulation versus no treatment, Outcome 1 Motor impairment - muscle tone.

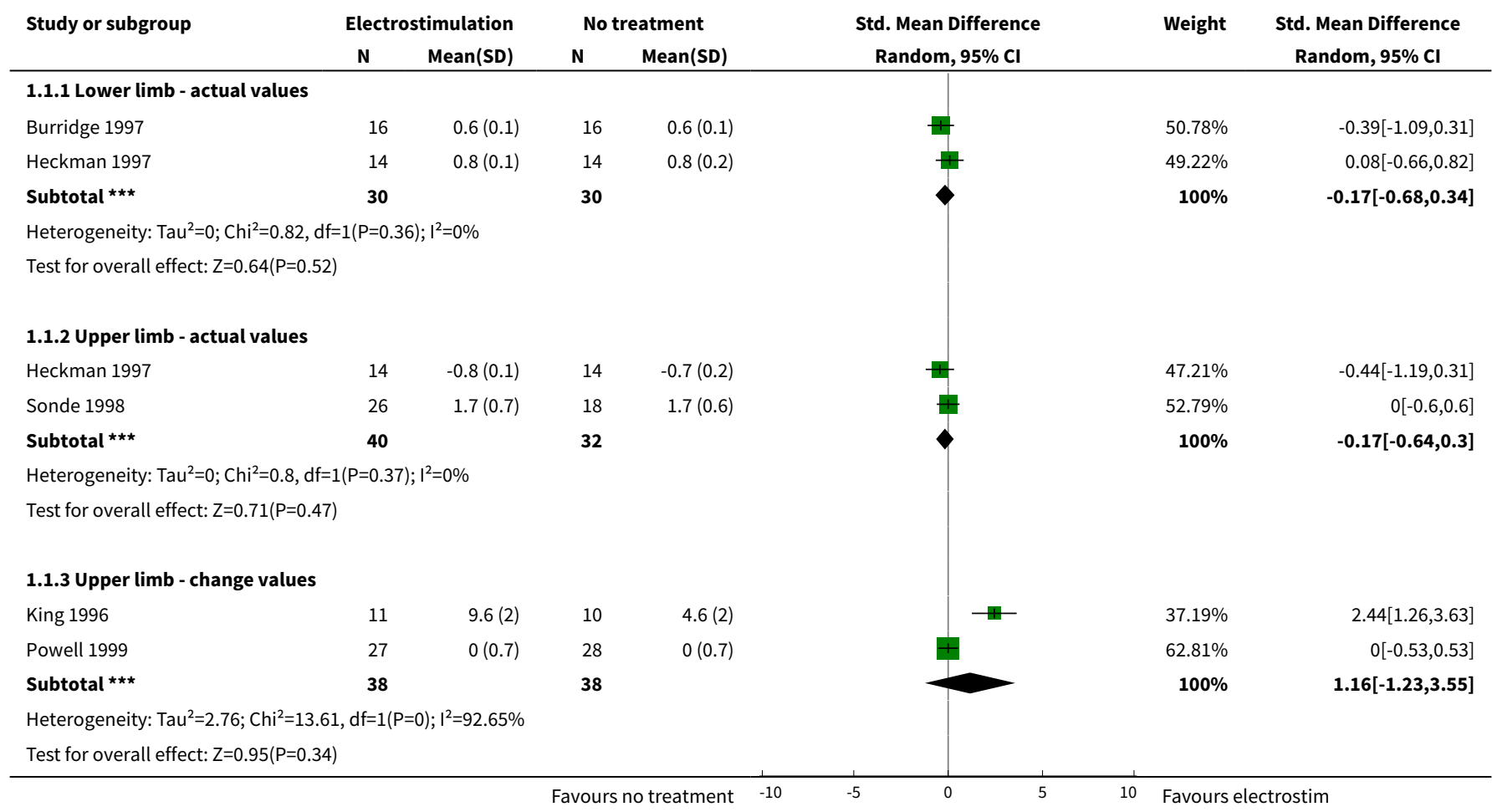

Analysis 1.2. Comparison 1 Electrostimulation versus no treatment, Outcome 2 Motor impairment - muscle function.

\begin{tabular}{|c|c|c|c|c|c|c|c|}
\hline \multirow[t]{2}{*}{ Study or subgroup } & \multicolumn{2}{|c|}{ Electrostimulation } & \multicolumn{2}{|c|}{ No treatment } & \multirow{2}{*}{$\begin{array}{c}\text { Std. Mean Difference } \\
\text { Random, } 95 \% \mathrm{Cl}\end{array}$} & \multirow[t]{2}{*}{ Weight } & \multirow{2}{*}{$\begin{array}{c}\text { Std. Mean Difference } \\
\text { Random, } 95 \% \mathrm{Cl}\end{array}$} \\
\hline & $\mathbf{N}$ & Mean(SD) & $\mathbf{N}$ & Mean(SD) & & & \\
\hline \multicolumn{8}{|c|}{ 1.2.1 Joint moment - actual values } \\
\hline Merletti 1978 & 24 & $9.5(4.1)$ & 25 & $7.2(4.6)$ & & $100 \%$ & $0.52[-0.05,1.09]$ \\
\hline 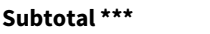 & 24 & & 25 & & & $100 \%$ & $0.52[-0.05,1.09]$ \\
\hline
\end{tabular}




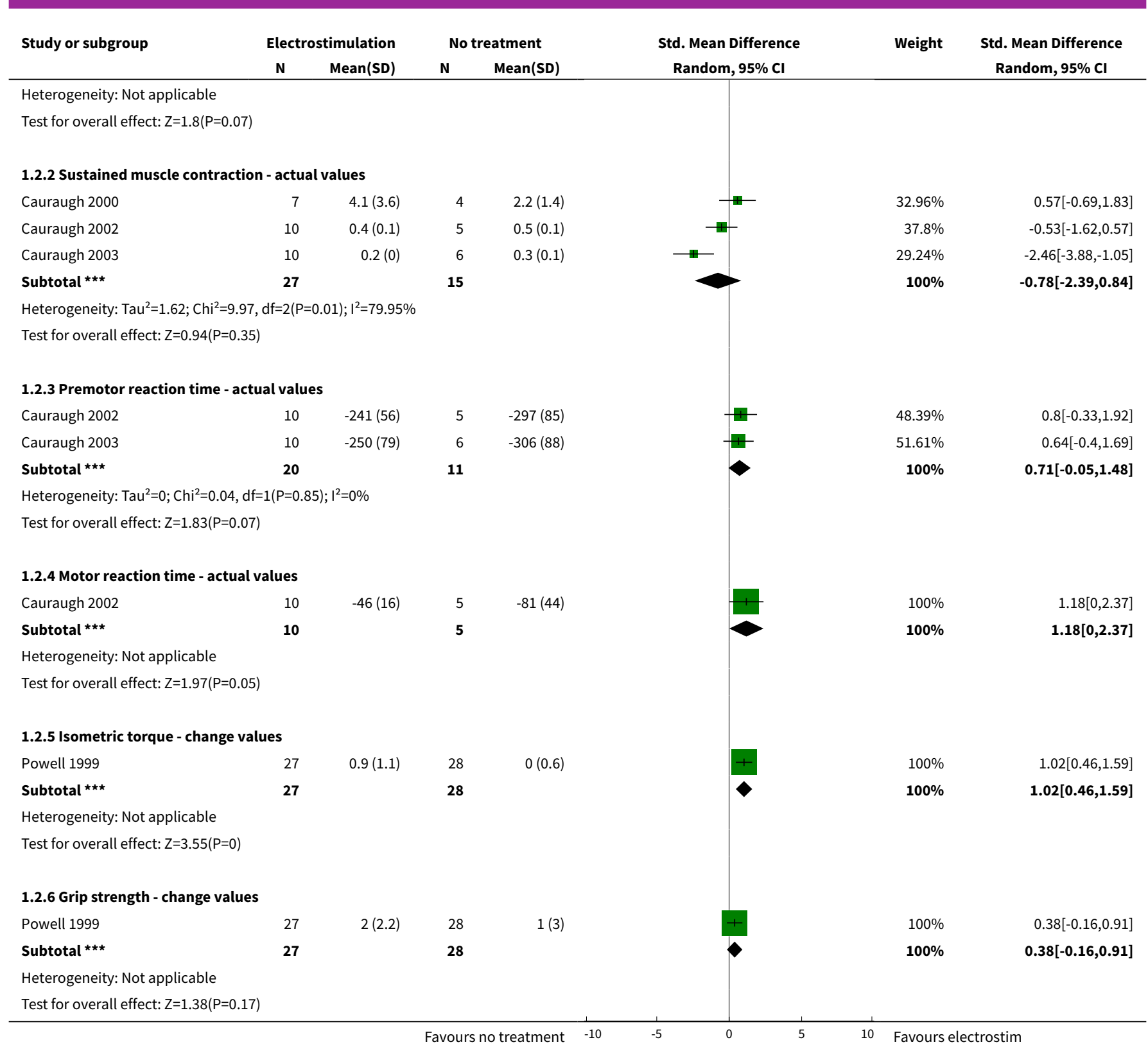

\section{Analysis 1.3. Comparison 1 Electrostimulation versus no treatment, Outcome 3 Motor impairment - active joint range of movement.}

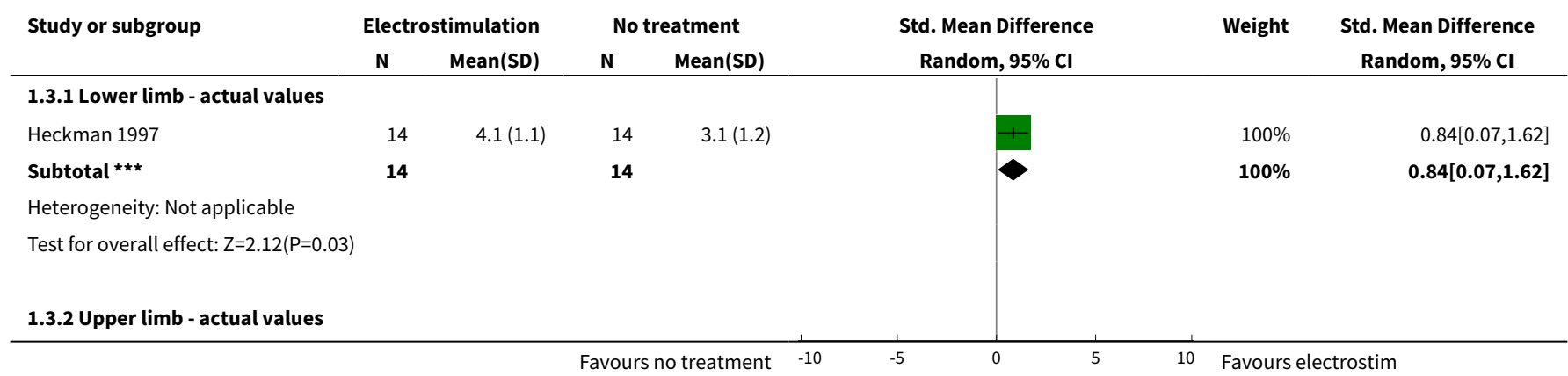




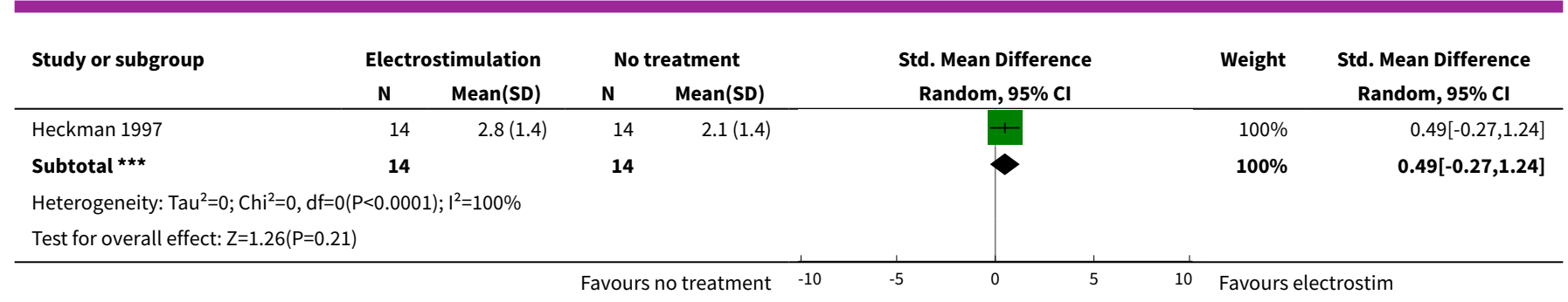

Analysis 1.4. Comparison 1 Electrostimulation versus no treatment, Outcome 4 Motor impairment - physiological cost index.

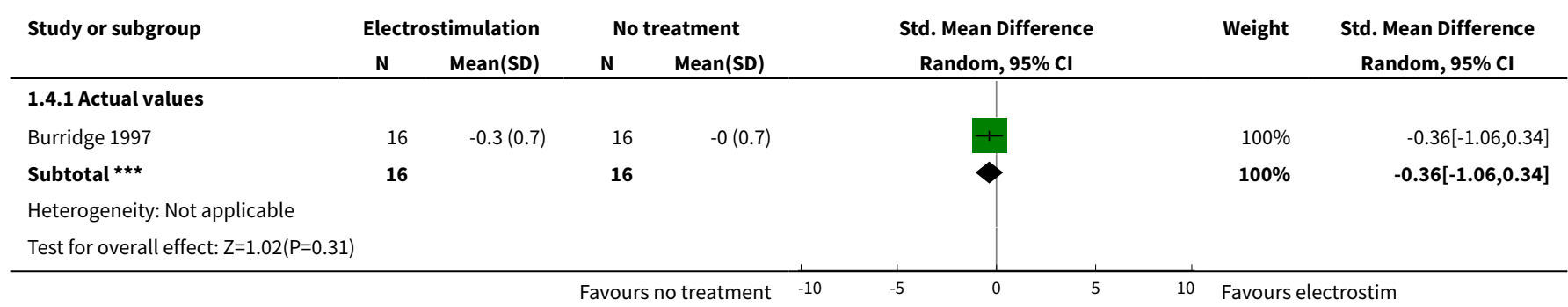

Analysis 1.5. Comparison 1 Electrostimulation versus no treatment, Outcome 5 Motor impairment - Fugl Meyer Assessment.

\begin{tabular}{|c|c|c|c|c|c|c|c|}
\hline \multirow[t]{2}{*}{ Study or subgroup } & \multicolumn{2}{|c|}{ Electrostimulation } & \multicolumn{2}{|c|}{ No treatment } & \multirow{2}{*}{$\begin{array}{c}\text { Std. Mean Difference } \\
\text { Random, } 95 \% \mathrm{Cl}\end{array}$} & \multirow[t]{2}{*}{ Weight } & \multirow{2}{*}{$\begin{array}{c}\text { Std. Mean Difference } \\
\text { Random, } 95 \% \mathrm{Cl}\end{array}$} \\
\hline & $\mathbf{N}$ & Mean(SD) & $\mathbf{N}$ & Mean(SD) & & & \\
\hline \multicolumn{8}{|l|}{ 1.5.1 Actual values } \\
\hline Macdonell 1994 & 20 & $17.2(6.8)$ & 18 & $15.8(6.6)$ & $\#$ & $33.34 \%$ & $0.2[-0.43,0.84]$ \\
\hline Pei 2001 & 43 & $45.9(5.2)$ & 43 & $30.7(3.3)$ & $\Psi$ & $33.21 \%$ & $3.48[2.8,4.16]$ \\
\hline Sonde 1998 & 26 & $28.6(16.9)$ & 18 & $27.7(16.3)$ & $F$ & $33.45 \%$ & $0.05[-0.55,0.65]$ \\
\hline 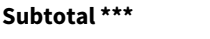 & 89 & & 79 & & & $100 \%$ & $1.24[-0.88,3.37]$ \\
\hline Test for overall effect & & & & & & & \\
\hline
\end{tabular}

Analysis 1.6. Comparison 1 Electrostimulation versus no treatment, Outcome 6 Normality of movement.

\begin{tabular}{|c|c|c|c|c|c|c|c|}
\hline \multirow[t]{2}{*}{ Study or subgroup } & \multicolumn{2}{|c|}{ Electrostimulation } & \multicolumn{2}{|c|}{ No treatment } & \multirow{2}{*}{$\begin{array}{c}\text { Std. Mean Difference } \\
\text { Random, } 95 \% \mathrm{CI}\end{array}$} & \multirow[t]{2}{*}{ Weight } & \multirow{2}{*}{$\begin{array}{c}\text { Std. Mean Difference } \\
\text { Random, } 95 \% \mathrm{Cl}\end{array}$} \\
\hline & $\mathbf{N}$ & Mean(SD) & $\mathbf{N}$ & Mean(SD) & & & \\
\hline \multicolumn{8}{|c|}{ 1.6.1 Gait velocity - actual values } \\
\hline Burridge 1997 & 16 & $0.6(0.4)$ & 16 & $0.5(0.3)$ & & $100 \%$ & $0.32[-0.38,1.01]$ \\
\hline Subtotal $* \star \star$ & 16 & & 16 & & & $100 \%$ & $0.32[-0.38,1.01]$ \\
\hline \multicolumn{8}{|c|}{ Heterogeneity: Not applicable } \\
\hline \multicolumn{8}{|c|}{ Test for overall effect: $Z=0.89(P=0.38)$} \\
\hline \multicolumn{8}{|c|}{ 1.6.2 Peak hip angle during swing phase - actual values } \\
\hline Daly 2004 & 8 & $31.3(10.1)$ & 7 & $37.8(7.1)$ & & $100 \%$ & $-0.69[-1.75,0.36]$ \\
\hline
\end{tabular}




\begin{tabular}{|c|c|c|c|c|c|c|c|}
\hline \multirow[t]{2}{*}{ Study or subgroup } & \multicolumn{2}{|c|}{ Electrostimulation } & \multicolumn{2}{|c|}{ No treatment } & \multirow{2}{*}{$\begin{array}{c}\text { Std. Mean Difference } \\
\text { Random, } 95 \% \mathrm{Cl}\end{array}$} & \multirow[t]{2}{*}{ Weight } & \multirow{2}{*}{$\begin{array}{c}\text { Std. Mean Difference } \\
\text { Random, } 95 \% \mathrm{Cl}\end{array}$} \\
\hline & $\mathbf{N}$ & $\operatorname{Mean}(S D)$ & $\mathbf{N}$ & Mean(SD) & & & \\
\hline Subtotal $\star \star \star$ & 8 & & 7 & & & $100 \%$ & $-0.69[-1.75,0.36]$ \\
\hline \multicolumn{8}{|c|}{ Heterogeneity: Not applicable } \\
\hline \multicolumn{8}{|c|}{ Test for overall effect: $Z=1.29(P=0.2)$} \\
\hline \multicolumn{8}{|c|}{ 1.6.3 Peak knee angle during swing phase - actual values } \\
\hline Daly 2004 & 8 & $33.5(15.9)$ & 7 & $32.4(11.8)$ & & $100 \%$ & $0.07[-0.94,1.09]$ \\
\hline Subtotal $\star \star \star$ & 8 & & 7 & & & $100 \%$ & $0.07[-0.94,1.09]$ \\
\hline \multicolumn{8}{|c|}{ Heterogeneity: Not applicable } \\
\hline \multicolumn{8}{|c|}{ Test for overall effect: $Z=0.14(P=0.89)$} \\
\hline \multicolumn{8}{|c|}{ 1.6.4 Peak ankle angle during swing phase - actual values } \\
\hline Daly 2004 & 8 & $5(3.9)$ & 7 & $4.6(6.6)$ & & $100 \%$ & $0.07[-0.94,1.09]$ \\
\hline 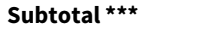 & 8 & & 7 & & & $100 \%$ & $0.07[-0.94,1.09]$ \\
\hline \multicolumn{8}{|c|}{ Heterogeneity: Not applicable } \\
\hline \multicolumn{8}{|c|}{ Test for overall effect: $Z=0.14(P=0.89)$} \\
\hline \multicolumn{8}{|c|}{ 1.6.5 Timing of peak hip angle (\% gait cycle) - actual values } \\
\hline Daly 2004 & 8 & $-68.9(12.6)$ & 7 & $-57.7(11.9)$ & & $100 \%$ & $-0.86[-1.93,0.22]$ \\
\hline Subtotal $\star \star \star ~$ & 8 & & 7 & & & $100 \%$ & $-0.86[-1.93,0.22]$ \\
\hline \multicolumn{8}{|c|}{ Heterogeneity: Not applicable } \\
\hline \multicolumn{8}{|c|}{ Test for overall effect: $Z=1.56(P=0.12)$} \\
\hline \multicolumn{8}{|c|}{ 1.6.6 Timing of peak knee angle (\% gait cycle) - actual values } \\
\hline Daly 2004 & 8 & $-30.4(13.8)$ & 7 & $-28.5(6.6)$ & & $100 \%$ & $-0.17[-1.18,0.85]$ \\
\hline Subtotal $\star \star \star$ & 8 & & 7 & & & $100 \%$ & $-0.17[-1.18,0.85]$ \\
\hline \multicolumn{8}{|c|}{ Heterogeneity: Not applicable } \\
\hline \multicolumn{8}{|c|}{ Test for overall effect: $Z=0.32(P=0.75)$} \\
\hline \multicolumn{8}{|c|}{ 1.6.7 Timing of peak ankle angle (\% gait cycle) - actual values } \\
\hline Daly 2004 & 8 & $-53.9(14.3)$ & 7 & $-49.7(21.4)$ & & $100 \%$ & $-0.22[-1.24,0.8]$ \\
\hline Subtotal $\star \star \star$ & 8 & & 7 & & & $100 \%$ & $-0.22[-1.24,0.8]$ \\
\hline \multicolumn{8}{|c|}{ Heterogeneity: Not applicable } \\
\hline Test for overall effect & & & & & & & \\
\hline
\end{tabular}

\section{Analysis 1.7. Comparison 1 Electrostimulation versus no treatment, Outcome 7 Functional motor ability.}

\begin{tabular}{|c|c|c|c|c|c|c|c|}
\hline \multirow[t]{2}{*}{ Study or subgroup } & \multicolumn{2}{|c|}{ Electrostimulation } & \multicolumn{2}{|c|}{ No treatment } & \multirow{2}{*}{$\begin{array}{c}\text { Std. Mean Difference } \\
\text { Random, } 95 \% \mathrm{Cl}\end{array}$} & \multirow[t]{2}{*}{ Weight } & \multirow{2}{*}{$\begin{array}{c}\text { Std. Mean Difference } \\
\text { Random, } 95 \% \mathrm{Cl}\end{array}$} \\
\hline & $\mathbf{N}$ & $\operatorname{Mean}(\mathrm{SD})$ & $\mathbf{N}$ & Mean(SD) & & & \\
\hline \multicolumn{8}{|c|}{ 1.7.1 Motor Assessment Scale - actual values } \\
\hline Linn 1999 & 20 & $3(2.3)$ & 20 & $2.9(2.3)$ & & $100 \%$ & $0.02[-0.6,0.64]$ \\
\hline 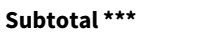 & 20 & & 20 & & & $100 \%$ & $0.02[-0.6,0.64]$ \\
\hline \multicolumn{8}{|c|}{ Heterogeneity: Not applicable } \\
\hline \multicolumn{8}{|c|}{ Test for overall effect: $Z=0.07(P=0.95)$} \\
\hline \multicolumn{8}{|c|}{ 1.7.2 Box and Blocks Test - actual values } \\
\hline Cauraugh 2000 & 7 & $15.9(11.4)$ & 4 & $4.8(4.5)$ & 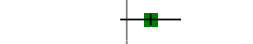 & $32.05 \%$ & $1.06[-0.29,2.41]$ \\
\hline Cauraugh 2002 & 10 & $24.7(18.5)$ & 5 & $17.4(18.7)$ & \#- & $38.2 \%$ & $0.37[-0.71,1.45]$ \\
\hline Cauraugh 2003 & 10 & $27.8(4.9)$ & 6 & $14.5(4.6)$ & —- & $29.75 \%$ & $2.62[1.17,4.08]$ \\
\hline & & & 0 & atment $\quad-10$ & -5 & Favours & ostim \\
\hline
\end{tabular}




\begin{tabular}{|c|c|c|c|c|c|c|c|}
\hline \multirow[t]{2}{*}{ Study or subgroup } & \multicolumn{2}{|c|}{ Electrostimulation } & \multicolumn{2}{|c|}{ No treatment } & \multirow{2}{*}{$\begin{array}{c}\text { Std. Mean Difference } \\
\text { Random, } 95 \% \mathrm{Cl} \\
\end{array}$} & \multirow[t]{2}{*}{ Weight } & \multirow{2}{*}{$\begin{array}{c}\text { Std. Mean Difference } \\
\text { Random, } 95 \% \mathrm{Cl}\end{array}$} \\
\hline & $\mathbf{N}$ & Mean(SD) & $\mathbf{N}$ & $\operatorname{Mean}(\mathrm{SD})$ & & & \\
\hline 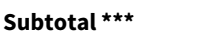 & 27 & & 15 & & & $100 \%$ & $1.28[-0,2.56]$ \\
\hline \multicolumn{8}{|c|}{ Heterogeneity: $\mathrm{Tau}^{2}=0.85 ; \mathrm{Chi}^{2}=5.93, \mathrm{df}=2(\mathrm{P}=0.05) ; \mathrm{I}^{2}=66.29 \%$} \\
\hline \multicolumn{8}{|c|}{ Test for overall effect: $\mathrm{Z}=1.96(\mathrm{P}=0.05)$} \\
\hline \multicolumn{8}{|c|}{ 1.7.3 Upper Extremity Drawing Test - actual values } \\
\hline Popovic 2003 & 14 & $1.4(2.7)$ & 14 & $4.9(2.1)$ & & $100 \%$ & $-1.4[-2.25,-0.56]$ \\
\hline Subtotal $\star \star \star ~$ & 14 & & 14 & & & $100 \%$ & $-1.4[-2.25,-0.56]$ \\
\hline \multicolumn{8}{|c|}{ Heterogeneity: Not applicable } \\
\hline \multicolumn{8}{|c|}{ Test for overall effect: $Z=3.28(P=0)$} \\
\hline \multicolumn{8}{|c|}{ 1.7.4 Action Research Arm Test - change values } \\
\hline Powell 1999 & 27 & $10(21.5)$ & 28 & $2(10.4)$ & & $100 \%$ & $0.47[-0.07,1.01]$ \\
\hline 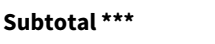 & 27 & & 28 & & & $100 \%$ & $0.47[-0.07,1.01]$ \\
\hline \multicolumn{8}{|c|}{ Heterogeneity: Not applicable } \\
\hline \multicolumn{8}{|c|}{ Test for overall effect: $Z=1.72(P=0.09)$} \\
\hline \multicolumn{8}{|c|}{ 1.7.5 Nine Hole Peg Test - change values } \\
\hline Powell 1999 & 27 & $0(0.1)$ & 28 & $0(0.1)$ & & $100 \%$ & $0[-0.53,0.53]$ \\
\hline Subtotal $\star \star \star$ & 27 & & 28 & & & $100 \%$ & $0[-0.53,0.53]$ \\
\hline \multicolumn{8}{|c|}{ Heterogeneity: Not applicable } \\
\hline \multicolumn{8}{|c|}{ Test for overall effect: Not applicable } \\
\hline & & & vours & treatment & -10 & 10 Favours $€$ & stim \\
\hline
\end{tabular}

\section{Analysis 1.8. Comparison 1 Electrostimulation versus no treatment, Outcome 8 Global ADL.}

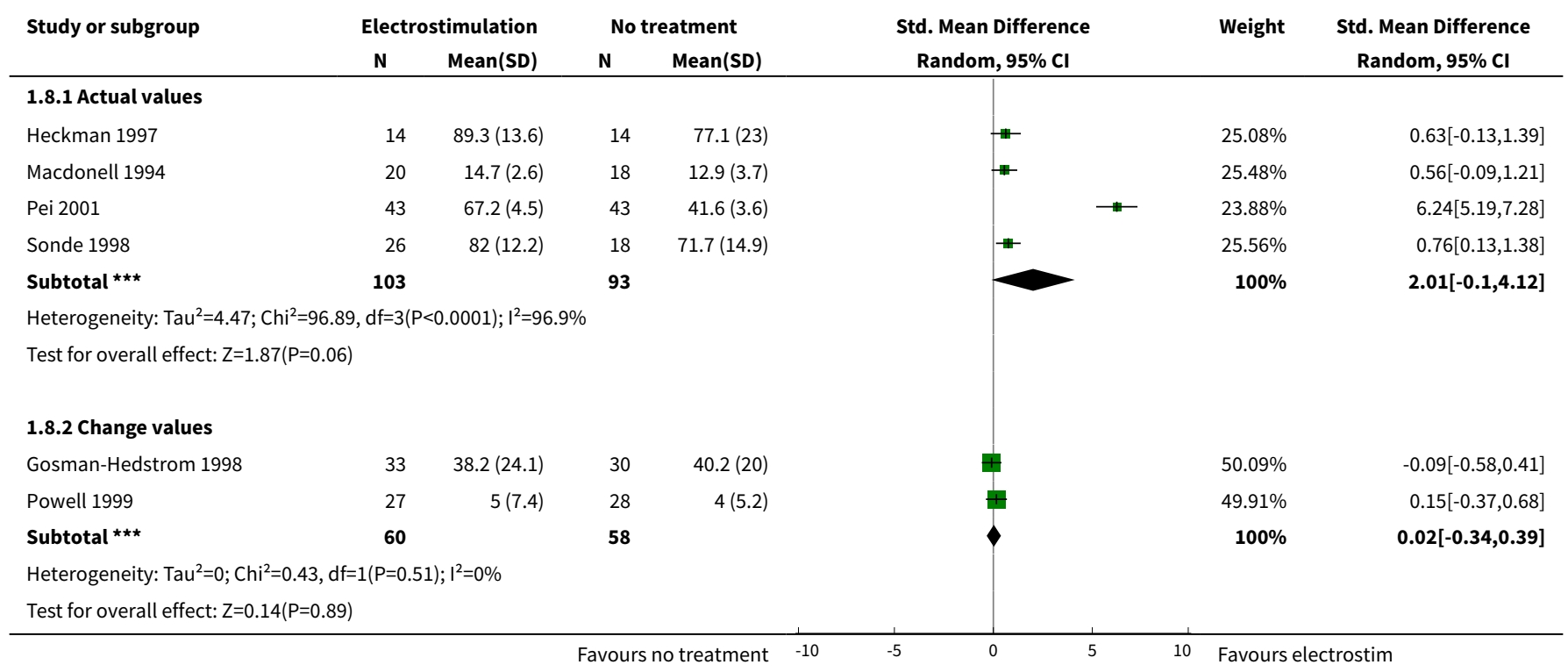




\section{Comparison 2. Electrostimulation versus placebo}

\begin{tabular}{|c|c|c|c|c|}
\hline Outcome or subgroup title & $\begin{array}{l}\text { No. of } \\
\text { studies }\end{array}$ & $\begin{array}{l}\text { No. of } \\
\text { partici- } \\
\text { pants }\end{array}$ & Statistical method & Effect size \\
\hline 1 Motor impairment - muscle function & 2 & & $\begin{array}{l}\text { Std. Mean Difference (IV, Ran- } \\
\text { dom, } 95 \% \mathrm{Cl} \text { ) }\end{array}$ & Subtotals only \\
\hline 1.1 Isometric muscle strength - actual values & 2 & 44 & $\begin{array}{l}\text { Std. Mean Difference (IV, Ran- } \\
\text { dom, } 95 \% \mathrm{Cl} \text { ) }\end{array}$ & $0.72[-0.15,1.59]$ \\
\hline 1.2 Co-contraction - actual values & 1 & 28 & $\begin{array}{l}\text { Std. Mean Difference (IV, Ran- } \\
\text { dom, } 95 \% \mathrm{Cl} \text { ) }\end{array}$ & $0.93[0.14,1.72]$ \\
\hline 2 Motor impairment - Fugl Meyer Assessment & 1 & & $\begin{array}{l}\text { Std. Mean Difference (IV, Ran- } \\
\text { dom, } 95 \% \mathrm{Cl} \text { ) }\end{array}$ & Subtotals only \\
\hline 2.1 Change values & 1 & 28 & $\begin{array}{l}\text { Std. Mean Difference (IV, Ran- } \\
\text { dom, } 95 \% \mathrm{Cl} \text { ) }\end{array}$ & $0.76[-0.01,1.53]$ \\
\hline 3 Normality of movement & 2 & & $\begin{array}{l}\text { Std. Mean Difference (IV, Ran- } \\
\text { dom, } 95 \% \mathrm{Cl} \text { ) }\end{array}$ & Subtotals only \\
\hline 3.1 Gait velocity - actual values & 1 & 94 & $\begin{array}{l}\text { Std. Mean Difference (IV, Ran- } \\
\text { dom, } 95 \% \mathrm{Cl} \text { ) }\end{array}$ & $-0.19[-0.59,0.22]$ \\
\hline 3.2 Motor Activity Log, how well - actual values & 1 & 16 & $\begin{array}{l}\text { Std. Mean Difference (IV, Ran- } \\
\text { dom, } 95 \% \mathrm{Cl} \text { ) }\end{array}$ & $0.30[-0.69,1.28]$ \\
\hline 4 Functional motor ability & 3 & & $\begin{array}{l}\text { Std. Mean Difference (IV, Ran- } \\
\text { dom, } 95 \% \mathrm{CI} \text { ) }\end{array}$ & Subtotals only \\
\hline 4.1 Rivermead Mobility Index - actual values & 1 & 94 & $\begin{array}{l}\text { Std. Mean Difference (IV, Ran- } \\
\text { dom, } 95 \% \mathrm{CI} \text { ) }\end{array}$ & $0.0[-0.40,0.40]$ \\
\hline 4.2 Timed Up \& Go Test - actual values & 1 & 28 & $\begin{array}{l}\text { Std. Mean Difference (IV, Ran- } \\
\text { dom, } 95 \% \mathrm{CI} \text { ) }\end{array}$ & $-4.59[-6.09,-3.10]$ \\
\hline 4.3 Box and Blocks Test - actual values & 1 & 16 & $\begin{array}{l}\text { Std. Mean Difference (IV, Ran- } \\
\text { dom, } 95 \% \mathrm{CI} \text { ) }\end{array}$ & $0.16[-0.82,1.15]$ \\
\hline $\begin{array}{l}\text { 4.4 Jebsen Hand Function Test, page turning - ac- } \\
\text { tual values }\end{array}$ & 1 & 16 & $\begin{array}{l}\text { Std. Mean Difference (IV, Ran- } \\
\text { dom, } 95 \% \mathrm{CI} \text { ) }\end{array}$ & $0.16[-0.82,1.14]$ \\
\hline $\begin{array}{l}4.5 \text { Jebsen Hand Function Test, small objects - ac- } \\
\text { tual values }\end{array}$ & 1 & 16 & $\begin{array}{l}\text { Std. Mean Difference (IV, Ran- } \\
\text { dom, } 95 \% \mathrm{CI} \text { ) }\end{array}$ & $0.57[-0.44,1.57]$ \\
\hline $\begin{array}{l}\text { 4.6 Jebsen Hand Function Test, feeding - actual } \\
\text { values }\end{array}$ & 1 & 16 & $\begin{array}{l}\text { Std. Mean Difference (IV, Ran- } \\
\text { dom, } 95 \% \mathrm{CI} \text { ) }\end{array}$ & $1.36[0.24,2.48]$ \\
\hline $\begin{array}{l}4.7 \text { Jebsen Hand Function Test, stacking - actual } \\
\text { values }\end{array}$ & 1 & 16 & $\begin{array}{l}\text { Std. Mean Difference (IV, Ran- } \\
\text { dom, } 95 \% \mathrm{CI} \text { ) }\end{array}$ & $0.54[-0.47,1.54]$ \\
\hline $\begin{array}{l}4.8 \text { Jebsen Hand Function Test, light cans - actual } \\
\text { values }\end{array}$ & 1 & 16 & $\begin{array}{l}\text { Std. Mean Difference (IV, Ran- } \\
\text { dom, } 95 \% \mathrm{CI} \text { ) }\end{array}$ & $-0.45[-1.45,0.55]$ \\
\hline $\begin{array}{l}4.9 \text { Jebsen Hand Function Test, heavy cans - actu- } \\
\text { al values }\end{array}$ & 1 & 16 & $\begin{array}{l}\text { Std. Mean Difference (IV, Ran- } \\
\text { dom, } 95 \% \mathrm{CI} \text { ) }\end{array}$ & $-0.16[-1.15,0.82]$ \\
\hline
\end{tabular}




\begin{tabular}{lllll}
\hline Outcome or subgroup title & $\begin{array}{l}\text { No. of } \\
\text { studies }\end{array}$ & $\begin{array}{l}\text { No. of } \\
\text { partici- } \\
\text { pants }\end{array}$ & Statistical method & Effect size \\
\hline 5 Global ADL & 3 & & $\begin{array}{l}\text { Std. Mean Difference (IV, Ran- } \\
\text { dom, 95\% CI) }\end{array}$ & Subtotals only \\
\hline 5.1 Actual values & 2 & 154 & $\begin{array}{l}\text { Std. Mean Difference (IV, Ran- } \\
\text { dom, 95\% CI) }\end{array}$ & $0.77[-0.99,2.53]$ \\
\hline 5.2 Change values & 1 & 28 & $\begin{array}{l}\text { Std. Mean Difference (IV, Ran- } \\
\text { dom, 95\% CI) }\end{array}$ & $0.15[-0.60,0.89]$ \\
\hline
\end{tabular}

Analysis 2.1. Comparison 2 Electrostimulation versus placebo, Outcome 1 Motor impairment - muscle function.

\begin{tabular}{|c|c|c|c|c|c|c|c|}
\hline \multirow[t]{2}{*}{ Study or subgroup } & \multicolumn{2}{|c|}{ Electrostimulation } & \multicolumn{2}{|c|}{ Placebo } & \multirow{2}{*}{$\begin{array}{c}\text { Std. Mean Difference } \\
\text { Random, } 95 \% \mathrm{Cl}\end{array}$} & \multirow[t]{2}{*}{ Weight } & \multirow{2}{*}{$\begin{array}{c}\text { Std. Mean Difference } \\
\text { Random, } 95 \% \mathrm{Cl}\end{array}$} \\
\hline & $\mathbf{N}$ & Mean(SD) & $\mathbf{N}$ & Mean(SD) & & & \\
\hline \multicolumn{8}{|c|}{ 2.1.1 Isometric muscle strength - actual values } \\
\hline Kimberley 2004 & 8 & $12.9(22.4)$ & 8 & $8.9(6.5)$ & & $40.2 \%$ & $0.23[-0.75,1.21]$ \\
\hline Yan 2005 & 13 & $9(4.6)$ & 15 & $4.6(3)$ & & $59.8 \%$ & $1.12[0.31,1.92]$ \\
\hline Subtotal $\star \star \star$ & 21 & & 23 & & & $100 \%$ & $0.72[-0.15,1.59]$ \\
\hline \multicolumn{8}{|c|}{ Heterogeneity: $\mathrm{Tau}^{2}=0.18 ; \mathrm{Chi}^{2}=1.87, \mathrm{df}=1(\mathrm{P}=0.17) ; \mathrm{I}^{2}=46.5 \%$} \\
\hline \multicolumn{8}{|c|}{ 2.1.2 Co-contraction - actual values } \\
\hline Yan 2005 & 13 & $-7.8(5.3)$ & 15 & $-26.5(26.2)$ & & $100 \%$ & $0.93[0.14,1.72]$ \\
\hline 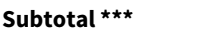 & 13 & & 15 & & & $100 \%$ & $0.93[0.14,1.72]$ \\
\hline \multicolumn{8}{|c|}{ Heterogeneity: Not applicable } \\
\hline Test for overall effect & & & & & & & \\
\hline
\end{tabular}

\section{Analysis 2.2. Comparison 2 Electrostimulation versus placebo, Outcome 2 Motor impairment - Fugl Meyer Assessment.}

\begin{tabular}{|c|c|c|c|c|c|c|c|}
\hline \multirow[t]{2}{*}{ Study or subgroup } & \multicolumn{2}{|c|}{ Electrostimulation } & \multicolumn{2}{|c|}{ Placebo } & \multirow{2}{*}{$\begin{array}{c}\text { Std. Mean Difference } \\
\text { Random, } 95 \% \mathrm{Cl}\end{array}$} & \multirow[t]{2}{*}{ Weight } & \multirow{2}{*}{$\begin{array}{c}\text { Std. Mean Difference } \\
\text { Random, } 95 \% \mathrm{Cl}\end{array}$} \\
\hline & $\mathbf{N}$ & Mean(SD) & $\mathbf{N}$ & Mean(SD) & & & \\
\hline \multicolumn{8}{|l|}{ 2.2.1 Change values } \\
\hline Chae 1998 & 14 & $13.1(10.3)$ & 14 & $6.5(6.1)$ & + & $100 \%$ & $0.76[-0.01,1.53]$ \\
\hline Subtotal $\star \star \star$ & 14 & & 14 & & & $100 \%$ & $0.76[-0.01,1.53]$ \\
\hline \multicolumn{8}{|c|}{ Heterogeneity: Not applicable } \\
\hline \multicolumn{8}{|c|}{ Test for overall effect: $Z=1.92(P=0.05)$} \\
\hline
\end{tabular}


Analysis 2.3. Comparison 2 Electrostimulation versus placebo, Outcome 3 Normality of movement.

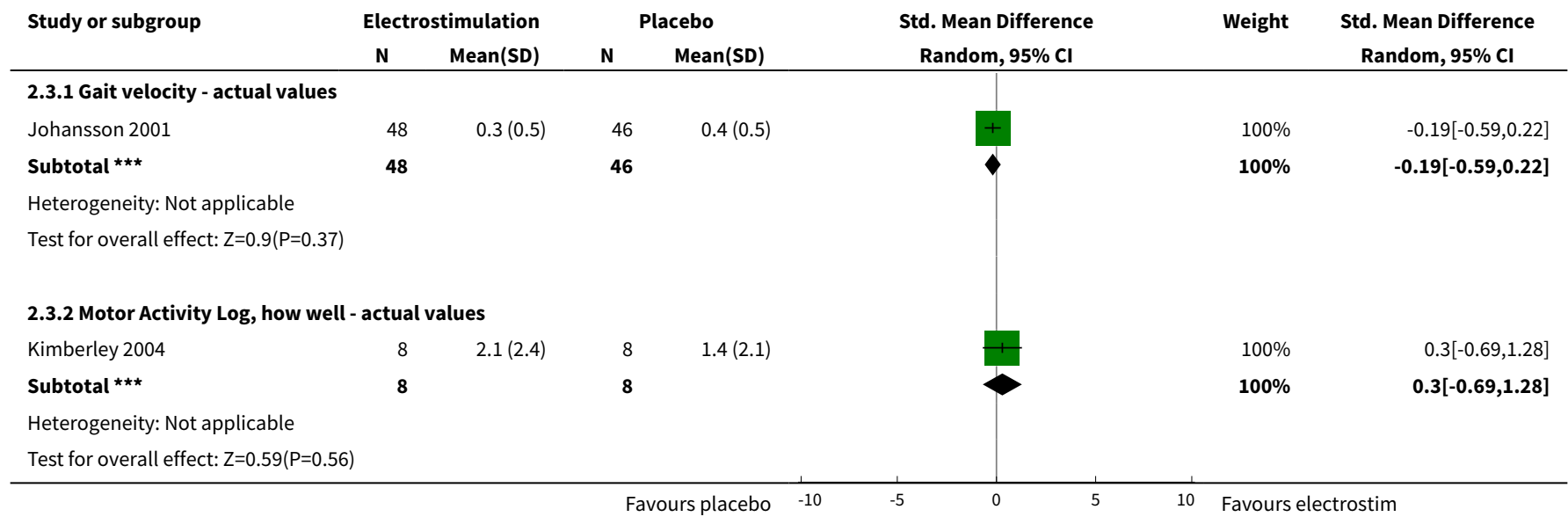

Analysis 2.4. Comparison 2 Electrostimulation versus placebo, Outcome 4 Functional motor ability.

\begin{tabular}{|c|c|c|c|c|c|c|c|}
\hline \multirow[t]{2}{*}{ Study or subgroup } & \multicolumn{2}{|c|}{ Electrostimulation } & \multicolumn{2}{|c|}{ Placebo } & \multirow{2}{*}{$\begin{array}{c}\text { Std. Mean Difference } \\
\text { Random, } 95 \% \mathrm{Cl}\end{array}$} & \multirow[t]{2}{*}{ Weight } & \multirow{2}{*}{$\begin{array}{c}\text { Std. Mean Difference } \\
\text { Random, } 95 \% \mathrm{Cl}\end{array}$} \\
\hline & $\mathbf{N}$ & Mean(SD) & $\mathbf{N}$ & $\operatorname{Mean}(\mathrm{SD})$ & & & \\
\hline \multicolumn{8}{|c|}{ 2.4.1 Rivermead Mobility Index - actual values } \\
\hline Johansson 2001 & 48 & $7(5.9)$ & 46 & $7(6.7)$ & & $100 \%$ & $0[-0.4,0.4]$ \\
\hline Subtotal $\star \star \star$ & 48 & & 46 & & & $100 \%$ & $0[-0.4,0.4]$ \\
\hline \multicolumn{8}{|c|}{ Heterogeneity: Not applicable } \\
\hline \multicolumn{8}{|c|}{ Test for overall effect: Not applicable } \\
\hline \multicolumn{8}{|c|}{ 2.4.2 Timed Up \& Go Test - actual values } \\
\hline Yan 2005 & 13 & $-39.2(3.4)$ & 15 & $-16.6(5.7)$ & & $100 \%$ & $-4.59[-6.09,-3.1]$ \\
\hline Subtotal $\star \star \star$ & 13 & & 15 & & & $100 \%$ & $-4.59[-6.09,-3.1]$ \\
\hline \multicolumn{8}{|c|}{ Heterogeneity: Not applicable } \\
\hline \multicolumn{8}{|c|}{ Test for overall effect: $Z=6.02(P<0.0001)$} \\
\hline Kimberley 2004 & 8 & $27(13.6)$ & 8 & $24.3(17.3)$ & & $100 \%$ & $0.16[-0.82,1.15]$ \\
\hline Subtotal $\star \star \star$ & 8 & & 8 & & & $100 \%$ & $0.16[-0.82,1.15]$ \\
\hline \multicolumn{8}{|c|}{ Heterogeneity: Not applicable } \\
\hline \multicolumn{8}{|c|}{ Test for overall effect: $Z=0.33(P=0.74)$} \\
\hline \multicolumn{8}{|c|}{ 2.4.4 Jebsen Hand Function Test, page turning - actual values } \\
\hline Kimberley 2004 & 8 & $-17.1(16.1)$ & 8 & $-19.5(12.2)$ & & $100 \%$ & $0.16[-0.82,1.14]$ \\
\hline Subtotal $* \star \star$ & 8 & & 8 & & & $100 \%$ & $0.16[-0.82,1.14]$ \\
\hline \multicolumn{8}{|c|}{ Heterogeneity: Not applicable } \\
\hline \multicolumn{8}{|c|}{ Test for overall effect: $\mathrm{Z}=0.32(\mathrm{P}=0.75)$} \\
\hline \multicolumn{8}{|c|}{ 2.4.5 Jebsen Hand Function Test, small objects - actual values } \\
\hline Kimberley 2004 & 8 & $-25(15)$ & 8 & $-41.4(35.5)$ & & $100 \%$ & $0.57[-0.44,1.57]$ \\
\hline \multicolumn{8}{|c|}{ Heterogeneity: Not applicable } \\
\hline \multicolumn{8}{|c|}{ Test for overall effect: $Z=1.11(P=0.27)$} \\
\hline \multicolumn{8}{|c|}{ 2.4.6 Jebsen Hand Function Test, feeding - actual values } \\
\hline & & & & urs placebo -10 & 0 & 10 Favour & tim \\
\hline
\end{tabular}




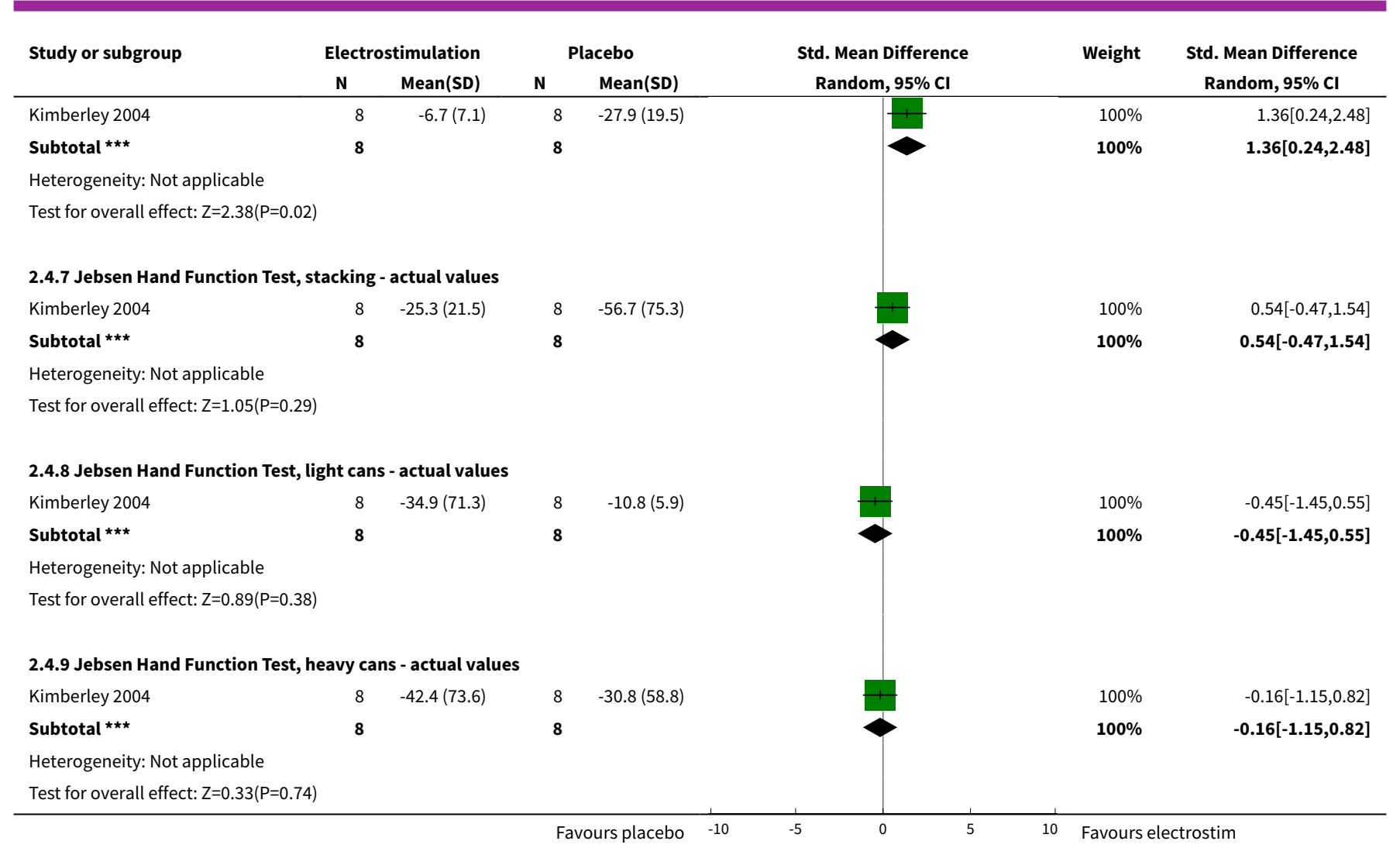

Analysis 2.5. Comparison 2 Electrostimulation versus placebo, Outcome 5 Global ADL.

\begin{tabular}{|c|c|c|c|c|c|c|c|}
\hline \multirow[t]{2}{*}{ Study or subgroup } & \multicolumn{2}{|c|}{ Electrostimulation } & \multicolumn{2}{|c|}{ Placebo } & \multirow{2}{*}{$\begin{array}{c}\text { Std. Mean Difference } \\
\text { Random, } 95 \% \mathrm{Cl}\end{array}$} & \multirow[t]{2}{*}{ Weight } & \multirow{2}{*}{$\begin{array}{c}\text { Std. Mean Difference } \\
\text { Random, } 95 \% \mathrm{Cl}\end{array}$} \\
\hline & $\mathbf{N}$ & Mean(SD) & $\mathbf{N}$ & Mean(SD) & & & \\
\hline \multicolumn{8}{|l|}{ 2.5.1 Actual values } \\
\hline Johansson 2001 & 48 & $68.6(28.6)$ & 46 & $71.7(23.2)$ & 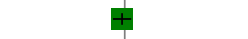 & $51.22 \%$ & $-0.12[-0.52,0.29]$ \\
\hline Tekeoolu 1998 & 30 & $80.4(10)$ & 30 & $60.4(13.3)$ & \# & $48.78 \%$ & $1.68[1.08,2.27]$ \\
\hline Subtotal $\star \star \star$ & 78 & & 76 & & & $100 \%$ & $0.77[-0.99,2.53]$ \\
\hline \multicolumn{8}{|c|}{ Heterogeneity: $\mathrm{Tau}^{2}=1.54 ; \mathrm{Chi}^{2}=23.98, \mathrm{df}=1(\mathrm{P}<0.0001) ; \mathrm{I}^{2}=95.83 \%$} \\
\hline \multicolumn{8}{|c|}{ Test for overall effect: $Z=0.85(P=0.39)$} \\
\hline \multicolumn{8}{|l|}{ 2.5.2 Change values } \\
\hline Chae 1998 & 14 & $11.3(3)$ & 14 & $10.6(5.9)$ & & $100 \%$ & $0.15[-0.6,0.89]$ \\
\hline 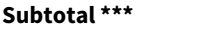 & 14 & & 14 & & & $100 \%$ & $0.15[-0.6,0.89]$ \\
\hline \multicolumn{8}{|c|}{ Heterogeneity: Not applicable } \\
\hline Test for overall effect & & & & & & & \\
\hline
\end{tabular}


Comparison 3. Electrostimulation versus conventional therapy

\begin{tabular}{|c|c|c|c|c|}
\hline Outcome or subgroup title & $\begin{array}{l}\text { No. of } \\
\text { studies }\end{array}$ & $\begin{array}{l}\text { No. of } \\
\text { partici- } \\
\text { pants }\end{array}$ & Statistical method & Effect size \\
\hline 1 Motor impairment - muscle tone & 1 & & $\begin{array}{l}\text { Std. Mean Difference (IV, Random, } \\
95 \% \mathrm{CI})\end{array}$ & Subtotals only \\
\hline 1.1 Lower limb - actual values & 1 & 23 & $\begin{array}{l}\text { Std. Mean Difference (IV, Random, } \\
95 \% \mathrm{CI})\end{array}$ & $0.63[-0.21,1.47]$ \\
\hline $\begin{array}{l}2 \text { Motor impairment - physiological cost in- } \\
\text { dex }\end{array}$ & 1 & & $\begin{array}{l}\text { Std. Mean Difference (IV, Random, } \\
95 \% \mathrm{CI})\end{array}$ & Subtotals only \\
\hline 2.1 Actual values & 1 & 23 & $\begin{array}{l}\text { Std. Mean Difference (IV, Random, } \\
95 \% \mathrm{CI})\end{array}$ & $0.13[-0.69,0.95]$ \\
\hline $\begin{array}{l}3 \text { Motor impairment - Fugl Meyer Assess- } \\
\text { ment }\end{array}$ & 2 & & $\begin{array}{l}\text { Std. Mean Difference (IV, Random, } \\
95 \% \mathrm{CI})\end{array}$ & Subtotals only \\
\hline 3.1 Actual values & 2 & 29 & $\begin{array}{l}\text { Std. Mean Difference (IV, Random, } \\
95 \% \mathrm{CI})\end{array}$ & $1.06[0.25,1.88]$ \\
\hline 4 Normality of movement & 3 & & $\begin{array}{l}\text { Std. Mean Difference (IV, Random, } \\
95 \% \mathrm{CI})\end{array}$ & Subtotals only \\
\hline 4.1 Gait velocity - actual values & 2 & 41 & $\begin{array}{l}\text { Std. Mean Difference (IV, Random, } \\
95 \% \mathrm{CI})\end{array}$ & $0.18[-1.14,1.50]$ \\
\hline 4.2 Stride length - actual values & 2 & 34 & $\begin{array}{l}\text { Std. Mean Difference (IV, Random, } \\
95 \% \mathrm{CI})\end{array}$ & $0.35[-0.93,1.63]$ \\
\hline $\begin{array}{l}\text { 4.3 Minimum knee angle during swing phase } \\
\text { - actual values }\end{array}$ & 1 & 16 & $\begin{array}{l}\text { Std. Mean Difference (IV, Random, } \\
95 \% \mathrm{CI})\end{array}$ & $-0.15[-1.13,0.83]$ \\
\hline $\begin{array}{l}\text { 4.4 Mimimum ankle angle during swing } \\
\text { phase - actual values }\end{array}$ & 1 & 16 & $\begin{array}{l}\text { Std. Mean Difference (IV, Random, } \\
95 \% \mathrm{CI})\end{array}$ & $-0.66[-1.67,0.36]$ \\
\hline 4.5 Gait cycle time - actual values & 1 & 17 & $\begin{array}{l}\text { Std. Mean Difference (IV, Random, } \\
95 \% \mathrm{CI})\end{array}$ & $0.74[-0.25,1.74]$ \\
\hline 4.6 Cadence - actual values & 1 & 19 & $\begin{array}{l}\text { Std. Mean Difference (IV, Random, } \\
95 \% \mathrm{CI})\end{array}$ & $0.61[-0.32,1.54]$ \\
\hline 5 Functional motor ability & 1 & & $\begin{array}{l}\text { Std. Mean Difference (IV, Random, } \\
95 \% \mathrm{CI})\end{array}$ & Subtotals only \\
\hline 5.1 Rivermead Mobility Index - actual values & 1 & 23 & $\begin{array}{l}\text { Std. Mean Difference (IV, Random, } \\
95 \% \mathrm{CI})\end{array}$ & $-0.31[-1.14,0.51]$ \\
\hline 5.2 Walking endurance - actual values & 1 & 23 & $\begin{array}{l}\text { Std. Mean Difference (IV, Random, } \\
95 \% \mathrm{CI})\end{array}$ & $-0.30[-1.12,0.52]$ \\
\hline 6 Global ADL & 1 & & $\begin{array}{l}\text { Std. Mean Difference (IV, Random, } \\
95 \% \mathrm{CI})\end{array}$ & Subtotals only \\
\hline 6.1 Actual values & 1 & 9 & $\begin{array}{l}\text { Std. Mean Difference (IV, Random, } \\
95 \% \mathrm{CI})\end{array}$ & $1.59[-0.05,3.22]$ \\
\hline
\end{tabular}


Analysis 3.1. Comparison 3 Electrostimulation versus conventional therapy, Outcome 1 Motor impairment - muscle tone.

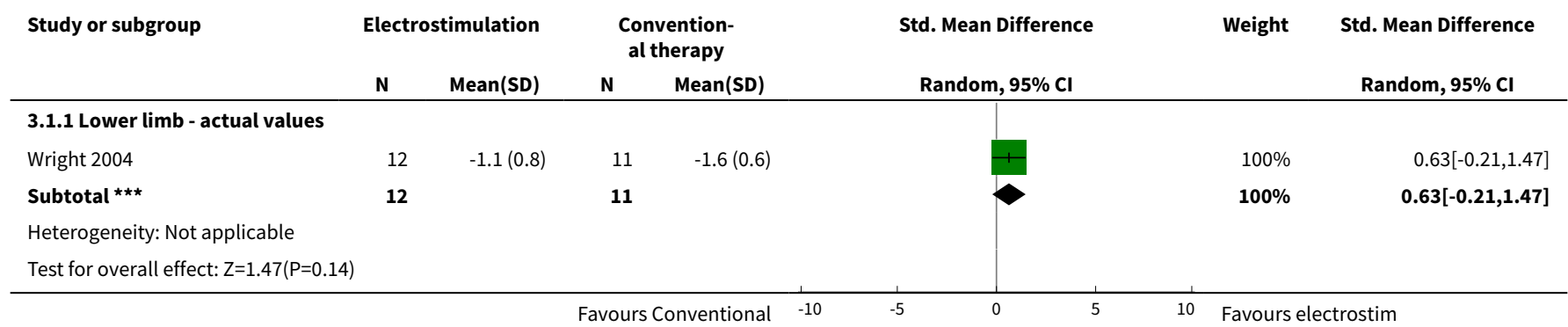

\section{Analysis 3.2. Comparison 3 Electrostimulation versus conventional} therapy, Outcome 2 Motor impairment - physiological cost index.

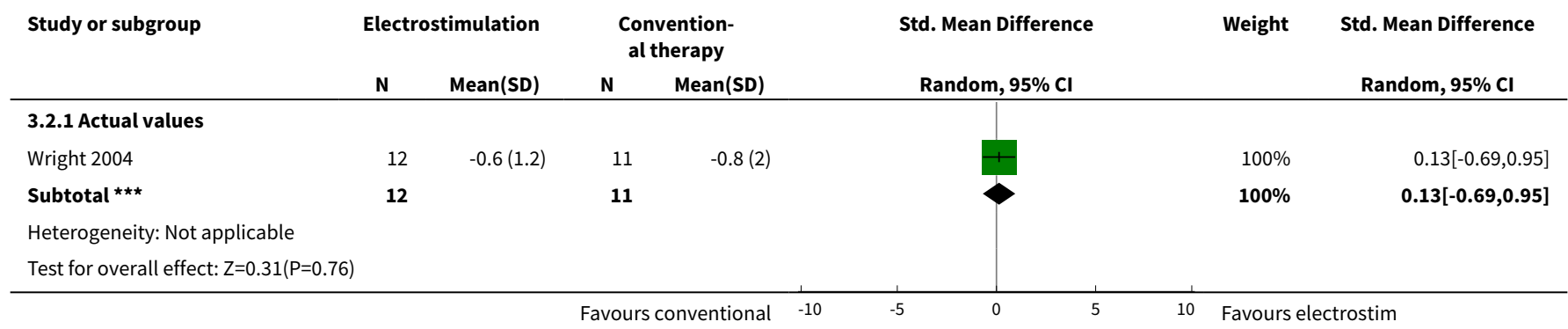

\section{Analysis 3.3. Comparison 3 Electrostimulation versus conventional} therapy, Outcome 3 Motor impairment - Fugl Meyer Assessment.

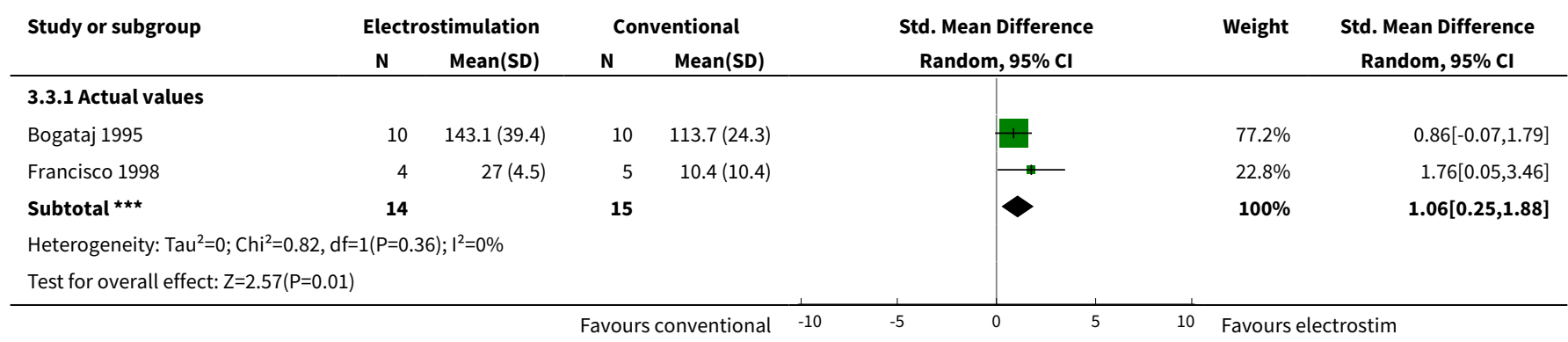

Analysis 3.4. Comparison 3 Electrostimulation versus conventional therapy, Outcome 4 Normality of movement.

\begin{tabular}{|c|c|c|c|c|c|c|c|}
\hline \multirow[t]{2}{*}{ Study or subgroup } & \multicolumn{2}{|c|}{ Electrostimulation } & \multicolumn{2}{|c|}{$\begin{array}{l}\text { Convention- } \\
\text { al therapy }\end{array}$} & \multirow{2}{*}{$\begin{array}{l}\text { Std. Mean Difference } \\
\text { Random, } 95 \% \mathrm{Cl}\end{array}$} & \multirow[t]{2}{*}{ Weight } & \multirow{2}{*}{$\begin{array}{l}\text { Std. Mean Difference } \\
\text { Random, } 95 \% \mathrm{Cl} \\
\end{array}$} \\
\hline & $\mathbf{N}$ & Mean(SD) & $\mathbf{N}$ & Mean(SD) & & & \\
\hline \multicolumn{8}{|c|}{ 3.4.1 Gait velocity - actual values } \\
\hline Bogataj 1995 & 8 & $0.4(0.2)$ & 10 & $0.3(0.1)$ & +1- & $45.66 \%$ & $0.88[-0.1,1.87]$ \\
\hline
\end{tabular}




\begin{tabular}{|c|c|c|c|c|c|c|c|}
\hline \multirow[t]{2}{*}{ Study or subgroup } & \multicolumn{2}{|c|}{ Electrostimulation } & \multicolumn{2}{|c|}{$\begin{array}{l}\text { Convention- } \\
\text { al therapy }\end{array}$} & \multirow{2}{*}{$\begin{array}{l}\text { Std. Mean Difference } \\
\text { Random, } 95 \% \mathrm{Cl}\end{array}$} & \multirow[t]{2}{*}{ Weight } & \multirow{2}{*}{$\begin{array}{l}\text { Std. Mean Difference } \\
\text { Random, } 95 \% \mathrm{Cl}\end{array}$} \\
\hline & $\mathbf{N}$ & Mean(SD) & $\mathbf{N}$ & Mean(SD) & & & \\
\hline Wright 2004 & 12 & $0.3(0.2)$ & 11 & $0.5(0.3)$ & & $54.34 \%$ & $-0.47[-1.3,0.37]$ \\
\hline Subtotal $* \star \star$ & 20 & & 21 & & & $100 \%$ & $0.18[-1.14,1.5]$ \\
\hline \multicolumn{8}{|c|}{ Heterogeneity: $\operatorname{Tau}^{2}=0.7 ; \mathrm{Chi}^{2}=4.22, \mathrm{df}=1(\mathrm{P}=0.04) ; \mathrm{I}^{2}=76.28 \%$} \\
\hline \multicolumn{8}{|c|}{ Test for overall effect: $Z=0.27(P=0.79)$} \\
\hline \multicolumn{8}{|c|}{ 3.4.2 Stride length - actual values } \\
\hline Bogataj 1995 & 8 & $0.8(0.2)$ & 10 & $0.6(0.2)$ & & $49.61 \%$ & $1.01[0,2.01]$ \\
\hline Cozean 1988 & 8 & $0.5(0.1)$ & 8 & $0.5(0.2)$ & & $50.39 \%$ & $-0.3[-1.29,0.69]$ \\
\hline 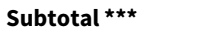 & 16 & & 18 & & & $100 \%$ & $0.35[-0.93,1.63]$ \\
\hline \multicolumn{8}{|c|}{ Heterogeneity: $\mathrm{Tau}^{2}=0.59 ; \mathrm{Chi}^{2}=3.3, \mathrm{df}=1(\mathrm{P}=0.07) ; \mathrm{I}^{2}=69.74 \%$} \\
\hline \multicolumn{8}{|c|}{ Test for overall effect: $Z=0.54(P=0.59)$} \\
\hline \multicolumn{8}{|c|}{ 3.4.3 Minimum knee angle during swing phase - actual values } \\
\hline Cozean 1988 & 8 & $-151(15)$ & 8 & $-149(9)$ & & $100 \%$ & $-0.15[-1.13,0.83]$ \\
\hline Subtotal $* \star \star$ & 8 & & 8 & & & $100 \%$ & $-0.15[-1.13,0.83]$ \\
\hline \multicolumn{8}{|c|}{ Heterogeneity: Not applicable } \\
\hline \multicolumn{8}{|c|}{ Test for overall effect: $\mathrm{Z}=0.31(\mathrm{P}=0.76)$} \\
\hline \multicolumn{8}{|c|}{ 3.4.4 Mimimum ankle angle during swing phase - actual values } \\
\hline Cozean 1988 & 8 & $-116(9)$ & 8 & $-109(11)$ & & $100 \%$ & $-0.66[-1.67,0.36]$ \\
\hline 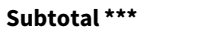 & 8 & & 8 & & & $100 \%$ & $-0.66[-1.67,0.36]$ \\
\hline \multicolumn{8}{|c|}{ Heterogeneity: Not applicable } \\
\hline \multicolumn{8}{|c|}{ Test for overall effect: $\mathrm{Z}=1.27(\mathrm{P}=0.2)$} \\
\hline \multicolumn{8}{|c|}{ 3.4.5 Gait cycle time - actual values } \\
\hline Cozean 1988 & 8 & $-2.4(0.7)$ & 9 & $-3(1)$ & & $100 \%$ & $0.74[-0.25,1.74]$ \\
\hline Subtotal $\star \star \star ~$ & 8 & & 9 & & & $100 \%$ & $0.74[-0.25,1.74]$ \\
\hline \multicolumn{8}{|c|}{ Heterogeneity: Not applicable } \\
\hline \multicolumn{8}{|c|}{ Test for overall effect: $Z=1.46(P=0.14)$} \\
\hline \multicolumn{8}{|c|}{ 3.4.6 Cadence - actual values } \\
\hline Bogataj 1995 & 9 & $0.5(0.1)$ & 10 & $0.4(0.1)$ & & $100 \%$ & $0.61[-0.32,1.54]$ \\
\hline 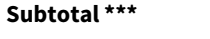 & 9 & & 10 & & & $100 \%$ & $0.61[-0.32,1.54]$ \\
\hline \multicolumn{8}{|c|}{ Heterogeneity: Not applicable } \\
\hline Test for overall effec & & & & & & & \\
\hline
\end{tabular}

\section{Analysis 3.5. Comparison 3 Electrostimulation versus conventional therapy, Outcome 5 Functional motor ability.}

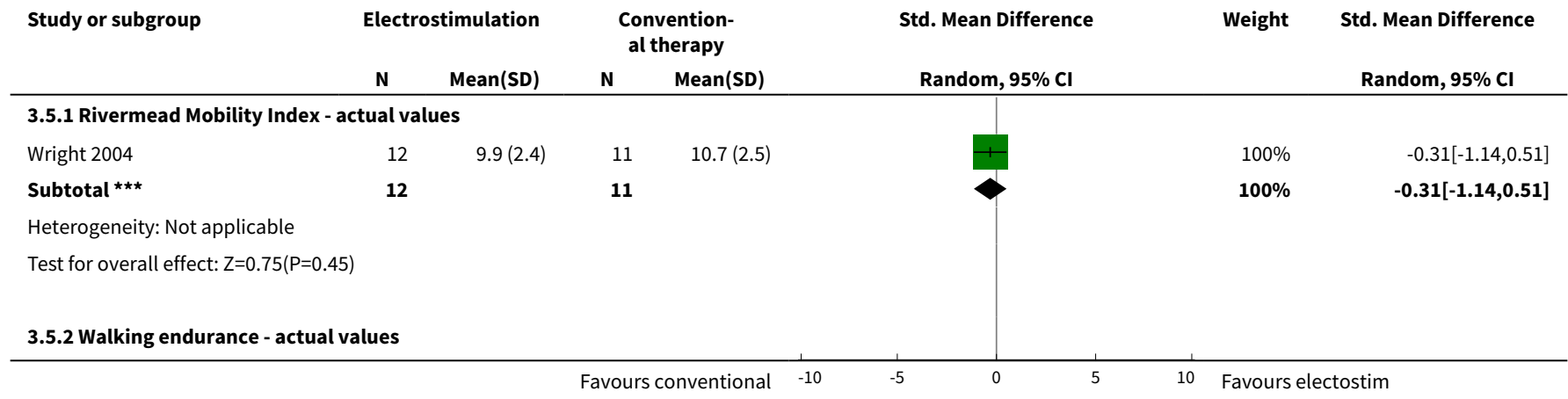




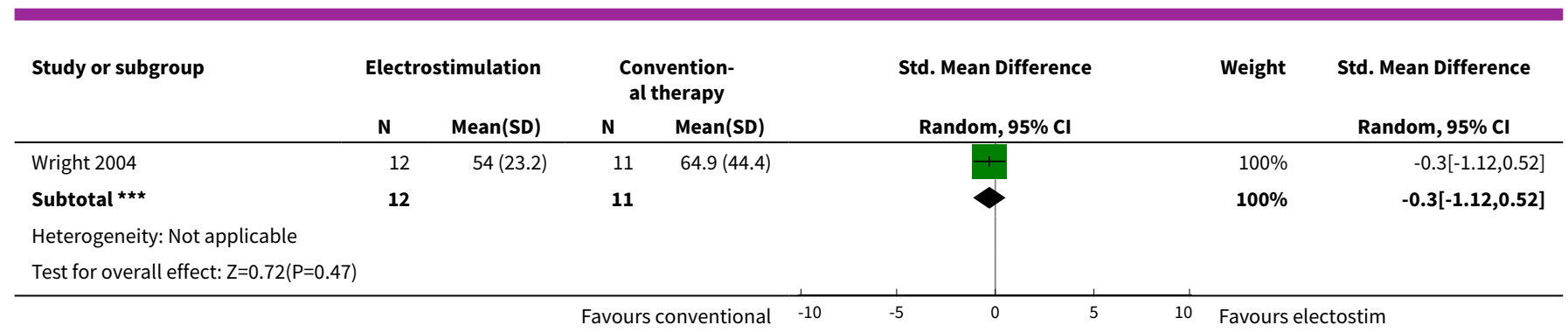

Analysis 3.6. Comparison 3 Electrostimulation versus conventional therapy, Outcome 6 Global ADL.

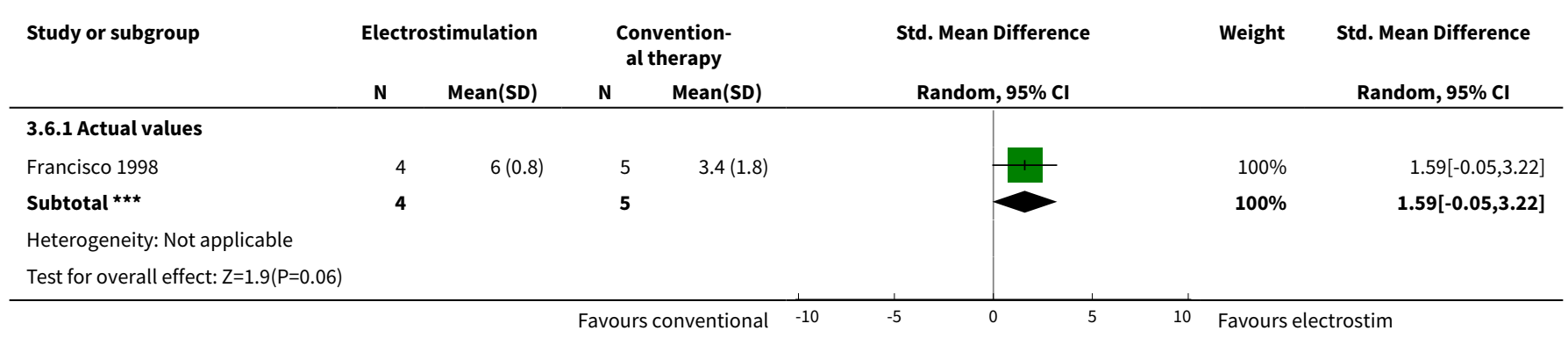

\section{Comparison 4. Acceptability of electrostimulation}

\begin{tabular}{lllll}
\hline Outcome or subgroup title & $\begin{array}{l}\text { No. of } \\
\text { studies }\end{array}$ & $\begin{array}{l}\text { No. of } \\
\text { partici- } \\
\text { pants }\end{array}$ & Statistical method & Effect size \\
\hline $\begin{array}{l}1 \text { Electrostimulation versus no treatment. Number of with- } \\
\text { drawals (surrogate adverse events) }\end{array}$ & 15 & 554 & $\begin{array}{l}\text { Risk Ratio (M-H, Random, } \\
95 \% \mathrm{Cl})\end{array}$ & $\begin{array}{l}1.09 \text { [0.39, } \\
3.06]\end{array}$ \\
\hline $\begin{array}{l}2 \text { Electrostimulation versus placebo. Number of withdrawals } \\
\text { surrogate adverse events) }\end{array}$ & 5 & 252 & $\begin{array}{l}\text { Risk Ratio (M-H, Random, } \\
95 \% \text { Cl) }\end{array}$ & $\begin{array}{l}1.11 \text { [0.60, } \\
2.06]\end{array}$ \\
\hline $\begin{array}{l}3 \text { ES versus conventional. No of withdrawals (surrogate ad- } \\
\text { verse events) - assume Francisco withdrawals control }\end{array}$ & 4 & 78 & $\begin{array}{l}\text { Risk Ratio (M-H, Random, } \\
95 \% \text { Cl) }\end{array}$ & $\begin{array}{l}0.51[0.07, \\
3.95]\end{array}$ \\
\hline $\begin{array}{l}4 \text { ES versus conventional. No of withdrawals (surrogate ad- } \\
\text { verse events) - assume Francisco withdrawals treatment }\end{array}$ & 4 & 78 & $\begin{array}{l}\text { Risk Ratio (M-H, Random, } \\
95 \% \mathrm{Cl})\end{array}$ & $\begin{array}{l}3.21 \text { [0.58, } \\
17.85]\end{array}$ \\
\hline
\end{tabular}

Analysis 4.1. Comparison 4 Acceptability of electrostimulation, Outcome 1 Electrostimulation versus no treatment. Number of withdrawals (surrogate adverse events).

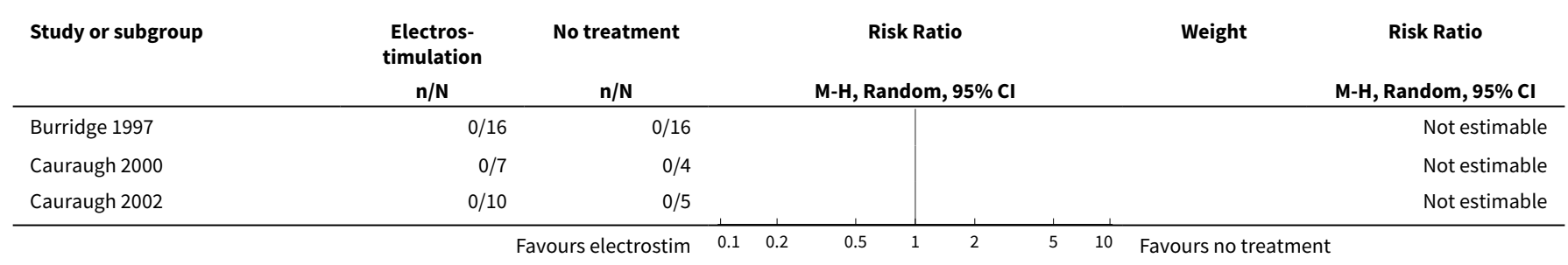




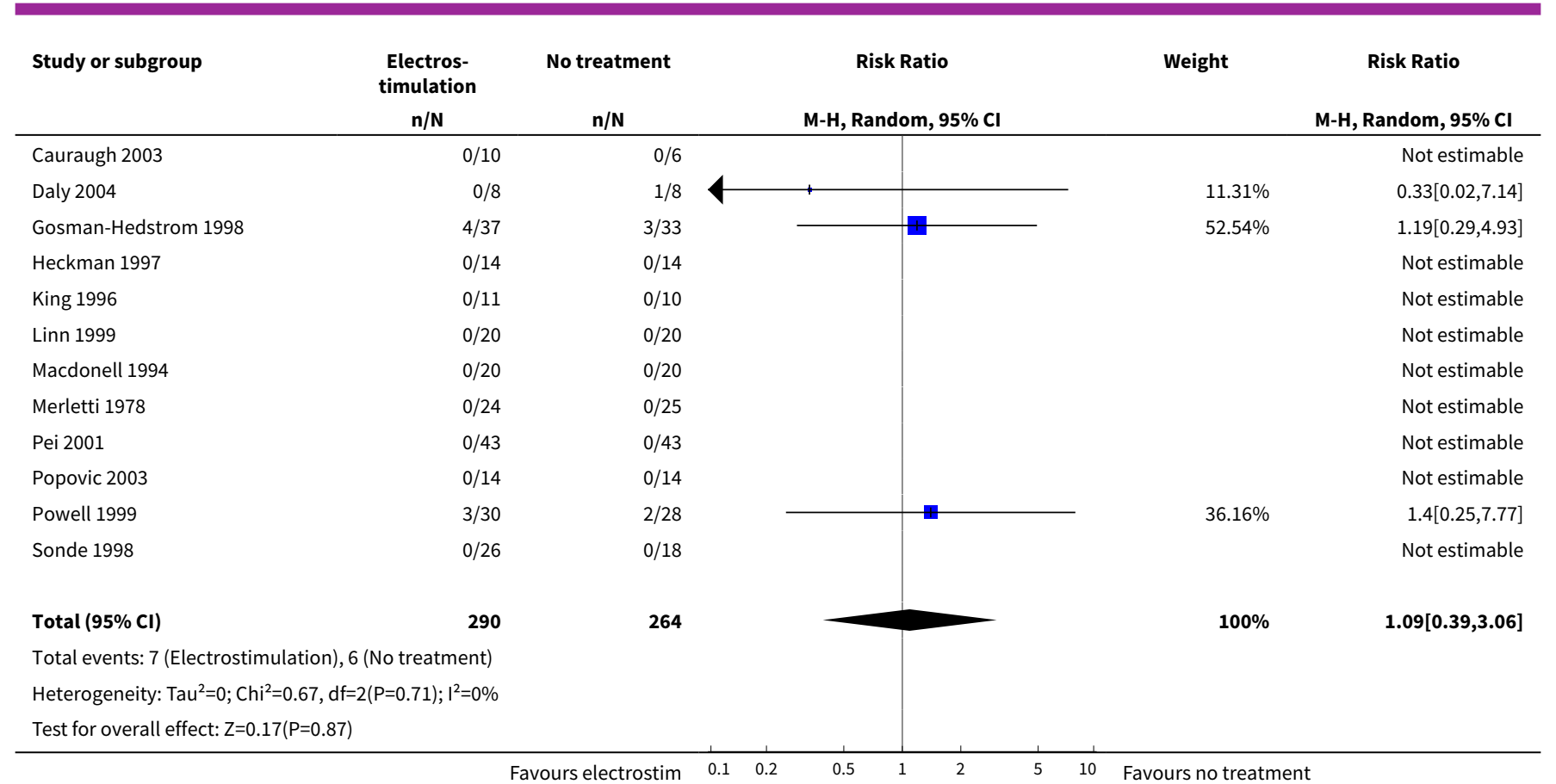

Analysis 4.2. Comparison 4 Acceptability of electrostimulation, Outcome 2 Electrostimulation versus placebo. Number of withdrawals (surrogate adverse events).

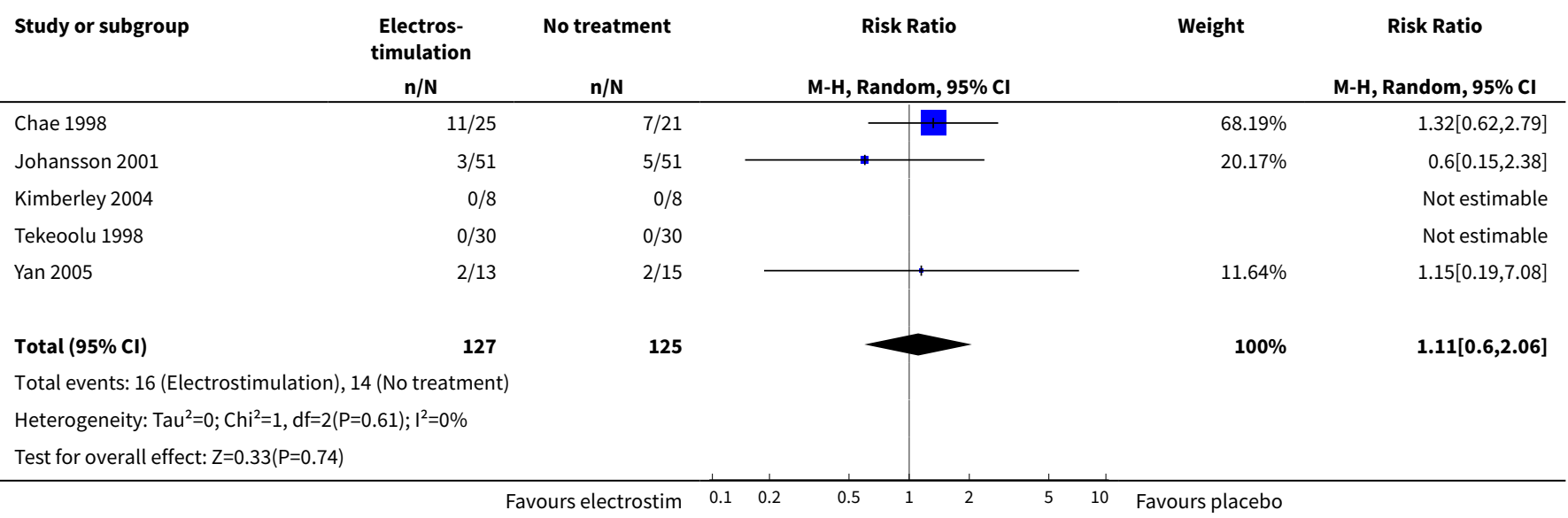

Analysis 4.3. Comparison 4 Acceptability of electrostimulation, Outcome 3 ES versus conventional. No of withdrawals (surrogate adverse events) - assume Francisco withdrawals control.

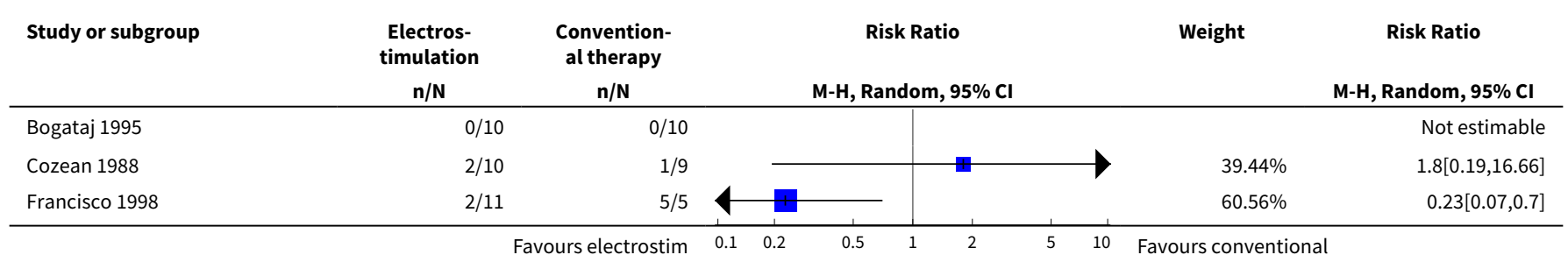




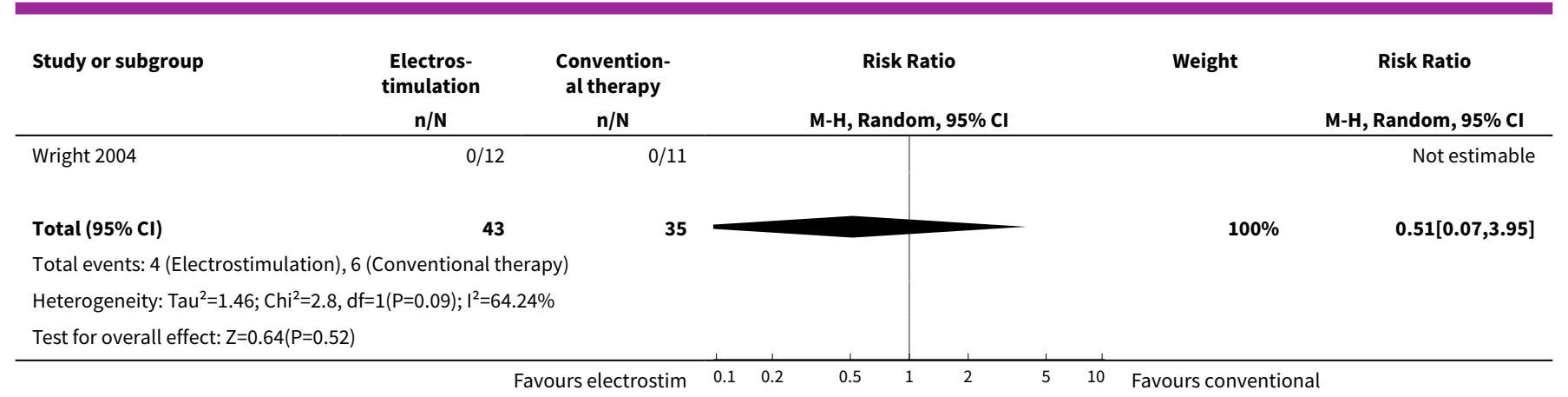

Analysis 4.4. Comparison 4 Acceptability of electrostimulation, Outcome 4 ES versus conventional. No of withdrawals (surrogate adverse events) - assume Francisco withdrawals treatment.

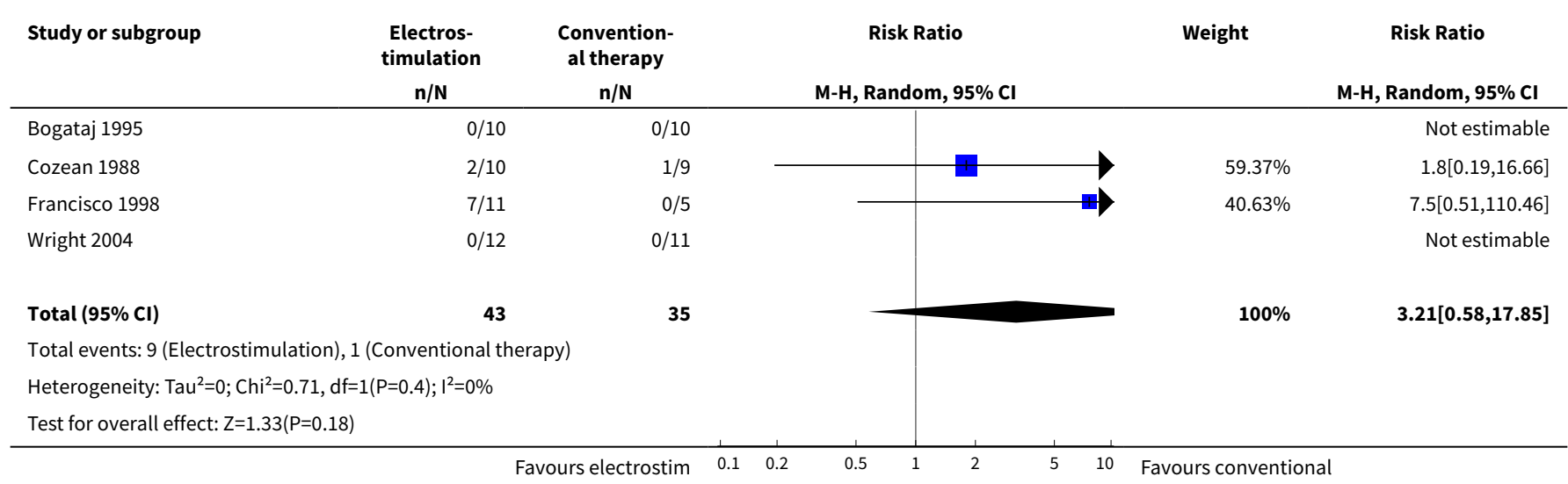

\section{ADDITIONAL TABLES}

Table 1. Description of types of electrostimulation

\begin{tabular}{llllll}
\hline & & $\begin{array}{l}\text { External elec- } \\
\text { trode }\end{array}$ & External electrode & $\begin{array}{l}\text { Internal elec- } \\
\text { trode }\end{array}$ & Internal electrode \\
& & No contraction & $\begin{array}{l}\text { Contraction pro- } \\
\text { duced }\end{array}$ & No contraction & $\begin{array}{l}\text { Contraction pro- } \\
\text { duced }\end{array}$ \\
\hline Paretic limb active & $\begin{array}{l}\text { Triggered or intermittent } \\
\text { stimulus }\end{array}$ & Category 1 & Category 5 & Category 9 & Category 13 \\
\hline Paretic limb active & Constant stimulus & Category 2 & Category 6 & Category10 & Category14 \\
\hline $\begin{array}{l}\text { Paretic limb inac- } \\
\text { tive }\end{array}$ & $\begin{array}{l}\text { Triggered or intermittent } \\
\text { stimulus }\end{array}$ & Category 3 & Category 7 & Category 11 & Category 15 \\
\hline $\begin{array}{l}\text { Paretic limb inac- } \\
\text { tive }\end{array}$ & Constant stimulus & Category 4 & Category 8 & Category 12 & Category 16 \\
\hline
\end{tabular}




\begin{tabular}{|c|c|c|c|c|c|c|c|c|c|}
\hline Study ID & $\begin{array}{l}\text { Allocate } \\
\text { conceal- } \\
\text { ment }\end{array}$ & $\begin{array}{l}\text { Gener- } \\
\text { ate allo- } \\
\text { cate }\end{array}$ & $\begin{array}{l}\text { Partic- } \\
\text { ipants } \\
\text { blinded }\end{array}$ & $\begin{array}{l}\text { Providers } \\
\text { blinded }\end{array}$ & $\begin{array}{l}\text { Differ- } \\
\text { ences in } \\
\text { care }\end{array}$ & $\begin{array}{l}\text { Proto- } \\
\text { col devi- } \\
\text { ations }\end{array}$ & $\begin{array}{l}\text { Analy- } \\
\text { sis devi- } \\
\text { ations }\end{array}$ & $\begin{array}{l}\text { Asses- } \\
\text { sors } \\
\text { blinded }\end{array}$ & $\begin{array}{l}\text { Select } \\
\text { report } \\
\text { result }\end{array}$ \\
\hline Bogataj 1995 & C & C & D & D & C & $A$ & $\mathrm{C}$ & C & C \\
\hline Burridge 1997 & C & C & D & D & C & A & A & C & A \\
\hline Cauraugh 2000 & B & B & C & D & A & A & $A$ & B & C \\
\hline Cauraugh 2002 & B & B & C & D & A & A & A & C & A \\
\hline Cauraugh 2003 & A & A & $\mathrm{C}$ & $\mathrm{D}$ & A & $A$ & A & B & $A$ \\
\hline Chae 1998 & C & C & A & D & A & C & $\mathrm{C}$ & A & A \\
\hline Cozean 1988 & B & B & A & A & A & A & A & A & C \\
\hline Daly unpublished & B & B & D & D & A & A & $\mathrm{C}$ & B & A \\
\hline Francisco 1998 & B & A & C & D & A & A & A & A & A \\
\hline Gosman-Hedstrom 1998 & A & A & $\mathrm{D}$ & $\mathrm{D}$ & A & A & A & A & $A$ \\
\hline Heckman 1997 & B & C & $\mathrm{C}$ & $\mathrm{D}$ & A & $A$ & A & B & C \\
\hline Johansson 2001 & $A$ & A & D & $\mathrm{D}$ & A & $A$ & $A$ & A & $C$ \\
\hline Kimberley 2004 & B & B & A & A & A & A & A & A & A \\
\hline King 1996 & B & B & $\mathrm{C}$ & $\mathrm{D}$ & B & $A$ & A & B & A \\
\hline Linn 1999 & B & B & C & $\mathrm{D}$ & A & $A$ & A & A & $A$ \\
\hline Macdonell 1994 & B & B & $\mathrm{D}$ & $\mathrm{D}$ & A & B & B & A & A \\
\hline Merletti 1978 & B & B & $\mathrm{D}$ & $\mathrm{D}$ & A & B & B & B & C \\
\hline Pei 2001 & B & B & $\mathrm{D}$ & D & C & A & B & B & B \\
\hline Popovic 2003 & B & C & $\mathrm{C}$ & C & A & $A$ & A & A & $A$ \\
\hline
\end{tabular}




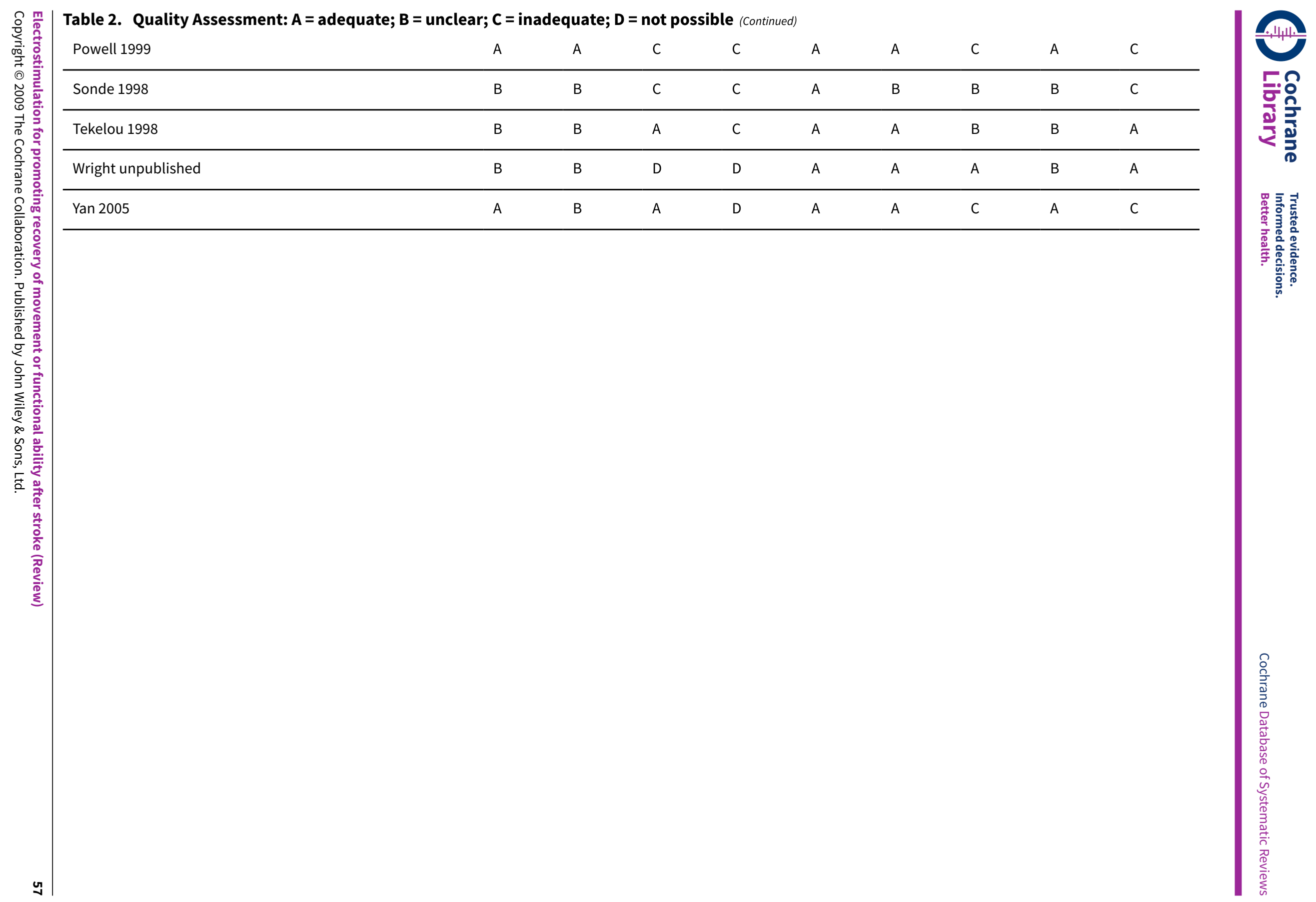




\section{APPEN DICES}

\section{Appendix 1. MEDLINE search strategy}

The following search strategy, using a combination of controlled vocabulary (MeSH) and free text terms, was used for MEDLINE and CENTRAL and was modified to suit other databases.

Search strategy MEDLINE (Ovid) and CENTRAL

1. exp cerebrovascular disorders/

2. (stroke\$ or cva or poststroke or post-stroke).tw.

3. (cerebrovasc $\$$ or cerebral vascular).tw.

4. (cerebral or cerebellar or brain $\$$ or vertebrobasilar).tw.

5. (infarct\$ or isch?emi\$ or thrombo or emboli\$ or apoplexy).tw.

6. 4 and 5

7. (cerebral or brain or subarachnoid).tw.

8. (haemorrhage or hemorrhage or haematoma or hematoma or bleed\$).tw.

9. 7 and 8

10. exp hemiplegia/

11. (hempar\$ or hemipleg\$).tw.

12. 1 or 2 or 3 or 6 or 9 or 10 or 11

13. electric stimulation therapy/

14. electroacupuncture/

15. transcutaneous electric nerve stimulation/

16. electric stimulation/

17. electrostimulation.tw.

18. electrotherapy.tw.

19. (tens or fes).tw.

20. (neuromuscular adj5 stimulat\$).tw.

21. transcutaneous nerve stimulation.tw.

22. electroacupuncture.tw.

23. (peroneal adj5 stimulat\$).tw.

24. (electric\$ adj5 stimulat\$).tw.

25. or/13-24

26. 12 and 25

27. limit 26 to human

28. (migrain\$ or epilep\$ or myocard\$ or cardiol\$ or headache\$ or heart\$ or parkinson\$).ti.

29. 27 not 28

WHAT'S NEW

\begin{tabular}{lll}
\hline Date & Event & Description \\
\hline 19 August 2008 & Amended & Converted to new review format. \\
\hline
\end{tabular}

\section{CONTRIBUTIONSOF AUTHORS}

VP contributed to writing the protocol, supervised the literature search and identification of papers, analysed and interpreted results and led writing of the review.

LK contributed to the literature search, identification of papers, analysis and interpretation of results and writing of the review. AP contributed to writing the protocol, analysis and interpretation of results and writing of the review.

$\mathrm{AB}-\mathrm{H}$ contributed to the literature search, identification of papers and writing of the review.

$\mathrm{PL}$ advised on the protocol and contributed to the analysis and interpretation of results as well as writing the review.

\section{DECLARATIONS OF INTEREST}

None known 


\section{SOURCES OF SUPPORT}

\section{Internal sources}

- No sources of support supplied

\section{External sources}

- The Health Foundation, UK.

\section{N DEX TERMS}

\section{Medical Subject Headings (MeSH)}

${ }^{\star}$ Recovery of Function; *Stroke Rehabilitation; Activities of Daily Living; Electric Stimulation Therapy [adverse effects] [ ${ }^{\star}$ methods]; Motor Activity; Randomized Controlled Trials as Topic

\section{MeSH check words}

Humans 